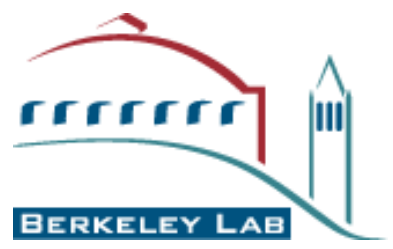

\title{
Reactive Transport and Coupled THM Processes in Engineering Barrier Systems (EBS)
}

\author{
Carl Steefel, Jonny Rutqvist, Chin-Fu Tsang, Hui-Hai Liu, Eric Sonnenthal, \\ Jim Houseworth and Jens Birkholzer
}

Lawrence Berkeley National Laboratory (LBNL) 


\section{Table of Contents}

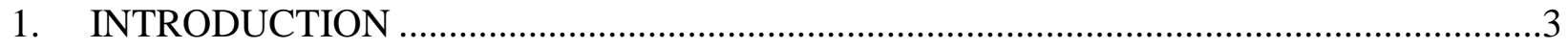

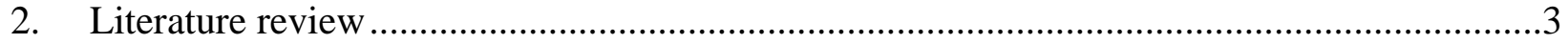

2.1. THMC Processes in Buffer Material (Bentonite) ………............................................ 4

2.1.1. Discussion of Key Issues in Coupled THMC Processes in Bentonite Buffer ........ 4

2.1.2. A Summary of Three Major International Activities and Suggested Needs for

Further Research ........................................................................................................ 7

2.2. Reactive-Diffusive Transport in the EBS ………............................................... 12

2.2.1. Formulation for Montmorillonite Interlayer Water ............................................... 13

2.2.2. Formulation for Diffuse Double Layer ............................................................... 14

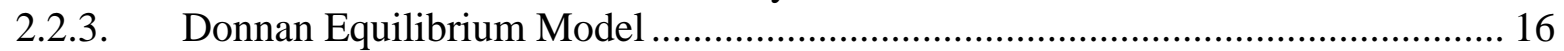

2.2.4. Diffusive Transport......................................................................................... 17

2.2.5. Limitations to the Model..................................................................................... 18

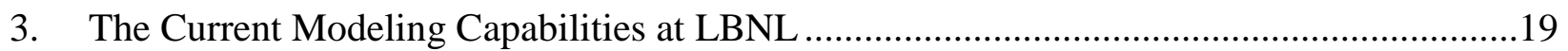

3.1 Modeling Tools for Coupled THM processes ............................................................. 19

3.1.1. The ROCMAS Code......................................................................................... 20

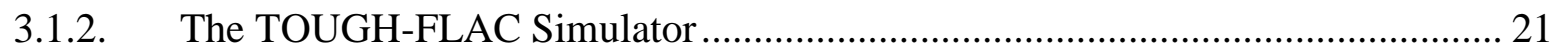

3.1.3. Comparison of ROCMAS and TOUGH-FLAC to Other THM codes .................. 24

3.1.4. Modeling of the Proposed Swedish High Level Waste Repository........................ 25

3.2. Modeling Tools for Reactive Transport.......................................................................... 27

3.2.1. CrunchFlow Code for Diffuse Double Layer Transport........................................ 28

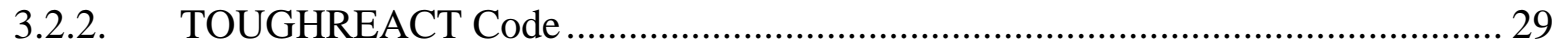

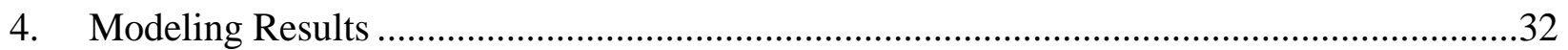

4.1. Implementation and Testing of the Barcelona Basic Model...................................... 32

4.1.1. BBM Equations and implementation procedure..................................................... 33

4.1.2. TOUGH-FLAC BBM module and input data ....................................................... 39

4.1.3. Simulation Test to Verify the BBM Implementation .......................................... 39

4.1.4. Simulation Tests Using TOUGH-FLAC with BBM and Swelling ...................... 43

4.1.5. Simulation of a Generic Repository in Clay Host Rock .......................................... 50

4.1.6. Summary of THM EBS Research and Next Step ………………………............. 55

4.2. Simulation of Transport Experiments using Diffuse Layer and Ion Equilibrium

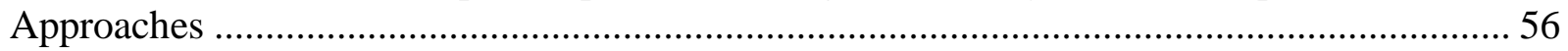

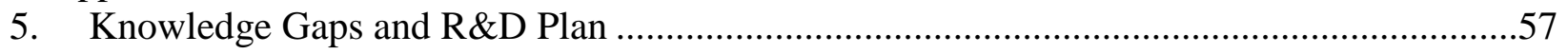

5.1. Knowledge Gaps ..................................................................................................... 57

5.2. Research \& Development Plans for the EBS................................................................ 59

5.2.1. Near-term R\&D Plans .................................................................................... 59

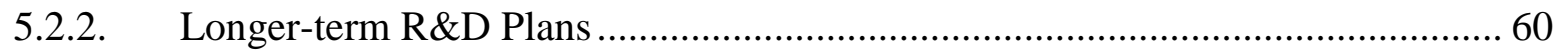

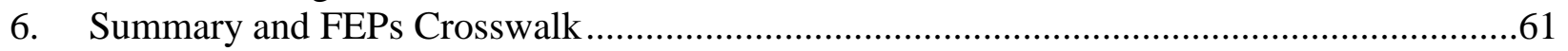

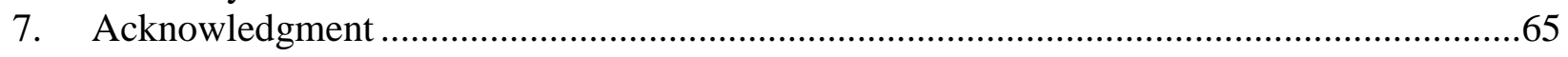

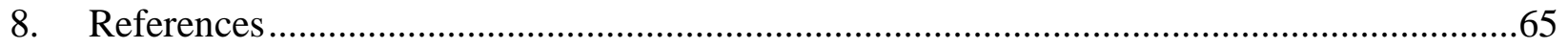

Appendix: Key References for THMC Processes in EBS-Bentonite ...............................................75 


\section{INTRODUCTION}

Geological repositories for disposal of high-level nuclear wastes generally rely on a multi-barrier system to isolate radioactive wastes from the biosphere. The multi-barrier system typically consists of a natural barrier system, including repository host rock and its surrounding subsurface environment, and an engineering barrier system (EBS). EBS represents the man-made, engineered materials placed within a repository, including the waste form, waste canisters, buffer materials, backfill and seals (OECD, 2003). EBS plays a significant role in the containment and long-term retardation of radionuclide release.

EBS is involved in complex thermal, hydrogeological, mechanical, chemical and biological processes, such as heat release due to radionuclide decay, multiphase flow (including gas release due to canister corrosion), swelling of buffer materials, radionuclide diffusive transport, waste dissolution and chemical reactions. All these processes are related to each other. An in-depth understanding of these coupled processes is critical for the performance assessment (PA) for EBS and the entire repository. Within the EBS group of Used Fuel Disposition (UFD) Campaign, LBNL is currently focused on (1) thermal-hydraulic-mechanical-chemical (THMC) processes in buffer materials (bentonite) and (2) diffusive transport in EBS associated with clay host rock, with a long-term goal to develop a full understanding of (and needed modeling capabilities to simulate) impacts of coupled processes on radionuclide transport in different components of EBS, as well as the interaction between near-field host rock (e.g., clay) and EBS and how they effect radionuclide release.

This final report documents the progress that LBNL has made in its focus areas. Specifically, Section 2 summarizes progress on literature review for THMC processes and reactive-diffusive radionuclide transport in bentonite. The literature review provides a picture of the state-of-the-art of the relevant research areas addressed by LBNL. Section 3 documents the current modeling tools, available at LBNL, for the EBS study. This may be important for identifying future modeling activities within the EBS group with these current capabilities and needs for future EBS modeling development. Section 4 presents the results of geomechanical modeling using the Barcelona Basic Model (BBM) constitutive relationship for thermo-elasto-plastic media such as bentonite and an update on reactive-diffusive transport modeling approaches through bentonite in the EBS. Section 5 discusses identified knowledge gaps and technical issues as well as shortand long-term R\&D plans.

\section{LITERATURE REVIEW}

This section summarizes LBNL's current literature-review results in two focus areas: (1) THMC processes within EBS buffer materials to better understand bentonite behavior and stability, and (2) diffusive transport within bentonite to better understand radionuclide release into the natural system. The literature review intends to provide a comprehensive picture of the current status of research activities in the two areas, and to help identify the relevant technical issues and gaps of interest to the UFD campaign that require resolution in future studies. A list of technical issues and gaps (identified based on the current literature-review results) is provided in Section 5.1. 


\subsection{THMC Processes in Buffer Material (Bentonite)}

For the Engineered Barrier System EBS-Bentonite literature review, a list of key recent references has been developed and appended to this chapter. These are mainly papers published over the last five years. In addition to these references, there are also many activities concerning the EBS in a number of on-going international collaborative projects. These include:

(a) DECOVALEX project

(b) THERESA and TIMODAZ projects, sponsored by European Commission

(d) EBS Task Force, sponsored by SKB which includes the BRIE (Bentonite-Rock Interaction Experiment) task

The above three are all international cooperative projects, involving participation of most of the countries active in this field. Some of these projects include very valuable data sets from major multi-year field experiments.

The main component of the EBS used in a number of countries is bentonite or a bentonite-sand mixture. Bentonite is a clay with a high content of smectite minerals, having properties very suitable for isolating radioactive waste canisters (Alonso and Ledesma, 2005; Pusch 2006; Pusch and Yong, 2006). It has a very low hydraulic conductivity and very low anion diffusion capacity and low transport capacity of positive charged radionuclides. Thus it can serve as a good buffer around the waste canisters. Mechanically, its high swelling potential makes possible self sealing of openings within the EBS system and of gaps between the bentonite with the rock and with the radioactive waste canister. Its thermal conductivity is adequate to conduct heat away from the canister so that the canister can be maintained at a temperature $100^{\circ} \mathrm{C}$ or below. Further it has good colloid and microbial filtration capability. With these properties, a bentonite buffer generally is expected to fulfill the following functions:

- To limit the canister corrosion rate by minimizing groundwater access

- To conduct heat away from the canister

- To provide a mechanical buffer between the rock and the canister and to keep the canister in place in the deposition hole

- To reduce the potential for microbial activity

- To act as a medium that allows mainly solute diffusion and provide for large sorptive surfaces to retard any released radionuclides

\subsubsection{Discussion of Key Issues in Coupled THMC Processes in Bentonite Buffer}

There are three phases in the evolution of the bentonite buffer in a radioactive waste repository. The first phase is the installation and initial water intake of the buffer over a period of 0 to 100 years dependent on repository design. The second phase is dominated by heat input from the 
waste canister with a significant time-varying temperature gradient, with the temperature intially increasing and then returning to ambient over a period of 100 to 1000 years. The third phase is the long-term period with tectonic or glacial processes under ambient or reduced temperature conditions from 1000 to a million years.

When a bentonite buffer is installed around waste canisters in a repository, it is initially partially saturated with water. Water intake is a slow process because of the very low permeability of the bentonite and the surrounding crystalline or argillaceous rock. Flow through crystalline rock is mainly through fractures, which controls the rate and locations of incoming water for saturating the bentonite, such that bentonite wetting and swelling could well be uneven over its interface with the rock, resulting in uneven swelling pressure. For argillaceous rock, fracture flow is potentially less significant and wetting of the bentonite could be controlled by inflow from the rock matrix. Further, if the incoming flow from the rock is high, the bentonite will uptake the water under a positive pressure. However if the incoming flow is low, the uptake of water from the bentonite will create a negative pressure, which will dehydrate the rock in the immediate neighborhood.

Next, the heat released from radioactive waste begins to heat up the near field of the bentoniterock system. Processes involved in the evolution of the bentonite buffer include thermally induced distribution of initial pore water in the clay during the early thermal phases (Tong, et al., 2009; Thomas et al., 2009). On the outer part of the bentonite buffer, water is uptaken from the rock-water interface, with potential swelling of the bentonite in this region. On the inner part of the bentonite buffer, next to the heat-releasing waste canister, moisture content decreases (desiccation), with potential shrinkage. Over time, the expansion of the bentonite as it is being hydrated may displace the position of the waste canister enveloped within it, as well as the position of the buffer-backfill interface. Chemically within the bentonite buffer, there may be the dissolution of buffer minerals and precipitation of chemical compounds (Castellanos et al., 2008; Seetharam et al., 2006)

Major physical processes related to long-term stability of the bentonite buffer are erodability, colloidal transport and filtering, and microbiological filtering (Birgersson et al., 2009; Birgersson and Karnland, 2009). Major chemical processes that may affect the chemical stability of the bentonite buffer after water saturation include dissolution and precipitation, conversion of smectite in the buffer to nonexpansive mineral forms, and cementation by precipitated complexes (Pusch and Yong, 2006).

Five areas of concern in recent studies of the bentonite buffer have been discussed. The first is the buffer hydration process and timing. The second is the thermo-hydro-mechanical (THM) processes involved in bentonite behavior. The third is the issue of homogenization, gaps, and bentonite pellets, and the fourth is piping and erosion. The fifth and final area of concern is chemical and mineralogical interactions. These are discussed below.

The hydration process is important for understanding the evolution of the waste repository and plays a significant role in the maximum temperature experienced by the canister (Tong et al., 2010). Also, if hydration is slow, it may influence the chemical state of the buffer. A particular issue of interest is the effect of uneven water wetting on the bentonite buffer from water coming 
from individual fractures in the rock surrounding the buffer. It is also related to the question, what is the best way to understand and model the rock buffer interface? This question is being addressed in a new proposed project called BRIE (Bentonite Rock Interaction Experiment) being planned at the Äspö Hard Rock Laboratory in Sweden (see below). One problem to be investigated in this project is whether there is a need to develop special hydromechanical properties for the interface between bentonite and rock.

Concerning the understanding of THM processes in the bentonite, it has been noted that for some experiments, the models tend to overpredict the rate of hydration. This may be caused either by inaccuracies in parameter values, or by a faulty conceptual model of the THM processes. Some proposed additional phenomena (Cleall et al., 2007; Li et al., 2009) that could be included in our understanding and modelling of the buffer include (a) the effect of microstructural evolution (Sanchez et al., 2005) (b) the existence of different states of water in the bentonite, (c) the existence of a threshold hydraulic gradient for water flow and (d) thermo-osmosis (Zheng and Samper (2008); Zheng et al., 2010). A proper inclusion of relevant THM processes, together with thermodynamical constraints, is needed for extrapolation of bentonite behavior over a long time frame.

The buffer emplacement around waste canisters involves the use of bentonite blocks, which typically have gaps between individual blocks and between blocks and the rock. These gaps are often filled with bentonite pellets and pellet-powder mixture (Dixon et al., 2008). A concern that then arises is whether and how homogenization of bentonite density will take place. Here, homogenization refers to a process whereby all gaps are filled by the swelling and deforming bentonite blocks and pellets. A related question is, how well understood are the potential irreversible effects in large swelling and compression cycles? It is not expected that complete homogenization will be attained even if the buffer were of the same material, since the effects of swelling and compression cycles are expected to be irreversible. To have a proper study of this issue, THM models that include large strain formulations are needed.

The fourth area of concern is piping and erosion of the bentonite buffer (Birgersson et al., 2009; Birgersson and Karnland, 2009), which may cause significant mass loss during initial stages of the repository existence and during glaciation periods. In particular, water flow through the bentonite pellet fillings will cause bentonite erosion. The extent of pellet erosion depends on salinity, water flow rate, and granularity. Empirical erosion models and computer codes have been developed to evaluate the process and to suggest criteria, for example, on the maximum flow rate in order to limit the erosion potential. The flow rate may possibly be controlled by grouting or emplacement of plugs in the repository system.

Concerning chemical and mineralogical interaction in the bentonite buffer, a number of mineral reactions have been considered: (a) dissolution and precipitation of minerals, (b) ion-exchange such as from $\mathrm{Na}$ to $\mathrm{Ca}$, (c) illitization and dissolution. The potential for release of colloids due to ion exchange, as well as the potential for diffusive transport of ions through the bentonite, needs to be evaluated. Furthermore, the possible chemical impact on THM processes leading to irreversible effects needs to be studied. To consider this possibility, multicomponent reactive transport models for repository environments are being developed (Kimura et al., 2010; Seetharam et al., 2007, 2009; Guimaraes, et al., 2006, 2007; Xie, et al., 2004; 2006). A major 
development during the last few years is the re-establishment of the "chemical view" of bentonite (Birgersson and Karnland, 2009). This basic approach is primarily based on the ion equilibrium between an external solution and the bentonite interlayer pore-water, and has been demonstrated to explain the diffusional behavior of bentonite. Moreover, it provides a basic coupling between the chemistry and the hydromechanical processes. This approach should probably be important to consider for clay rock as well.

The above discussion is on the main component of the EBS, that is the bentonite. For a waste repository in clay formation, in addition to the buffer (which may be a bentonite-sand mixture, compacted pellets or clay from the site itself), there is also the concrete lining and steel support, forming part of the EBS system. Three major areas of knowledge gaps concerning the EBS in a clay repository have been identified (EC, 2010; Tsang et al., 2010): They are:

- Hydric condition, during the early stages before backfill and closure, between the tunnel air humidity and rock moisture conditions in the presence of the lining. This condition could well not be in equilibrium;

- Chemically interaction between the lining and steel support with the clay, modifying the clay properties,

- Over time, lining and steel support will degrade with potential release of gases, and thus gas transport through the EBS system and how the clay expands to fill the space of the degraded components are also problems of concern.

\subsubsection{A Summary of Three Major International Activities and Suggested Needs for Further Research}

In this section we shall describe three major on-going or recent research activities related to Engineering Barrier System-bentonite buffer and summarize the needs for further research identified by these projects.

\subsubsection{The THERESA and TIMODAZ Projects}

Within the European Commission (EC) Sixth Euratom Research and Training Framework Programme (FP6) on nuclear energy (EC, 2007) are two projects: the THERESA and TIMODAZ projects. Both are focused on coupled thermo-hyrdo-mechanical-chemical (THMC) processes in the near-field of a radioactive waste repository. Work has been done by a consortium of European research organizations over a four-year period and is planned to conclude about 2010 (EC, 2010)

The THERESA project is coordinated by the Royal Institute of Technology in Sweden and involves research organizations in seven countries: Sweden, Germany, The Netherlands, Spain, United Kingdom, Finland, and France. The project aims to develop scientific understanding, new approaches and methodologies for evaluating coupled THMC processes in the near-field, and to study their impact on performance assessment, repository design and construction, and post- 
closure monitoring of a waste repository. The project focuses on rock salt for the host rock, buffer materials (for crystalline rock repositories) and the buffer-rock interface.

Of particular interest is Work Package 4 (WP4) of this project, which focuses on modeling of coupled THM and THMC processes in buffer (mainly bentonite) and buffer-rock interfaces. The Centre International de Métodes Numeriés en Enginyeria (CIMNE) of Spain is the coordinator of this Work Package with participation of Cardiff University and Quintessa of UK, Posiva and Marintel of Finland and Institut de Radioprotection et de Sûreté Nucléaire (IRSN) of France. One of the main tasks within this Work Package is the study and modeling of the full-scale Canister Retrieval Test (CRT) at SKB’s Äspö Hard Rock Laboratory.

The goal of CRT was to demonstrate readiness for recovering emplaced waste canisters in a fullscale (8m high, $1.65 \mathrm{~m}$ diameter) deposition hole in crystalline rock with bentonite as buffer material. Canister and bentonite blocks were emplaced in 2000 and the hole was sealed with a plug. Then the heater in the canister was turned on and an artificial water supply was used to saturate the buffer. The saturation phase lasted for five years, until 2006. Over these years, continuous measurements of the wetting process, temperature, stresses and strains were conducted. In January 2006, the canister retrieval phase started with the canister successfully retrieved in May 2006. Bentonite from the deposition hole was then retrieved for laboratory testing. Data on mechanical strength, swelling pressure, hydraulic conductivity and chemical/mineralogical constitution of the bentonite over the experimental periods are becoming available.

The TIMODAZ project is coordinated by the Studie Centrum voor Kernenergie Centre Detude de L'Energie Nucleaire (SCK-CEN), Belgium, through the EURIDICE expertise group, with participation from research organizations of eight countries, Belgium, France, Switzerland, Germany, The Netherlands, Spain, Czech Republic, and United Kingdom. The rock type of interest in this project is clay, with three types being investigated: Boom clay found at the Belgium underground Research Laboratory HADES, Opalinus Clay existing at the Swiss Mont Terri Rock Laboratory; and the Callovo-Oxfordian argillite at the French Underground Research Laboratory at Bure. The approach is to conduct laboratory experiments, field tests and numerical modeling on coupled THMC processes in the near field. Here the near field is not only the buffer (e.g. bentonite, compacted pellets, cementitious materials) and the lining and steel support, but also the potential damaged zone in the near-field clay rock.

The THERESA and TIMODAZ projects held a joint Conference in Luxemberg, September 29October 1, 2009 to review the progress and accomplishments from both projects (EC, 2010). At the conference, a working group on bentonite buffer was convened and discussed the state-ofthe-art and open issues which are summarized in the last section. The group also came up with a table summarizing the processes in the buffer materials, their relevance to performance assessment (PA) and the need for further research (Åkesson, 2010). This is shown as Table 2.1-1 below. 
Table 2.1-1. Summary of processes, their relevance, and the need for further research (Åkesson, 2010)

\begin{tabular}{|c|c|c|c|c|}
\hline Processes & Relevance for PA & $\begin{array}{l}\text { Need for } \\
\text { experimental } \\
\text { data }\end{array}$ & $\begin{array}{l}\text { Need for code } \\
\text { development }\end{array}$ & $\begin{array}{l}\text { Need for } \\
\text { development of } \\
\text { conceptual models }\end{array}$ \\
\hline Barrier hydration & Moderate. & Yes & $\begin{array}{l}\text { If models can not } \\
\text { predict new } \\
\text { experiments }\end{array}$ & $\begin{array}{l}\text { If models can not } \\
\text { predict new } \\
\text { experiments }\end{array}$ \\
\hline Homogenization & $\begin{array}{l}\text { Yes. Remaining } \\
\text { heterogeneities } \\
\text { should be limited }\end{array}$ & Yes & Yes & Yes \\
\hline Piping and erosion & $\begin{array}{l}\text { Yes. Significant mass } \\
\text { loss should be } \\
\text { avoided }\end{array}$ & Yes & Yes & Yes \\
\hline $\begin{array}{l}\text { Enrichment of groundwater } \\
\text { substances }\end{array}$ & $\begin{array}{l}\text { Yes, short term } \\
\text { effects }\end{array}$ & No & Yes & No \\
\hline $\begin{array}{l}\text { Accessory mineral } \\
\text { dissolution/precipitation }\end{array}$ & $\begin{array}{l}\text { Yes, longer term } \\
\text { effects }\end{array}$ & Yes & Yes & Yes \\
\hline $\begin{array}{l}\text { Montmorillonite surface } \\
\text { reactions, Ion-exchange }\end{array}$ & Yes & No (Yes) & Yes & No (Yes) \\
\hline $\begin{array}{l}\text { Montmorillonite alteration } \\
\text { illitization/dissolution }\end{array}$ & Yes & Yes & Yes & Yes \\
\hline $\begin{array}{l}\text { Colloid release in Na- } \\
\text { montmorillonite }\end{array}$ & Yes & Yes & Yes & No \\
\hline High salinity & Yes & No (Yes) & Yes & No \\
\hline Diffusive transport & Yes & No (Yes) & Yes & No (Yes) \\
\hline
\end{tabular}

In addition to the THERESA and TIMODAZ projects, the European Commission FP6 program also supported the ESDRED (Engineering Studies and Demonstrations of Repository Design) project, coordinated by ANDRA, France with participation from nine countries; France, Finland, Spain, Switzerland, Sweden, Belgium, The Netherlands, Germany, and United Kingdom. Within this project, which lasted from 2004 to 2009, EBS for the different rock types have been studied, (Bock et al., 2008 Rothfuchs et al., 2007).

\subsubsection{2. Äspö Hard Rock Laboratory EBS Studies and the BRIE Project}

The Äspö Hard Rock Laboratory (HRL) operated by the Swedish Nuclear Fuel and Waste Management Company (SKB) has been the underground research facility for many aspects of nuclear waste disposal since 1995. While much of the work at the Laboratory is done to meet the needs of SKB, a substantial amount of activities are conducted as international cooperation. These international collaborative projects are coordinated by the Äspö International Joint Committee, currently composed of representatives from SKB (Sweden), ANDRA (France), BMWi (Germany), CRIEPI (Japan), JAEA (Japan), NWMO (Canada), and Posiva (Finland).

A substantial number of large scale field experiments and supporting activities are conducted at Äspö HRL in the area of engineered barrier system. The goal is to develop, test and demonstrate EBS methods and procedures under realistic conditions and at appropriate scales. In a recent progress report (SKB, 2009) the following on-going experiments and activities are listed.

- Prototype Repository: Demonstration of the integrated function of the repository and testing of predicted models, based on study of six deposition boreholes. 
- Long Term Test of Buffer Material (LOT Experiment): Data for validation of models and hypotheses concerning physical properties of bentonite buffer material and related processes in microbiology, radionuclide transport, copper corrosion and gas transport.

- Alternative Buffer Materials: Study of alternative clay materials potentially useful as buffer.

- Backfill and Plug Test: Study of a drift backfilled with a mixture of bentonite and crushed rock.

- Canister Retrieval Test: Demonstration of canister retrieval after surrounding bentonite buffer is fully saturated, with detailed monitoring of the wetting process, temperature, stresses and strains.

- Temperature Buffer Test: Study of THM behavior of buffer with temperature around and above $100^{\circ} \mathrm{C}$ during water saturation process.

- KBS-3 Method with Horizontal Emplacement: Developing methods for canister horizontal emplacement in a tunnel.

- Large Scale Gas Injection Test: Gas injection in a full scale KBS-3 deposition hole, with monitoring of full hydraulic behavior.

- Sealing Test of Tunnel at Great Depth: Testing of silica gel being a useful grout at water pressures prevailing at repository level.

- In Situ Corrosion Testing of Miniature Canisters: Study of corrosion processes inside a failed canister.

- Cleaning and Sealing of Investigational Boreholes: Identification and demonstration of best available techniques.

- Task Force on EBS.

The last activity, Task Force on EBS, is an international collaborative effort involving eight countries; Sweden, France, Germany, Japan, Switzerland, Finland, Canada and Czech Republic. Work is focused on THM modelling of processes during water transfer between buffer, backfill and near-field rock and on gas transport in saturated buffer. It was initiated in 2004 and the group has been meeting twice a year, the last being in Barcelona in May 2010. During this meeting, new issues were considered for future studies in the next phase of the Task Force. They are homogenization, erosion, gaps and interfaces, and effects of rock shear, as well as sensitivity studies and understanding of the relationship between simulation variables and performance results. These may be considered as open areas of research needing further investigation. 
Concerning the particular topic of gaps and interfaces, a new task has been initiated called Bentonite Rock Interaction Experiment (BRIE). This task has the goal of understanding water exchange across bentonite rock interfaces, better prediction of bentonite wetting process, better characterization methods, and establishment of deposition hole criteria. Modelling is made in advance of an in-parallel field experiment, thus allowing for a blind prediction to analyze effects of different conceptual models. The experiment, BRIE, is divided into two parts: Part I concerning selection and characterization of a test site within the Äspö HRl and one or two central boreholes, and Part II concerning bentonite deposition, monitoring of physical and chemical changes, and extraction of the bentonite buffer. Work on this test is at the beginning stage.

\subsubsection{The DECOVALEX Project}

The DECOVALEX project is an international project initiated in 1992 to study the coupled THM processes around a nuclear waste repository (Tsang et al., 2009). The development of the research field of coupled THM processes including both modelling and laboratory or field experiments over the last 18 years has been very much influenced by this project. Over this time period, about 10 countries have participated in the collaborative research. The latest phase DECOVAKEX-2011 will conclude in 2011. The phase prior to this, named DECOVALEXTHMC, had a task to study coupled THM effects in the near field, including those on the bentonite buffer.

This task (Nguyen et al., 2009, Chijimatsu et al., 2009) was coordinated by Canada Nuclear Safety Commission with participation from Sweden, Japan, Finland, and Canada. First, bentonite models were calibrated against results from laboratory experiments on bentonite. These are swelling pressure tests, water uptake tests, thermal gradient tests, (Börgesson and Hernelind, 1999) and the CEA mock-up THM test (Gatabin and Billaud, 2005).

After the calibration studies, THM analysis was conducted to evaluate the near field behavior of the repository and their implication on the performance of a hypothetical repository. The scenario is based on a Canadian case study with the repository situated at a depth of $650 \mathrm{~m}$ in a stable crystalline rock of the Canadian Shield. Canisters are placed according to a horizontal borehole emplacement method with the gap between the canisters and rock filled with a bentonite buffer material. Factors of concern in the study include temperature rise, damage zone determination, change in permeability, resaturation of the bentonite buffer, swelling pressure and perturbation in the hydraulic head distribution. These are calculated and studied for three phases: Excavation and waste emplacement (years 0-30), observation and monitoring (years 30-100), and post-closure period (years 100 to 1000 and more).

Results show that the permeability of the excavated damaged zone (EDZ) of the rock mass around the emplacement borehole could play a major role in the THM behavior in the near field. Thus an important open research area needing further study is the EDZ-EBS interaction. For sparsely fractured rock without EDZ, the bentonite is predicted to fully resaturate within a few decades, while for intact rock, full saturation might take more than 10,000 years. Temperature in all cases remain below $100^{\circ} \mathrm{C}$. The predicted maximum total stress on the bentonite (MX-80 bentonite has been used in the study) could exceed $15 \mathrm{MPa}$ which is the design pressure for the 
waste canister, when the rock mass is sparsely fractured. This result needs further research to confirm and to consider the implication.

\subsection{Reactive-Diffusive Transport in the EBS}

This subsection summarizes the literature review of reactive-diffusive transport in the EBS buffer materials, which is relevant for understanding the release and fate of radionuclide release into the natural system. Compacted bentonite has been proposed as backfill material in many of the European repositories, because of its very low permeability (Kim et al., 1993; Muurinen, 1994; Pusch, 2001; Molera and Eriksen, 2002; Bourg et al., 2003) and its strong sorptive properties (Eriksen et al., 1999; Ochs et al., 2001), both of which will limit the release of radionuclides. The low permeability of bentonite is largely due to the fact that it contains a high percentage of Na-montmorillonite, a clay that swells in water. The very low permeability of the compacted bentonite implies that transport of radionuclides away from the waste forms will be almost exclusively by molecular diffusion, with effective diffusivities far below that in water (Madsen, 1998; Ochs et al., 2001; Bourg et al., 2007). (This of course may change in the presence of advective pathways in the bentonite, which may result from insufficient homogenization, THMC-related fracturing, erosion, long-term degradation, etc. This is why THMC studies in Section 2 are so important.) Effective diffusivities for the compacted bentonite are very low as a result of its low porosity and the nanometer scale of the pores in the compacted clay. In much of the compacted bentonite, the pores are so small ( $<1$ nanometer) that the electrical double layers balancing the charge of the bentonite (typically negative at circumneutral $\mathrm{pH}$ ) overlap, thus potentially excluding anions altogether, or creating a deficiency in them with the Diffuse Double Layer balancing the surface mineral charge (Bourg et al, 2003; Bourg et al, 2006; Leroy et al, 2006; Gonçalvès et al, 2007).

Three types of water presence are recognized in compacted bentonite (Bourg et al, 2003; Wersin et al, 2004):

1. Interlayer water $\left(\boldsymbol{\varphi}_{I L)}\right.$ with only water and cations within the Tetrahedral-OctahedralTetrahedral (TOT) layers of the montmorillonite. Here, the cations balance the fixed charge of the TOT layers;

2. Diffuse double layer $\left(\boldsymbol{\varphi}_{D D L}\right)$ containing cations and anions, but with an excess of ions (normally cations) to balance the charge of the clay surface;

3. Bulk or free pore water $\left(\boldsymbol{\varphi}_{B}\right)$, which is charge balanced.

The proportions of each kind of water depend on the compaction of the bentonite, but also the ionic strength through its effect on the width of the Diffuse Double Layer. In addition, the nature of cation affects the swelling and therefore the interlayer spacing.

Similar effects are also observed in clay-rich (20-40\% typically) rocks that may be located in the near-field environment, although in this case the percentage of interlayer water may not be as significant. Examples are the Callovo-Ordovician (COX) formation considered as a host rock for the French high level waste repository (Leroy et al., 2007; Appelo et al., 2008; Jougnot et al., 2009), or the Opalinus Clay under investigation in Switzerland (Appelo and Wersin, 2007). In experimental studies, it is common to observe the effects of anion exclusion, which in a diffusive 
regime is reflected by a late arrival (or release) of the negatively charged ions relative to neutral species (Bazer-Bachi et al., 2007 Melkior et al., 2007).

\subsubsection{Formulation for Montmorillonite Interlayer Water}

The volume of interlayer water has been measured as a function of the degree of compaction as reflected in the dry density (Muurinen, et al., 2007). Strictly speaking, these results apply to montmorillonite with a large number of montmorillonite unit cells stacked on top of each other, since the interlayer porosity goes to zero as the grains become disperse. It was noted by Kozaki (1998) that a transition from 3 to 2 layer hydrates (corresponding to d001 spacing of 1.88 and $1.56 \mathrm{~nm}$ ) occurred as the dry density increased from 1300 to $1600 \mathrm{~kg} / \mathrm{m}^{3}$. This led Muurinen et al. (2007) to propose an increase in interlayer spacing (in units of meters):

$$
d_{I L}=1.41 \times 10^{-9}-4.9 \times 10^{-13} \rho_{d r y} .
$$

Bourg et al (2006) placed the transition between three and two-layer hydrates between 1420 and $1570 \mathrm{~kg} / \mathrm{m}^{3}$. The interlayer spacing also decreases with increasing $\mathrm{NaCl}$ concentration, leading to the suggestion (Kozaki, 2008) of an osmotic effect

$$
d_{I L}=1.41 \times 10^{-9}-4.9 \times 10^{-13} \rho_{d r y}+\gamma_{I L}\left(m_{B}-0.2\right)
$$

where $\gamma_{I L}$ is a coefficient (normally negative) and $m_{B}$ is the molality of the $\mathrm{NaCl}$ in the bulk water. The porosity of the interlayer then becomes

$$
\phi_{I L}=d_{I L} A_{\text {planar,int }} / 2 w_{\text {mont }} \rho_{d r y}
$$

where $A_{\text {planar,int }}$ is the surface area of the montmorillonite sheets stacked together (i.e., the internal surface area). Bourg et al. (2003) suggested a simpler linear relationship given by

$$
\phi_{I L} \approx 0.16 \rho_{d r y}
$$

They further suggested that the effective diffusion coefficient, $D^{*}$, is given by

$$
D^{*}=\frac{D_{\text {free }}\left(1-0.55 \rho_{d r y}\right)}{\tau^{2}}
$$

where $\tau^{2}$ is the tortuosity and $D_{\text {free }}$ is the diffusion coefficient in pure water. This suggested that free water disappeared from a compacted bentonite once the dry density reached a value of about $1800 \mathrm{~kg} / \mathrm{m}^{3}$, in good agreement with the results of Kim et al (1993). However, Bourg et al. (2006) suggested a model that took into account the change from three- to two-hydrate layers at about $1450 \mathrm{~kg} / \mathrm{m}^{3}$, which resulted in a nonlinear dependence of the interlayer porosity on dry density. 


\subsubsection{Formulation for Diffuse Double Layer}

A rigorous model for the diffuse layer could be derived from the combination of several equations, including the Poisson equation that describes the distribution of electrical potential, $\varphi$, in water:

$$
\frac{\partial^{2} \varphi}{\partial x^{2}}=-\frac{\rho_{z}}{\varepsilon}
$$

where $\varepsilon$ is the permittivity and $\rho_{z}$ is the volumetric charge density given by

$$
\rho_{z}=e \sum_{i} z_{i} C_{i}
$$

where $e$ is the elementary charge of an ion, $z_{i}$ is the charge of the ion, and $C_{i}$ is its concentration. The Boltzmann distribution gives an expression for the concentration $\overline{C_{i}(x)}$ in the diffuse layer

$$
\overline{C_{i}(x)}=C_{i} \exp \left(\frac{-z_{i} e \varphi(x)}{k_{B} T}\right),
$$

where $C_{i}$ is here the concentration in the bulk solution, $k_{B}$ is the Boltzmann constant, and $T$ is the absolute temperature. Combining Equations 2.2-6 through 2.2-8 yields the Poisson-Boltzmann equation

$$
\frac{\partial^{2} \varphi}{\partial x^{2}}=\frac{-e}{\varepsilon} \sum_{i} z_{i} C_{i} \exp \left(\frac{-z_{i} e \varphi(x)}{k_{B} T}\right)
$$

which can be solved exactly for various simple formulations (e.g., the Gouy-Chapman model). For an arbitrary multicomponent system, Equation 2.2-9 needs to solved numerically together with the diffusion equations for the various species. Note that Equation 2.2-9 predicts an exponentially decaying electrical potential that will tend to zero with distance from the charged surface (Figure 2.2-1). 


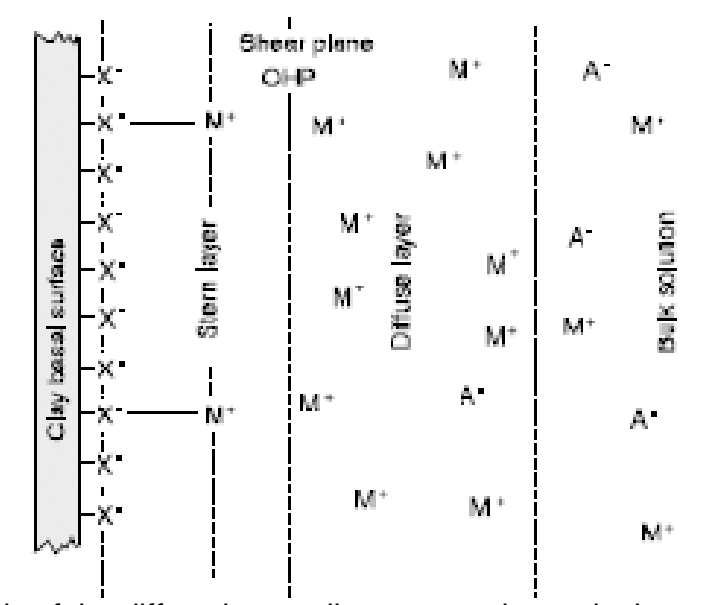

Figure 2.2-1: Schematic of the diffuse layer adjacent to a charged mineral surface. The counterions in the Stern Layer are calculated from a surface complexation model (either non-electrostatic or electrostatic) and is considered to be fixed, that is, inside of the shear plane. The diffuse layer, in contrast, is a swarm of mobile counter-ions that balance the charge of the mineral surface. Modified after Leroy et al., (2007).

Solving the full Poisson-Boltzmann equation is possible, but not normally very practical in the context of larger scale problems, since the scale of the diffuse layer is on the order of nanometers. Therefore, it is more practical to adopt an approach that treats porous medium as consisting of the three kinds of porosity corresponding to the kinds of water described above for compacted bentonite. For the Diffuse Double Layer, then, this involves defining a mean potential for the diffuse layer, the thickness of which will depend on the ionic strength of the solution. Its volume is given by the total surface area of charged mineral multiplied by the diffuse layer thickness:

$$
\phi_{D D L}=A_{e x t} \tau_{D D L} w_{m o n t} \rho_{d r y}
$$

where $A_{\text {ext }}$ is the external surface area of the montmorillonite, $\tau_{D D L}$ is the thickness of the diffuse layer, $w_{\text {mont }}$ is the weight fraction of montmorillonite in the bentonite, and $\rho_{d r y}$ is the dry density of the compacted bentonite. At $25^{\circ} \mathrm{C}$, the thickness of the diffuse layer can be approximated by the Debye length $\left(\kappa^{-1}\right.$, the distance over which the potential in the diffuse layer drops by $e$ );

$$
\tau_{D D L} \cong \kappa^{-1}=\frac{3.04 \times 10^{-10}}{\sqrt{I}},
$$

where $I$ is the ionic strength (Stumm, 1992). In some cases, the diffuse layers may overlap, resulting in a smaller volume for the total diffuse layer per unit volume of porous medium.

Computationally, the diffuse layer balances the charge on the mineral surface itself, that is, Stern layer at the interface between the minerals and the pore water. The composition of the Stern layer is normally calculated with a surface complexation model which may be either an electrostatic model (the Diffuse Double Layer Model of Dzombak and Morel, 1990, or potentially a Triple Layer Model, Leroy et al, 2007) or a non-electrostatic surface complexation model (Davis and Kent, 1990). The Stern Layer calculation includes a surface potential as an 
independent unknown if an electrostatic model is used. For the non-electrostatic case, only a set of secondary (non-component) surface complexes linearly related to the primary species in the bulk solution through mass action equations need to be calculated. The inclusion of an explicit diffuse layer, however, requires the introduction of a mean electrical potential for this volume as an independent unknown. This new unknown is solved through a charge balance equation and other relationships described further below.

\subsubsection{Donnan Equilibrium Model}

Several treatments of an explicit diffuse layer calculation based on a Donnan Equilibrium assumption have been presented in the literature (Wersin et al., 2004; Appelo et al., 2007; Leroy et al., 2007; Appelo et al., 2008). Typically, this involves an assumption that a Donnan Equilibrium condition applies, which equates the chemical potentials of the species in the diffuse layer and the bulk solution. Writing equations for the chemical potentials of the species $i$ in the macroporosity (superscript “B”) and microporosity (superscript “MP”) respectively, we have

$$
\begin{gathered}
\mu_{i}^{B}=\mu_{i}^{B, 0}+k_{B} T \ln a_{i}^{B} \\
\mu_{i}^{D D L}=\mu_{i}^{D D L, 0}+k_{B} T \ln a_{i}^{D D L}+q_{i} \varphi_{m}
\end{gathered}
$$

where the superscript 0 (first term on the right hand side) refers to the chemical potential at the reference state, $a_{i}$ are the species activities, $q_{i}$, is the charge of an ion (the elementary charge of a particle, $e$, multiplied by the valence of the ion, $z_{i}$ ), $k_{B}$ is the Boltzmann constant, and $\varphi_{m}$ is the mean electrical potential in the diffuse layer. The condition of Donnan Equilibrium implies that

$$
\begin{gathered}
\mu_{i}^{D D L}=\mu_{i}^{B} \\
\mu_{i}^{D D L, 0}=\mu_{i}^{B, 0} .
\end{gathered}
$$

Combining Equations 2.2-12, 2.2-13, 2.2-14, and 2.2-15 gives the Boltzmann distribution for the ion activities in the diffuse layer

$$
a_{i}^{D D L}=a_{i}^{B} \exp \left(\frac{-z_{i} e \varphi_{m}}{k_{B} T}\right)
$$

If the activity coefficients for the ions are assumed to be the same in the diffuse layer and the bulk water (probably not strictly true, but we would need a much more sophisticated model to improve on this assumption), then one can use Equation 2.2-16 to calculate concentrations in the diffuse layer as well

$$
C_{i}^{D D L}=C_{i}^{B} \exp \left(\frac{-z_{i} e \varphi_{m}}{k_{B} T}\right)
$$

Note that from Equation 2.2-17 it is possible to calculate all of the concentrations in the diffuse layer once its mean potential is determined numerically. The mean potential of the diffuse layer can be calculated with an additional charge balance equation

$$
\phi^{D D L} \sum_{i} z_{i} C_{i}^{D D L}=Q^{S L}
$$


where $Q^{S L}$ is the total charge in the Stern Layer calculated with the surface complexation model, $\phi^{D D L}$ is again the volume of the diffuse layer, and $C_{i}^{D D L}$ is the concentration in $\mathrm{mol} \mathrm{m}^{-3}$. The left hand side of Equation 2.2-18 gives a volumetric charge density in units of charge equivalents per unit volume porous medium. The surface charge is given by

$$
Q^{S L}=\sum_{k}^{N s} z_{k} \Gamma_{k}
$$

where $\Gamma_{k}$ is the concentration in units of moles sorbed species per unit volume porous medium and $z_{k}$ is the valence of the surface complex. By combining the Boltzmann equation (Eqn. 2.217), and the charge balance Equation 2.2-18, it is possible to calculate the mean potential of the diffuse layer, $\varphi_{m}$, along with the total concentrations of the primary species partitioned between the mineral surfaces (the Stern Layer), the diffuse layer, and the bulk solution. Since Equation 2.2-17 provides an algebraic relationship between the primary species in the bulk water and diffuse layer, it is not necessary to introduce the primary species in the diffuse layer as independent unknowns. In contrast, a kinetic treatment of the exchange between the two domains would require that the primary species in the diffuse layer be considered as independent unknowns. The total dissolved mass of a species, $T_{i}$, in units of moles per unit volume porous medium is calculated from:

$$
T_{i}=\phi^{B} S_{L} C_{i}^{B}+\phi^{D D L} C_{i}^{D D L}
$$

where we have not included any contribution from mass in the clay interlayers as part of the dissolved total. Here the term $S_{L}$ refers to the liquid saturation, which is assumed to be one in the case of the diffuse layer. The accumulation term for species $i$ is then given by

$$
\frac{\partial}{\partial t}\left[\phi^{B} S_{L} C_{i}^{B}+\phi^{D D L} C_{i}^{D D L}+\Gamma_{i}+\phi^{B} S_{G} C_{i}^{G}\right]
$$

where $\Gamma_{i}$ is the sorbed mass and $C_{i}^{G}$ is the concentration of species $i$ in the gas phase if present, and $S_{G}$ is the gas saturation. This formulation treats the mass of species $i$ in mineral phases as a separate pool that is kinetically controlled. Note that this approach conserves mass of component $i$ over the entire porous medium, that is, mass is dynamically partitioned between the various pools (bulk solution, diffuse layer, surface complexes, etc.).

\subsubsection{Diffusive Transport}

Different transport operators are applied to each of the terms in Equation 2.2-21, including advection, dispersion and species-specific diffusion for the aqueous phase residing in the bulk water, species-specific diffusion for ions in the diffuse layer, and both advection and diffusion for the gas phase if present. Conceptually this means that within in any one grid cell there may be as many as three coexisting continua: 1) bulk water, 2) diffuse double layer, and 3) interlayer water/porosity. These continua can be assumed to be at equilibrium, in which case a single primary variable can be used to describe all of them for a given element, or they can be treated kinetically, in which case primary independent unknowns are required for each of the porosity domains. In the case where equilibrium is assumed between the three (or two) domains, the transfer of mass between them is assumed to be instantaneous, implying that diffusion-controlled exchange between the two is not considered. However, diffusion within each continuum is 
possible (along with advection in the macroporosity), which requires that diffusion coefficients are provided separately for each of the continua. The model then calculates gradients within each continuum to determine the diffusive flux. The diffusive flux, $J_{i}$, in the case of the microporosity is given by (Steefel and Maher, 2009)

$$
J_{i}^{M P}=-\phi^{M P} D_{i}^{M P} \frac{\partial C_{i}^{M P}}{\partial x}+\frac{t_{i}^{M P}}{z_{i}} \phi^{M P} \sum_{j} z_{j} D_{j}^{M P} \frac{\partial C_{j}^{M P}}{\partial x}
$$

where $D_{i}^{M P}$ is the species-specific diffusion coefficient for the microporosity and $t_{i}^{M P}$ is the transference number, or the fraction of the current carried by any one ion, for the microporosity given by

$$
t_{i}=\frac{z_{i}^{2} u_{i}^{M P} C_{i}^{M P}}{\sum_{j} z_{j}^{2} u_{j}^{M P} C_{j}^{M P}}
$$

In this expression, $u_{i}$ refers to the mobility of ion $i$ in the microporosity. A similar expression applies to species-specific, multicomponent diffusion in the macroporosity (Steefel and Maher, 2009).

\subsubsection{Limitations to the Model}

There is currently some interest in the community in being able to describe the slow release of ions or contaminants from low conductivity zones via diffusion. This kinetic behavior, which is frequently observed in both laboratory experiments and field tests, involves a diffusive transfer that is by definition non-equilibrium, driven as it is by gradients in chemical potential. With the assumption of a Donnan Equilibrium between the Diffuse Double Layer and the bulk or free water, however, no such chemical potential gradients can exist, since the chemical potentials in the two domains are assumed equal in this case. While diffusion-controlled kinetic release from "immobile" domains is relatively easy to model when no electrostatic effects are important (as the hydrologic community has discovered), the problem is far more difficult when electrical potential effects on chemical potentials (or ion activities) are included. A full treatment in this case requires solving the multicomponent diffusion equation along with the Poisson-Boltzman equation (Equation 2.2-8) at the nanometer scale. While this is possible, there are difficulties in upscaling the results when larger length scales (e.g., a laboratory column or larger) are considered.

It is likely that the activity coefficients for ions in the bulk solution and the diffuse layer are not the same. This follows from the fact that there is evidence for a change in the dielectric constant of water immediately adjacent to the charged mineral surface. The changes in activity coefficients would further change the counter-ion concentrations in the diffuse layer. Since the chemical potentials and activities are assumed the same in the bulk solution and the diffuse layer, no difference in the stability of either aqueous complex, surface complexes, or minerals occur between the two domains. While the Donnan Equilibrium assumption means that important chemical changes in the immediate vicinity of the mineral surface are likely not captured, significantly more sophisticated modeling approaches would be needed to improve on this assumption. 


\section{THE CURRENT MODELING CAPABILITIES AT LBNL}

This section provides a review of current LBNL modeling capabilities available for studying coupled THMC processes and reactive transport in EBS buffer materials. This review intends to help plan UFD EBS-group modeling activities with the current existing capabilities and also to help identify needs to improve these capabilities for future research activities.

\subsection{Modeling Tools for Coupled THM processes}

For the past decade, LBNL has been active in the development and application of coupled thermal-hydrological-mechanical (THM) modeling of bentonite-clay and rock systems associated with geological disposal of spent nuclear fuel. As part of this effort, LBNL has since 1992 been involved as a research team in the international collaborative project DECOVALEX (Development of COupled Models and their VALidation against EXperiments in nuclear waste isolation). The modeling of THM processes in expansive (swelling) clay used as a buffer in most current disposal concepts in Europe, Asia and Canada, has been conducted using LBNL's ROCMAS finite element code. More recently, through the work within the Yucca Mountain Project, LBNL has developed an alternative model called TOUGH-FLAC, which is based on linking LBNL's TOUGH family multiphase flow codes to the commercial FLAC ${ }^{3 D}$ geomechanical code. The development of the ROCMAS and TOUGH-FLAC has always been driven by needs for solving field-scale, multiyear in situ experiments of EBS and rock systems, including

1) The Kamaishi Mine heater test, Japan

2) The FEBEX in situ experiment at the Grimsel Test Site, Switzerland

3) The Drift Scale Test at Yucca Mountain, Nevada

4) The Tunnel Sealing Experiment (TSX) at URL Canada

5) The French Tournemire site in indurate clay.

A large number of Bench Mark Tests (BMTs) have been simulated, focusing on long-term coupled THM processes, both in the near field and EBS of multiple-barrier nuclear waste repositories and in the surrounding rocks. These cases include ROCMAS and TOUGH-FLAC modeling of:

1) The Japanese H12 repository design with vertical deposition holes.

2) The proposed high-level nuclear waste repository in Sweden for the KBS-3 concept.

3) The Canadian conceptual design for a repository in granite with horizontal deposition tunnels.

4) The Spanish EBS system emplaced in granite with horizontal deposition tunnels.

Moreover, a large number of laboratory experiments have been simulated for model validation as well as for calibration of coupled THM properties of bentonite-sand mixtures.

In the past year, LBNL has implemented the Barcelona Basic Model (BBM) into TOUGH-FLAC for rigorous modeling of thermo-elasto-plastic behavior of unsaturated soils. The BBM can describe a large number of typical features of the mechanical behavior of unsaturated soils, 
including wetting-induced swelling or collapse strains depending on the magnitude of applied stress, the increase of shear strength and apparent preconsolidation stress with suction. The BBM's implementation into TOUGH-FLAC is currently being tested and was applied to model the last case of the Spanish EBS system mentioned above. In this section, we first present the two modeling tools, ROCMAS and TOUGH-FLAC, and thereafter we demonstrate the application of ROCMAS and TOUGH-FLAC to the proposed high-level nuclear waste repository in Sweden.

\subsubsection{The ROCMAS Code}

The ROCMAS code (ROCk Mass Analysis Scheme) is a finite-element code for analysis of coupled THM processes in saturated-unsaturated fractured porous media. It has been gradually developed and extended since the early 1980s, headed by J. Noorishad at the LBNL. A hydromechanical formulation for fractured rock, based on Biot's general effective stress theory (Biot, 1941), was first developed, and a nonisothermal version of ROCMAS was presented in Noorishad et al., (1984). While at the time numerical models existed for coupled THM processes in porous media, the ROCMAS code was probably the first for fractured rocks, to include discrete fractures with non-linear coupled hydraulic and geomechanical behavior. The formulation was further extended from fully saturated to partially saturated media by Noorishad and Tsang (1996) and thereafter in Rutqvist et al. (2001), completing the formulation regarding the heat equation and effects of grain compressibility implemented into a full three-dimensional version.

In ROCMAS, the formulation of coupled thermo-hydroelasticity in terms of Biot's theory of consolidation (Biot, 1941) is extended to partially saturated media through Philip and de Vries' (1957) theory for heat and moisture flow in soil. In this theory, three phases (solid, liquid, and gas) are present. However, it is assumed that the gas pressure $P_{g}$ is constant and equal to atmospheric pressure throughout the porous medium. As a consequence, vapor transport occurs only through molecular diffusion driven by a gradient in vapor concentration (density), while advection of vapor with bulk gas flow is neglected. The vapor density in the medium is governed by Kelvin's relation, assuming thermodynamic equilibrium for pore liquid in contact with its vapor, and phase transitions occur as evaporation-condensation processes. During heat transfer, coexisting fluid and solid components are assumed to be in local thermal equilibrium (i.e., locally they are at the same temperature). The mechanical behavior of the porous media consists of the gas, liquid and solid-matter responses to local pressure and the overall material (skeleton) response to effective stresses. Fractures are treated as a "porous medium" separate from the rock matrix and would be discretely defined by special fracture elements in a finite-element mesh. Therefore, the basic balance equations are the same for rock matrix and fracture materials, while some of the constitutive relations differ. With this approach and these assumptions, three balance equations-water mass balance, energy conservation and linear momentum balance-and a number of constitutive relations are required for a full description of the THM state. The ROCMAS code includes various versions of constitutive geomechanical models for solid rocks, soils and discrete fractures including (Noorishad and Tsang, 1996):

- Linear elastic solid

- Associated and non-associated strain softening/hardening elastoplastic continuum 
- Sandler/DeMaggio cap plasticity

- Oriented plasticity

- Compressible, dilating and strain softening elasto-plastic joints

- No tension continuum

The cap plasticity model may be applied to unconsolidated clay to model pore-collapse in addition to shear failure. However, for the EBS it must be extended to capture basic geomechanical behavior of unsaturated soil including saturation dependent strength and stiffness. A better option might be the Barcelona Basic Model that has been implemented in TOUGHFLAC.

\subsubsection{The TOUGH-FLAC Simulator}

The TOUGH-FLAC was developed as a pragmatic approach for modeling coupled multiphase flow, heat transport and geomechanics, by linking the two established codes TOUGH2 and FLAC $^{3 \mathrm{D}}$ (Rutqvist et al., 2002). In this approach, TOUGH2 (Pruess et al., 1999) is used for solving multiphase flow and heat transport equations, whereas FLAC ${ }^{3 \mathrm{D}}$ (Itasca, 2009) is used for solving geomechanical stress-strain equations. The TOUGH-FLAC simulator was originally developed for analysis of coupled THM processes associated with the Yucca Mountain Project. The FLAC ${ }^{3 \mathrm{D}}$ code was selected for the coupling to TOUGH2, because it is a well-established commercial code that has been extensively tested and verified. The two codes are sequentially coupled, but a TOUGH-FLAC simulation runs seamlessly. A great advantage with the adopted approach is that both codes are continuously developed and widely used in both academia and industry.

The simulator has been applied to study coupled geomechanical aspects under multiphase flow conditions for a wide range of applications, including nuclear waste disposal, $\mathrm{CO}_{2}$ sequestration, geothermal energy extraction, naturally occurring $\mathrm{CO}_{2}$ upwelling with surface deformations, and gas production from hydrate-bearing unconsolidated sediments. These applications have been accompanied with exploratory code developments. The most significant new development is a revised architecture compared to the earlier attempts, enabling a more rigorous and tight coupling procedure with improved computational efficiency. This development occurred when coupling the newly released TOUGH+ code to FLAC3D for the analysis of the geomechanical performance of hydrate-bearing unconsolidated sediments (Rutqvist and Moridis, 2009).

For analysis of coupled THM problems, the TOUGH2 and FLAC ${ }^{3 \mathrm{D}}$ are executed on compatible numerical grids and linked through a coupled THM model (Figure 3.1-1) with coupling functions serving to pass relevant information between the field equations that are solved in respective code. Depending on the problem and specific porous media (e.g., fractured rock, unsaturated clay, or hydrate-bearing sediments), a number of coupling functions have been developed. 


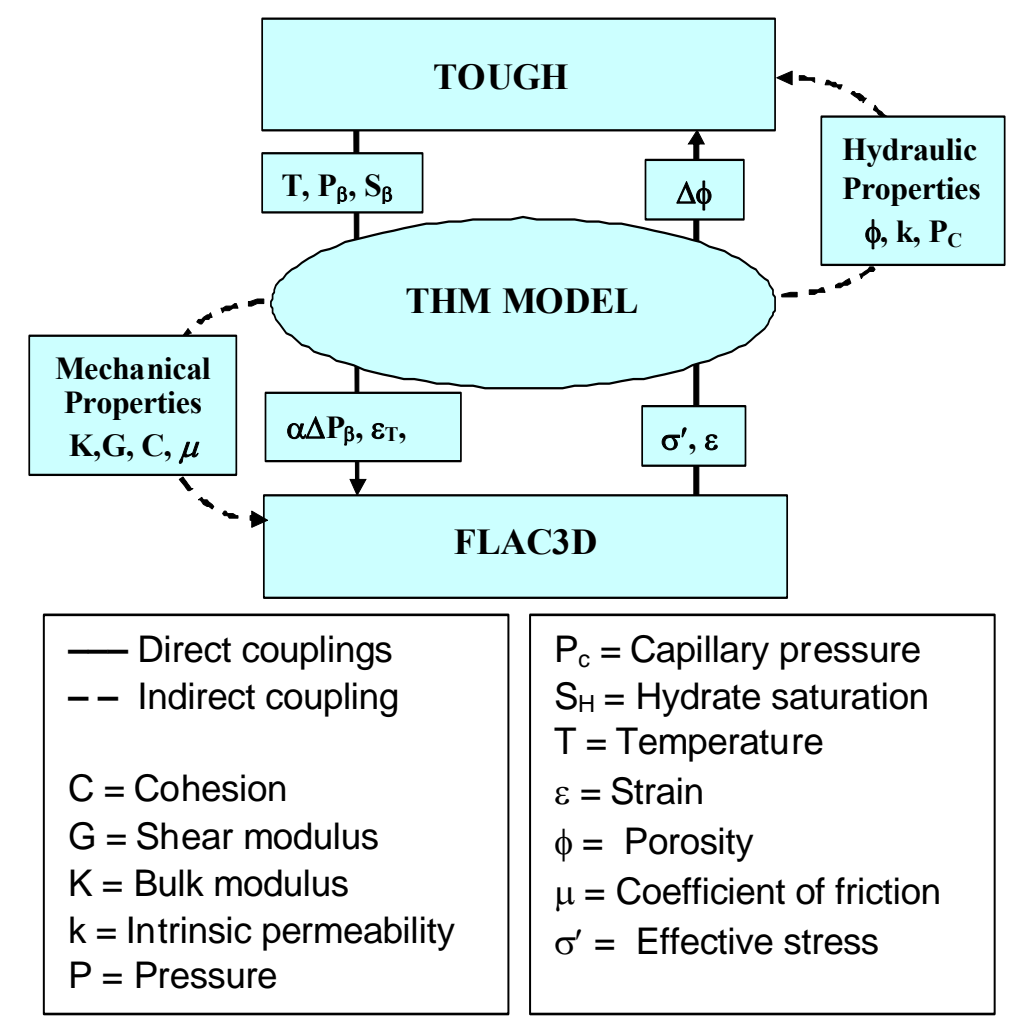

Figure 3.1-1. Schematic of linking TOUGH family code such as TOUGH+ and TOUGH2 with FLAC ${ }^{3 D}$ for a coupled THM simulation.

In FLAC $^{3 \mathrm{D}}$, the basic explicit dynamic calculation iterates between solving the equation of motion and the stress-strain constitutive equation using a sufficiently small time step to assure numerical stability. In one time step, the equation of motion is first invoked to calculate new velocities based on previous velocities and forces. The nodal velocities are then used to derive new strain rates and stress, which in turn are used to update the force vector. The final solution is reached (using a damped solution) when the body is in equilibrium or in steady-state flow (plastic flow), and the out of balance force goes to zero.

A large number of constitutive geomechanical models are readily available in FLAC ${ }^{3 \mathrm{D}}$, for both solid and interface elements, including:

- Elastic, isotropic, orthotropic, and transversely anisotropic

- Strain hardening/softening Mohr-Coulomb plasticity

- Ubiquitous joint (anisotropic) strain-hardening/softening bi-linear plasticity

- Double-yield plasticity

- Modified Cam-Clay

- Various creep models

The modified Cam-Clay may be applied to soft clay under saturated conditions. This model has been extended by the LBNL to the Barcelona Basic Model for thermo-elasto-plastic behavior of unsaturated soils (Rutqvist et al., 2009c). This type of model was recently applied by the group at the University of Cataluña, Barcelona, for modeling the thermo-elastoplastic behavior of the 
compacted bentonite at the FEBEX in situ experiment. Thus, it is a contemporary model for the coupled geomechanical behavior of compacted bentonite-sand mixtures associated with nuclear waste respositories. The various anisotropic elastic and plastic models are suitable for modeling of shale.

In Figure 3.1-1, the data exchanges between TOUGH and FLAC ${ }^{3 \mathrm{D}}$ are illustrated with arrows going through the central THM model. The arrow on the right-hand side of Figure 3-1-1 shows the transmission of the effective stress $\sigma^{\prime}$ and strain $\varepsilon$ (that are computed in FLAC ${ }^{3 \mathrm{D}}$ ) to TOUGH for calculation of the updated porosity $\phi$ and the corresponding porosity change $\Delta \phi$. This mechanically induced $\Delta \phi$ has an immediate effect on fluid flow behavior. For example, if a change in $\sigma^{\prime}$ and $\varepsilon$ causes $\phi$ to decrease, the pore pressure is expected to rise, especially if the permeability is low.

For porous deformable media, two models for mechanically induced porosity changes are implemented in the most recent version linking $\mathrm{FLAC}^{3 \mathrm{D}}$ to $\mathrm{TOUGH}+$

(i) A poroelastic model (based on the approach proposed by Settari and Mourits (1998) that considers macroscopic stress/strain changes and grain deformability

(ii) An empirical model (proposed by Rutqvist and Tsang, 2002) that describes a nonlinear change in porosity as a function of the effective mean stress

The $\Delta \phi$ computed from either of these models is used to estimate changes in $k$ by means of empirical equations. The updated $\phi$ and $k$ values are in turn used to estimate changes in the hydraulic and wettability properties of the porous medium (i.e., aqueous- and gas-phase relative permeabilities $k_{r A}$ and $k_{r G}$, and capillary pressure $P_{c}$ ) by employing appropriate scaling equations. For fractured media, a similar exponential empirical model has been applied to correct permeability for changes in the stress field (e.g., Rutqvist et al., 2002).

The arrow on the left side of Figure 3.1-1 depicts the flow of data obtained from TOUGH (namely the pressure $P$, temperature $T$, and phase saturations $S_{\beta}$ ) to FLAC ${ }^{3 \mathrm{D}}$ for processing and estimation of their impact on the effective stress $\alpha \Delta P_{\beta}$ ( $\alpha$ being Biot's effective stress parameter), as well as on thermal and swelling strains ( $\varepsilon_{T}$ and $\varepsilon_{s w}$, respectively). Capabilities for modeling of moisture swelling and geomechanical behavior of unsaturated soil have recently been implemented into TOUGH-FLAC. In this model, the swelling can either be introduced as a function of phase saturation or as a function of suction (or capillary pressure, $\mathrm{P}_{\mathrm{c}}$ ) using the Barcelona Basic Model for elastoplastic behavior of unsaturated soils (Rutqvist et al., 2009c).

Additionally, changes in $P, T$, and $S_{\beta}$ may also result in changes in other mechanical properties listed in Figure 3.1-1. These include the bulk modulus $K$, the shear modulus $G$, the cohesion $C$, and the coefficient of internal friction $\mu$. For example, in the case of hydrate-bearing sediment, geomechanical properties change as a function of solid-phase saturations, i.e., hydrate and ice saturations ( $S_{H}$ and $S_{I}$, respectively). In the case of unsaturated soil, the bulk modulus and friction angle is a function of suction. 


\subsubsection{Comparison of ROCMAS and TOUGH-FLAC to Other THM codes}

A steadily growing interest in coupled THM phenomena in geological media has encouraged development of many computer codes at various levels of sophistication. Among those recently applied in the field of rock mechanics are THAMES (Ohnishi and Kobayashi, 1996), MOTIF (Guvanasen and Chan, 1995), FRACON (Nguyen, 1996), FEHM (Bower and Zyvoloski, 1997), GeoSys/Rockflow, (Kolditz et al. 2003), FRT-THM, (Liu et al. 2006), FRIP (Pine and Cundall, 1985), FRACture (Kohl and Hopkirk, 1995) and GEOCRACK (Swenson et al. 1997). The first four of these have been applied mostly in the field of geological disposal of nuclear waste, while the last three have been applied to the field of hot-dry-rock geothermal energy. There are also a few commercially available codes that have been applied to study these phenomena. The most frequently applied in soil and rock mechanics are ABAQUS (Börgesson, 1996), a finite-element code; FLAC (Israelsson, 1996a), a finite-difference code; and UDEC (Israelsson, 1996b), a discrete-element code.

Some of the above mentioned codes have also (like ROCMAS) been adapted for analysis of THM processes in variably saturated media (e.g., FRACON, FLAC, ABAQUS). At the same time, other codes have emerged from the field of soil mechanics. One of these is COMPASS (Thomas et al., 1995), which simulates two-phase (gas and liquid) in partially saturated soil, coupled with heat transport and mechanical responses. The mechanical behavior in COMPASS is governed either by a state surface approach or the more recent BBM. Another code in this group is CODE-BRIGHT (Olivella et al. 1994), which originally was developed for nonisothermal multiphase flow of brine and gas in saline media. This code has recently been adapted and applied to engineered clay barrier systems having similar characteristics to COMPASS, with two-phase flow for transport of moisture and heat coupled with mechanical responses using the state-surface approach (Gens et al. 1998) or the BBM thermo-elasto-plastic model that has recently been implemented in TOUGH-FLAC.

A number of simulators have also been developed focusing on oil and gas reservoir engineering, including commercial finite-element packages such as VISAGE (Koutsabeloulis, 1998), GMCSTARS, and a number of academic codes. TOUGH-FLAC is in the class of coupled simulators that is built upon coupling of a reservoir simulator to a geomechanical code. It is a delicate operation to correctly change the porosity of the reservoir simulator upon a change in stress or strain in the mechanical code. The ideas of Settari and Mourits (1998) have been implemented in TOUGH-FLAC coupling as one alternative poro-elastic model. The correct poro-elastic consideration is important when comparing simulation results to that of fully coupled poroelastic finite element models of the Biot type. However, as described by Settari and Mourits (1998), in practice it is more important to consider the nonlinear stress-dependent effects on porosity and permeability over the range of stress expected in a problem. Such properties may be derived directly from laboratory data and fitted to theoretical or empirical functions (e.g., Liu et al., 2009) or by calibration to field experiments (e.g., Rutqvist et al., 2008a).

In summary, it can be concluded that a large number of simulators have been developed for the analysis of coupled THM processes over the past 30 years. The ROCMAS code and TOUGHFLAC are two different types of simulators that complement each other, have been extensively applied, and yet have the flexibilities for modifications and future improvements, such as linkage 
to TOUGHREACT for fully coupled THMC processes. When evaluating the capabilities of a code it is important to look at how it has been applied. The next section presents on example application of the ROCMAS and TOUGH-FLAC simulators related to nuclear waste isolation and EBS.

\subsubsection{Modeling of the Proposed Swedish High Level Waste Repository}

This example is part of LBNL's review of the Swedish Nuclear Fuel and Waste Management (SKB) program on coupled THM processes within the recent SR-Can project. SR-Can is SKB's preliminary assessment of long-term safety for a KBS-3 nuclear waste repository, and is a preparation stage for the SR-Site assessment, the report that will be used in SKB's application for a final repository. In this case the ROCMAS and TOUGH-FLAC codes were applied to analyze coupled THM processes at the two candidate sites, Forsmark and Laxemar, using data defined in SKB's site description models for respective sites. LBNL conducted a review and model analysis to address issues related to near-field behavior, such as buffer resaturation and the evolution of the excavation-disturbed zone, as well as far-field behavior, such as stress induced changes in hydrologic properties. The complete work is reported in Rutqvist and Tsang (2008). Here we focus on one example, related to the buffer/backfill/rock interaction for two alternative backfill options.

Figure 3.1-2 presents the model geometry representing one deposition hole and tunnel at the center of the repository. The model dimensions are different for Forsmark and Laxemar alternative, according to SKB's design that depends on site-specific conditions such as geology and in situ stress conditions. In 2009, the Forsmark site was selected by the SKB as the site for the SR-Site assessment.

Figure 3.1-3 presents the main difference in the backfill properties between the 30/70-mixture and Friedland Clay options considered in this case. One important issue identified in LBNL's modeling was that the initial suction pressure in the Friedland Clay was slightly higher than in bentonite buffer and much higher than in the rock. The high suction pressure in the Friedland Clay results in a strong potential for desaturation of the rock and even the possibility for suction of water from the buffer into the overlying backfill (Figures 3.1-4 and 3.1-5).

In the case of a very low rock permeability of $1 \times 10^{-20} \mathrm{~m}^{2}$, there is a strong desaturation of the rock surrounding the backfill and buffer, and total resaturation time for the two different backfill alternative varies between 20,000 to 40,000 years (Figure 3.1-5). Moreover, in the case of Friedland Clay, water would tend to be sucked from the buffer into the backfill rather than the reverse. The slow resaturation of the buffer implies that no substantial swelling pressure can develop before the thermal stress peak occurs at about 100 years. A lack of swelling pressure can have severe consequences for the development of rock failure and the EDZ around the deposition holes. 


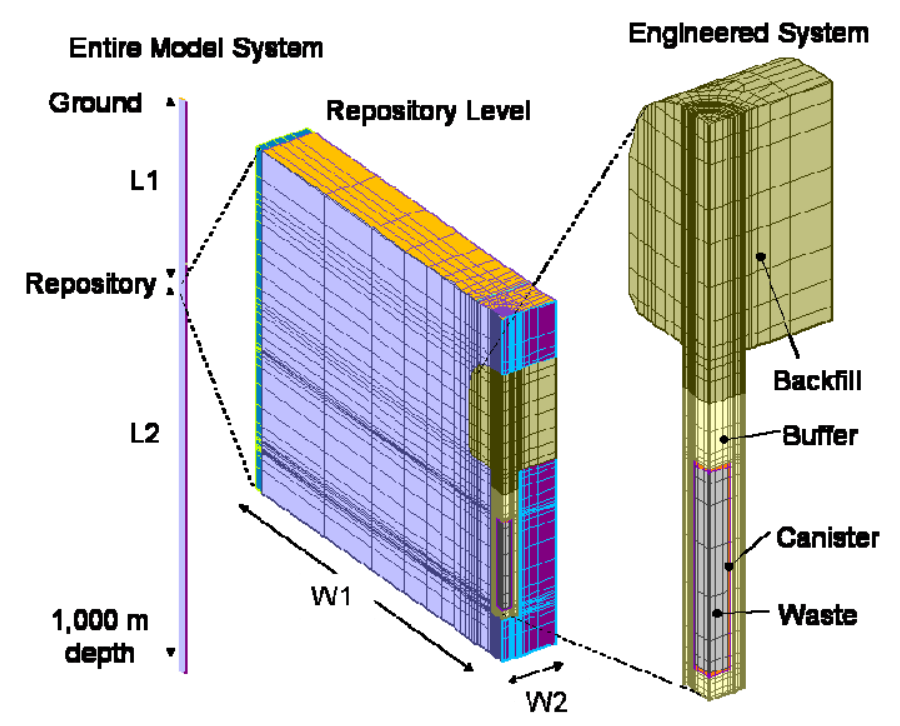

\begin{tabular}{|l|c|c|c|c|}
\hline & $\begin{array}{c}\text { Depth of } \\
\text { repository, L1 (m) }\end{array}$ & $\begin{array}{c}\text { Distance to } \\
\text { bottom, L2 (m) }\end{array}$ & $\begin{array}{c}\text { Half tunnel } \\
\text { spacing, W1 (m) }\end{array}$ & $\begin{array}{c}\text { Half canister } \\
\text { spacing, W2 (m) }\end{array}$ \\
\hline Laxemar & $500 \mathrm{~m}$ & $1,000 \mathrm{~m}$ & $40 / 2=20$ & $7.2 / 2=3.6$ \\
\hline Forsmark & $400 \mathrm{~m}$ & $1,000 \mathrm{~m}$ & $40 / 2=20$ & $6 / 3=3$ \\
\hline
\end{tabular}

Figure 3.1-2. Quarter symmetric finite element model for coupled THM simulations of KBS-3V repositories at Forsmark and Laxemar.
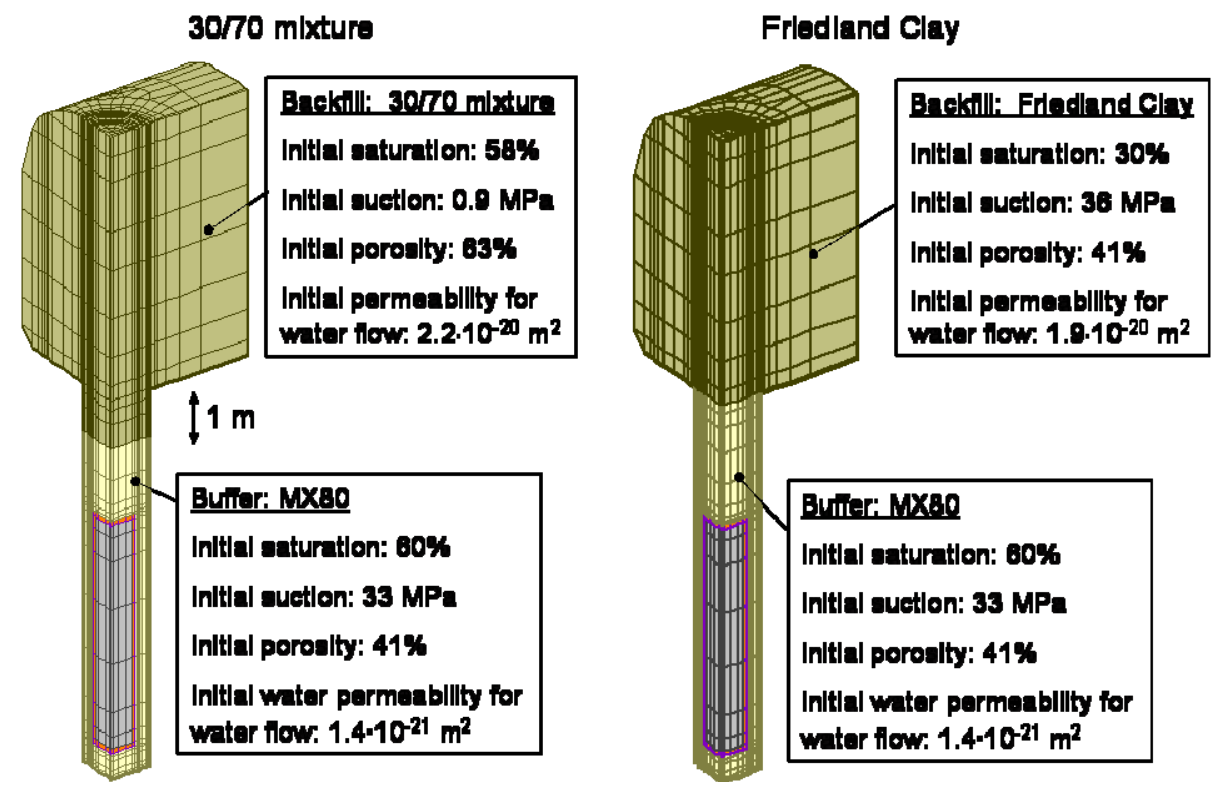

Figure 3.1-3. Comparison of material properties and initial conditions for two alternative backfill materials:

(a) 30/70 bentonite-rock mixture and (b) Friedland Clay. 
30/70-mixture backfill

1.

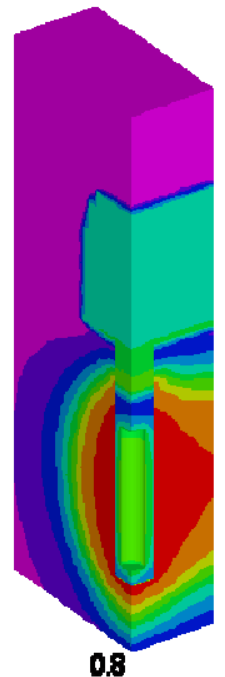

0.8

\section{Friedland clay backfill}

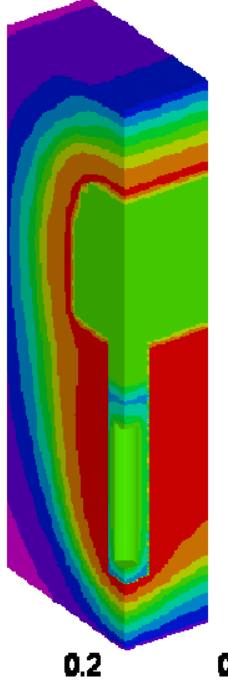

0.4

0.

\section{Llquld Saturation (-)}

Figure 3.1-4. Variation backfill properties when rock permeability is very low $\left(\mathrm{k}=1 \times 10^{-20} \mathrm{~m}^{2}\right)$ : Distribution of liquid saturation 1,000 years after emplacement for a repository located at Forsmark when the tunnels are backfilled with (a) 30/70-mixture and (b) Friedland Clay.
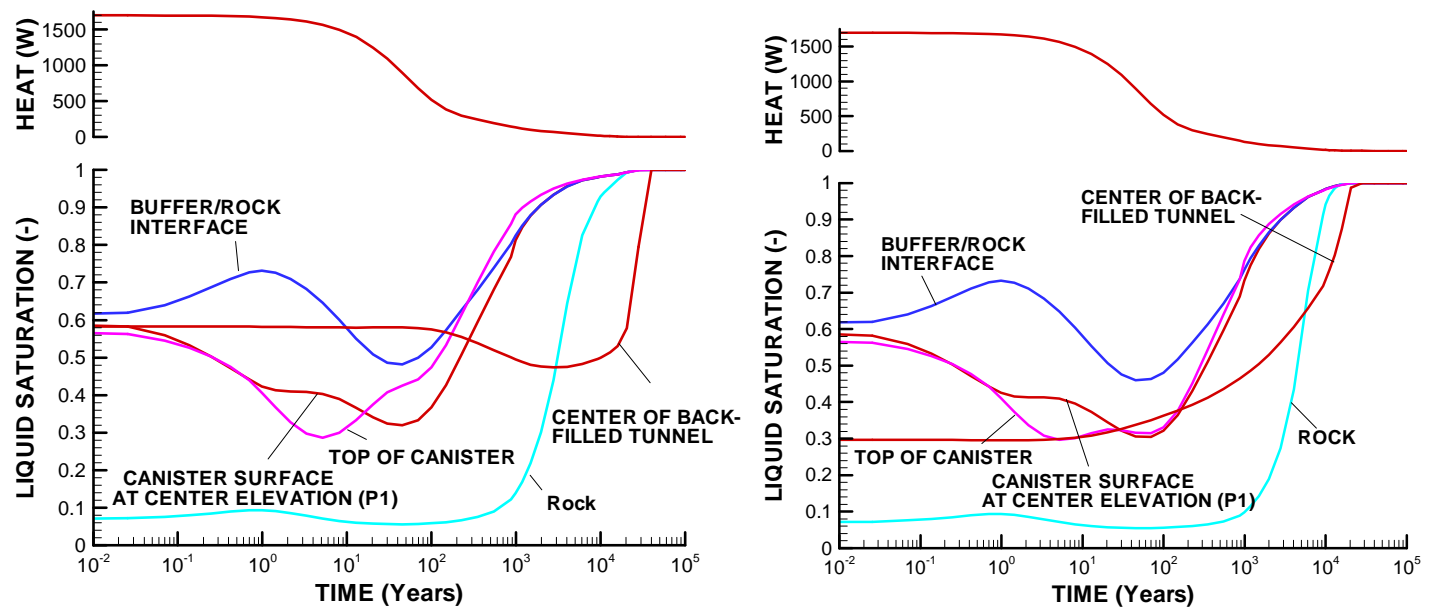

Figure 3.1-5. Variation of backfill properties when intrinsic rock permeability is low $\left(\mathrm{k}=1 \times 10^{-20} \mathrm{~m}^{2}\right)$ : Evolution of saturation at a repository located at Forsmark when the tunnels are backfilled with (a) 30/70-mixture and (b) Friedland Clay.

\subsection{Modeling Tools for Reactive Transport}

Two modeling tools, CrunchFlow and TOUGHREACT, are available at LBNL for modeling reactive transport processes. This subsection briefly reviews these two modeling tools. 


\subsubsection{CrunchFlow Code for Diffuse Double Layer Transport}

Currently at LBNL the capability exists for modeling of solute partitioning into an explicit diffuse double layer and associated diffusion within this layer using the code CrunchFlow. No such capability presently exists for calculation of diffusion in interlayer porosity, although this is not seen as a serious obstacle. In the code CrunchFlow, which has had capabilities for multicomponent diffusion since 2002 (see Giambalvo et al, 2002), the option for calculation of an explicit diffuse double layer has been recently added. To do so, the mean electrical potential of the diffuse layer is added as an independent unknown, which is determined in conjunction with the other primary variables by solving a charge balance equation for the diffuse layer balancing the mineral surface charge present in the Stern Layer. Since a Donnan Equilibrium condition is assumed, the concentrations of species in the diffuse layer are dependent variables algebraically linked to the primary species in the bulk water through the Boltzmann equation (Equation 2.2-17 in Section 2.2.3). Exchange between the diffuse double layer and the bulk water, therefore, is considered as instantaneous in this formulation. Species-specific diffusion with electrochemical migration (multicomponent diffusion) is considered in both domains (diffuse layer and bulk water). An example simulation showing the slower diffusion of the anion chloride out of a clay-rich rock as a result of its partial exclusion in the diffuse double layer is shown in Figure 3.2-1

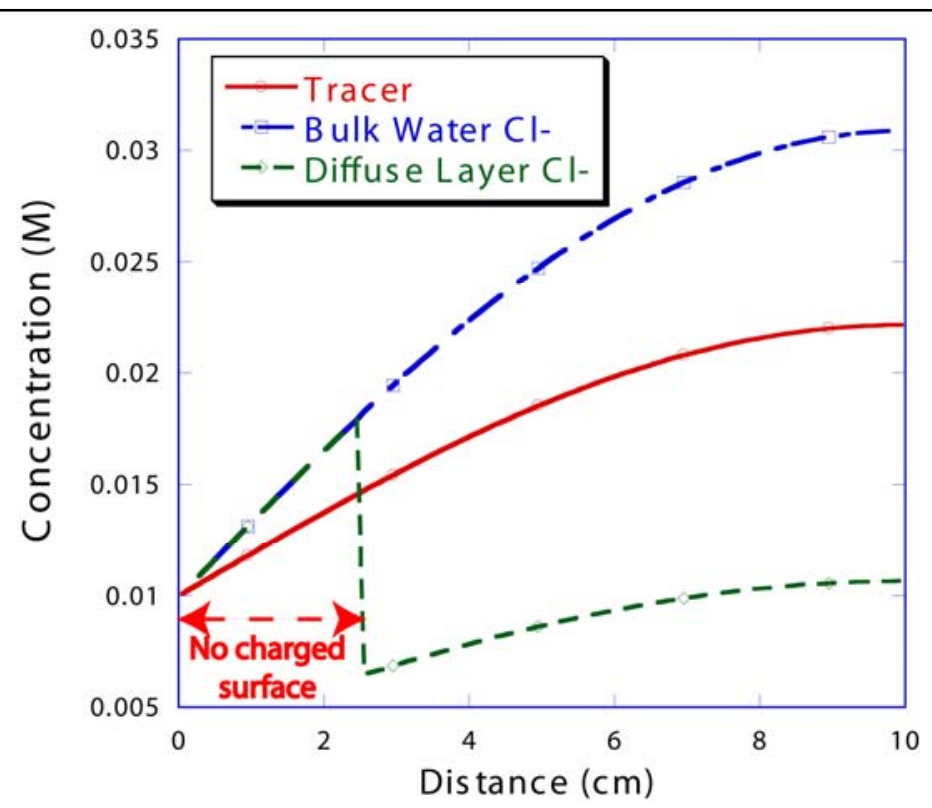

Figure 3.2-1 Spatial profile for the uncharged tracer and chloride in both the bulk water and diffuse layer where the charged illite surfaces result in anion exclusion. No charged surfaces within $1.5 \mathrm{~cm}$ of $X=0$, which produces a discontinuity in the diffuse layer profile at this position. Calculation using CrunchFlow. 


\subsubsection{TOUGHREACT Code}

Coupled modeling of subsurface multiphase fluid and heat flow, solute transport, and chemical reactions can be applied to many geologic systems and environmental problems, including geothermal systems, diagenetic and weathering processes, nuclear waste emplacement, acid mine drainage remediation, contaminant transport, and groundwater quality. TOUGHREACT has been developed as a comprehensive non-isothermal multi-component reactive fluid flow and geochemical transport simulator to investigate these and other problems (Xu et al., 2008). A number of subsurface thermo-physical-chemical processes are considered under various thermohydrological and geochemical conditions of pressure, temperature, water saturation, and ionic strength. TOUGHREACT can be applied to one-, two- or three-dimensional porous and fractured media with physical and chemical heterogeneity. The code can accommodate any number of chemical species present in liquid, gas and solid phases. A variety of equilibrium chemical reactions are considered, such as aqueous complexation, gas dissolution/exsolution, and cation exchange. Mineral dissolution/precipitation can take place subject to either local equilibrium or kinetic controls, with coupling to changes in porosity and permeability and capillary pressure in unsaturated systems. Chemical components can also be treated by linear adsorption and radioactive decay.

The first version of the non-isothermal reactive geochemical transport code TOUGHREACT was developed (Xu and Pruess, 1998) by introducing reactive geochemistry into the framework of the existing multi-phase fluid and heat flow code TOUGH2 (Pruess, 1991). TOUGHREACT was further enhanced with the addition of (1) treatment of mineral-water-gas reactive-transport under boiling conditions, (2) an improved HKF activity model for aqueous species, (3) gas species diffusion coefficients calculated as a function of pressure, temperature, and molecular properties, (4) mineral reactive surface area formulations for fractured and porous media, and (5) porosity, permeability, and capillary pressure changes owing to mineral precipitation/dissolution. Subsequently, TOUGH2 V2 was released with additional EOS modules and features (Pruess et al., 1999 which was incorporated into the present version of TOUGHREACT (Xu et al., 2008).

\subsubsection{Major Processes Treated by TOUGHREACT}

The major processes for fluid and heat flow are: (1) fluid flow in both liquid and gas phases occurs under pressure, viscous, and gravity forces; (2) interactions between flowing phases are represented by characteristic curves (relative permeability and capillary pressure); (3) heat flow by conduction and convection, and (4) diffusion of water vapor and air. Thermophysical and geochemical properties are calculated as a function of temperature, such as fluid (gas and liquid) density and viscosity, and thermodynamic and kinetic data for mineral-water-gas reactions. Transport of aqueous and gaseous species by advection and molecular diffusion are considered in both liquid and gas phases. Depending on the computer memory and CPU performance, any number of chemical species in the liquid, gas and solid phases can be accommodated. Aqueous complexation, acid-base, redox, gas dissolution/exsolution, and cation exchange are considered under the local equilibrium assumption. Mineral dissolution and precipitation can proceed either subject to local equilibrium or kinetic conditions. Linear adsorption and decay can be included. 


\subsubsection{Governing Equations}

The primary governing equations for multiphase fluid and heat flow, and chemical transport have the same structure, derived from the principle of mass (or energy) conservation. These equations are presented in $\mathrm{Xu}$ et al. (2008). Expressions for non-isothermal multiphase flow are given in Pruess (1987) and Pruess et al. (1999). The transport equations are written in terms of total dissolved concentrations of chemical components, which are concentrations of the basis species plus their associated aqueous secondary species (Yeh and Tripathi, 1991; Steefel and Lasaga, 1994; Walter and others, 1994; Lichtner, 1996; and Xu and Pruess, 2001). If kineticallycontrolled reactions occur between aqueous species, then additional ordinary differential equations need to be solved to link the total concentrations of the primary species with the evolving concentrations of the secondary species (Steefel and MacQuarrie, 1996). Kineticallycontrolled reactions between aqueous species are not considered in the present version. Slow aqueous phase reactions are common in the case of redox reactions and will be addressed in future development. Advection and diffusion processes are considered for both the aqueous and gaseous species. Aqueous species diffusion coefficients are assumed to be the same. Gaseous species, having a neutral valence, can have differing diffusion coefficients calculated as a function of T, P, molecular weight, and molecular diameter. The local chemical interactions in the transport equations are represented by reaction source/sink terms.

The primary governing equations must be complemented with constitutive local relationships that express all parameters as functions of fundamental thermophysical and chemical variables. The equations for chemical reactions are presented in Xu et al., (2008). Mass conservation in the closed chemical system is written in terms of basis (component) species. The species distribution must be governed by the total concentrations of the components. The oxygen is used for formulating redox reactions by attributing the oxidizing potential to the dissolved oxygen (Nordstrom and Muñoz, 1986; Wolery, 1992). In contrast to the free electron in the hypothetical electron approach (Yeh and Tripathi, 1991), oxygen can be present and can be transported in natural subsurface flow systems. The formulation for cation exchange is similar to that of Appelo and Postma (1993). For kinetically-controlled mineral dissolution and precipitation, a general form of rate law (Lasaga, 1984; Steefel and Lasaga, 1994; Palandri and Kharaka, 2004) is used (Xu et al., 2008). Thermodynamic and kinetic data are functions of temperature.

Temporal changes in porosity, permeability, and unsaturated hydrologic properties owing to mineral dissolution and precipitation can modify fluid flow. This feedback between transport and chemistry can be important (e.g., Raffensperger, 1996; Dobson et al., 2003), and can be treated by TOUGHREACT. Changes in porosity during the simulation are calculated from changes in mineral volume fractions. The porosity-permeability correlation in geologic media can be complex, depending on several factors, such as pore size distribution, pore shapes, connectivity (Verma and Pruess, 1988), and crystal morphology. Several porosity-permeability and fracture aperture-permeability relationships are included in the model (Xu et al., 2008). The code can also be set to monitor changes in porosity and permeability during the simulation without considering their effects on fluid flow. In unsaturated systems, capillary pressure can be modified via permeability and porosity changes using Leverett scaling (based on Slider, 1976). 


\subsubsection{Application of TOUGHREACT to Bentonite-Filled EBS}

This problem simulates water-rock interactions around nuclear waste packages emplaced in granitic host rock with bentonite backfill (Sonnenthal, 2008). This problem is based on data from the Swedish and Japanese nuclear waste programs, and was set up as a benchmark for the DECOVALEX-THMC project (Sonenthal, 2008). The grid for the simulations is shown in Figure 3.2-2. Because this benchmark problem was intended for simulations using various codes of various levels of complexity, it was set up in a very simplified manner (e.g., reactions under local equilibrium, no ion exchange). Therefore, this problem should not be taken as an accurate representation of a nuclear waste repository. Nevertheless, this problem illustrates typical coupled thermal-hydrological-chemical processes that could occur in the EBS around nuclear waste packages as influenced by the very different near-field mineralogy and water chemistry. These processes include a heat pulse from the waste package (from radioactive decay), rewetting of the bentonite, a temporary decrease in the liquid saturation in the granite near the granite/bentonite interface, and chemical reactions in the granite near the interface (e.g., plagioclase alteration to clay with reduction in porosity). In comparison to other test problems, the dominant mode of transport is diffusion of aqueous species.

In this problem, the heat load results in temperature at the canister-bentonite interface climbing to a maximum near $95^{\circ} \mathrm{C}$ after about 10 years, then dropping back to about $55^{\circ} \mathrm{C}$ after 100 years. A porosity decrease of about $4 \%$ is computed in the granite at the bentonite-granite interface after 1000 years mostly from the dissolution of albite. Minerals precipitating near the interface include Na-montmorillonite, K-feldspar, quartz and calcite.
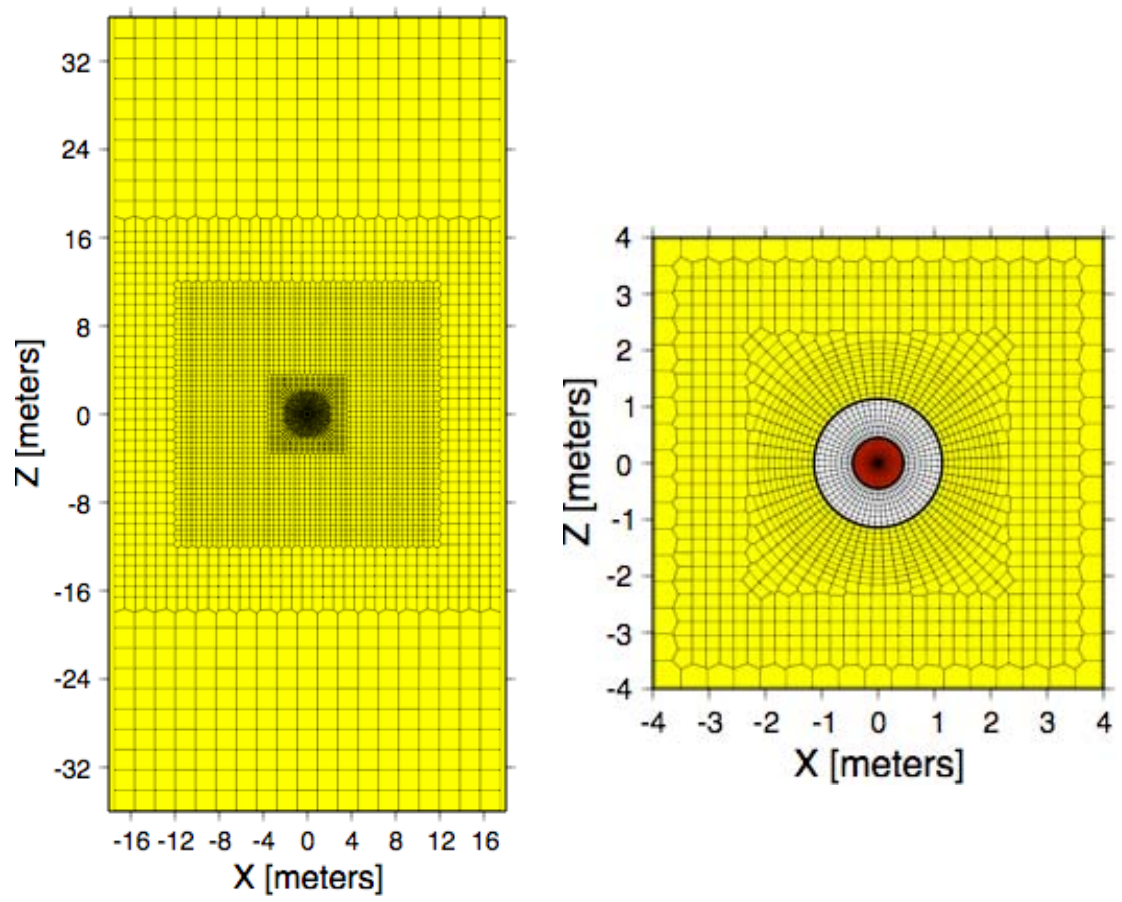

Figure 3.2-2. Two-dimensional numerical integral finite difference unstructured mesh for TOUGHREACT simulations (left) and enlargement of drift mesh (right) showing waste canister (red), bentonite buffer (white), and drift wall boundary. Mesh extends $500 \mathrm{~m}$ above and below the drift center, and $17.5 \mathrm{~m}$ to each side. 
Initially, there are small changes in the abundances of some minerals in the bentonite, owing to initial disequilibrium. The minor initial effects are overwhelmed by the heat- and transportinduced changes. By 1000 years, albite dissolution and quartz+calcite precipitation in the granite are evident (Figure 3.2-3). At this time, K-feldspar and calcite are dissolving in the bentonite near the margin of the granite, but were precipitated earlier in the hotter zone adjacent to the canister. The complex interplay of diffusion across the contact and the strong temperature gradients result in sharp changes in mineral dissolution/precipitation behavior traversing from the granite to the canister. Na-montmorillonite in the bentonite shows increased stability adjacent to the canister and also precipitates as a new secondary phase in the granite, but has dissolved in the bentonite at the margins of the drift.
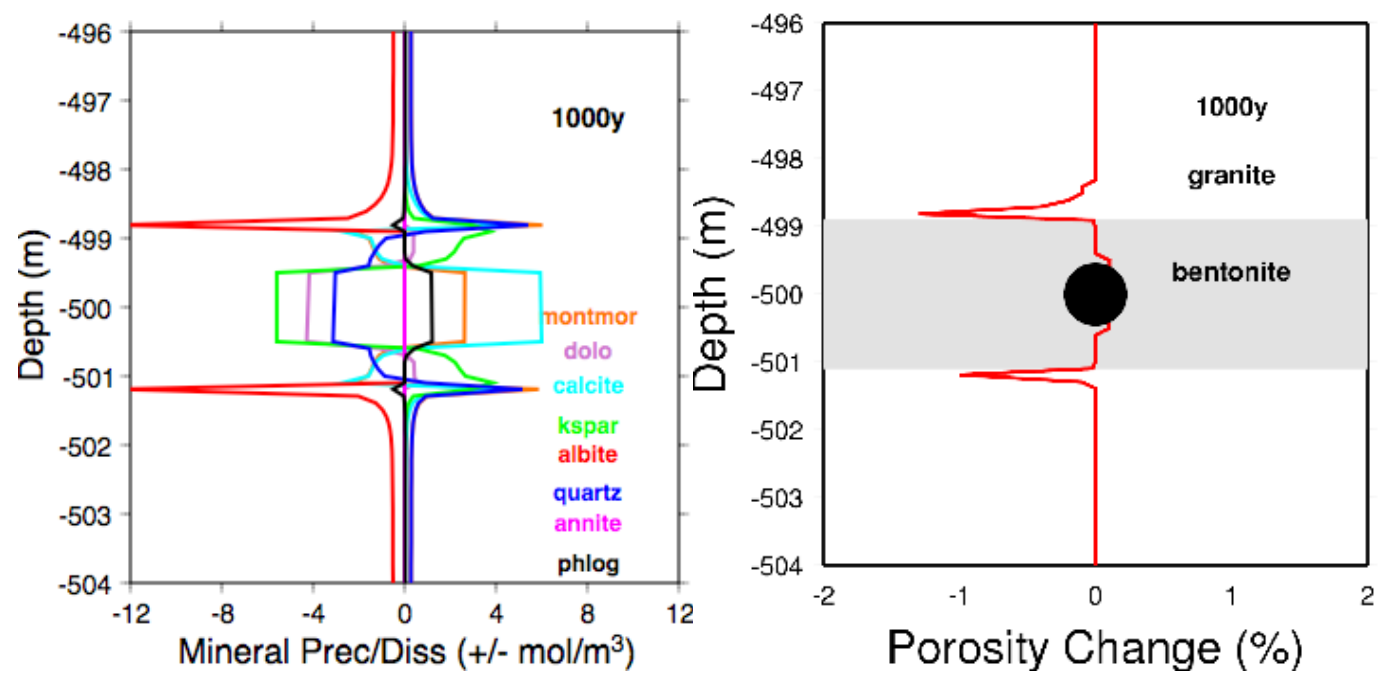

Figure 3.2-3. Mineralogical (left) and porosity (right) changes in bentonite and near-field granitic rock.

\section{MODELING RESULTS}

In this section, modeling results are presented for THM studies implementing and testing the Barcelona Basic Model (BBM) for thermo-elasto-plastic behavior in bentonite and for an update on reactive-diffusive transport model approaches for radionuclide diffusion in bentonite.

\subsection{Implementation and Testing of the Barcelona Basic Model}

This section presents implementation and testing of the Barcelona Basic Model (BBM) into TOUGH-FLAC for modeling of mechanical behavior of unsaturated soils, including bentonitesand mixtures for use a buffer material associated disposal of spent nuclear fuel. The BBM is a geomechanical constitutive model for capturing the elasto-plastic behavior of unsaturated soils. The model was first developed and presented in the early 1990s as an extension of the Modified Cam Clay (MCC) model to unsaturated soil conditions (Alonso et al., 1990). The model can describe many typical features of unsaturated-soil mechanical behavior, including wettinginduced swelling or collapse strains, depending on the magnitude of applied stress, as well as the increase in shear strength and apparent preconsolidation stress with suction (Gens et al., 2006). 
The BBM is the most advanced and accepted constitutive model used for modeling of bentonitebuffer behavior in the various European and Japanese nuclear waste programs. For example, the BBM was recently successfully applied to model the coupled thermal-hydrological-mechanical (THM) behavior of an unsaturated bentonite clay associated with the FEBEX in situ heater test at the Grimsel Test Site, Switzerland (Gens et al., 2009). The BBM has also been applied to other types of bentonite-sand mixtures such as MX-80, considered as an option for an isolating buffer in the Swedish KBS-3 repository concept (Kristensson and Åkesson, 2008a).

In the following subsections, we first present the relevant equations of the thermo-elasto-plastic BBM, its relationship to the MCC, and how it is implemented into TOUGH-FLAC. This is followed by the description and results of a number of simulation tests to verify the implementation of the BBM in comparison to published modeling, experimental, and laboratory data on THM behavior in unsaturated soils. Finally, we test and demonstrate the use of TOUGHFLAC with BBM for a problem related to geological disposal of nuclear waste, involving the coupled THM performance of a bentonite back-filled nuclear waste deposition tunnel.

\subsubsection{BBM Equations and implementation procedure}

We implemented a thermo-elasto-plastic version of the BBM in which the soil strength depends on both suction and temperature, and includes features for expansive (swelling) clay (Gens, 1995). Figure 4.1-1 presents the three-dimensional yield surface in $p^{\prime}-q-s$ space and $p^{\prime}-q-T$ space, where $p^{\prime}$ is net mean stress (i.e., total stress minus gas-phase pressure), $q$ is deviatoric stress (or shear stress), $s$ is suction, and $T$ is temperature (Gens, 1995). Under water-saturated conditions ( $s$ $=0$ ), the yield surface corresponds to the MCC ellipse (Roscoe and Burgland, 1968), and the size of the elastic domain increases as suction increases. The rate of increase, represented by the loading-collapse (LC) curve, is one of the fundamental characteristics of the BBM (Gens et al., 2006). Moreover, in the thermo-elasto-plastic version of the BBM, the size of the yield surface decreases with temperature (Figure 4.1-1). We implemented the BBM into TOUGH-FLAC by (1) extending an existing MCC module within the framework of the FLAC ${ }^{3 \mathrm{D}}$ User Defined Model (UDM) capability, and (2) adding computational routines for suction-dependent strains and net stress in unsaturated soils.

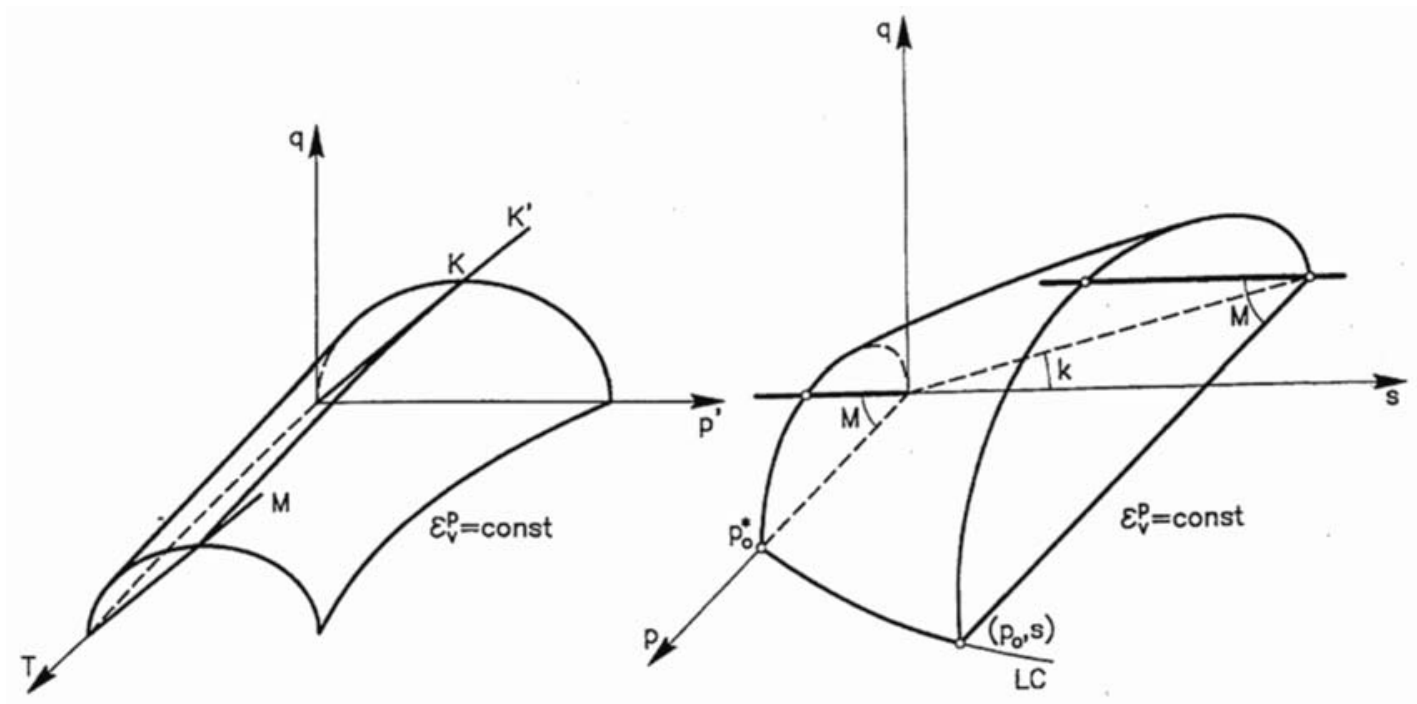


Figure 4.1-1. Three-dimensional representation of the yield surface in the thermo-elasto-plastic BBM (Gens, 1995).

\section{Stress State}

The conventional (Terzaghi) effective stress that can be expressed as

$$
\boldsymbol{\sigma}^{\prime}=\boldsymbol{\sigma}-p^{\phi} \mathbf{I}
$$

where $\sigma^{\prime}$ and $\sigma$ are, respectively, the effective and total stress tensors (positive for compression), $p^{\phi}$ is pore pressure, and I is the identity tensor. The stress state can be divided into a hydrostatic part $(1 / 3)$ trace $\left(\sigma^{\prime}\right) \mathrm{I}=p^{\prime} \mathrm{I}$ and deviatoric part $\mathrm{s}=\sigma^{\prime}-p^{\prime} \mathrm{I}$, where $p^{\prime}$ is the effective mean pressure (or effective mean stress) that can be expressed explicitly as:

$$
p^{\prime}=p-p^{\phi}=\frac{1}{3}\left(\sigma_{1}+\sigma_{2}+\sigma_{3}\right)-p^{\phi}
$$

where $p$ is total mean pressure (total mean stress), and $\sigma_{1}, \sigma_{2}$, and $\sigma_{3}$ are principal compressive stresses. The conventional effective mean stress is used for water saturated conditions in the original MCC model (Roscoe and Burgland, 1968) as well as in the FLAC ${ }^{3 \mathrm{D}}$ implementation of MCC (Itasca, 2009). In the BBM, however, under unsaturated conditions, the strains are related to changes in two independent stress variables, namely the net mean stress for which

$$
p^{\prime}=p-p^{g}
$$

and suction, $s$, is defined as

$$
s=p^{g}-p^{l}
$$

where $p^{g}$ and $p^{l}$ are gas- and liquid-phase pressures.

The deviatoric (von Mises) stress, $q$, is defined as:

$$
q=\sqrt{3 J_{2}}=\sqrt{3 \frac{1}{2} \mathbf{s} \cdot \mathbf{s}}=\sqrt{\frac{\left(\sigma_{1}^{\prime}-\sigma_{2}^{\prime}\right)^{2}+\left(\sigma_{2}^{\prime}-\sigma_{3}^{\prime}\right)^{2}+\left(\sigma_{1}^{\prime}-\sigma_{3}^{\prime}\right)^{2}}{2}}
$$

where $J_{2}$ is the second invariant of the effective deviatoric-stress tensor, s.

For the implementation of the BBM into TOUGH-FLAC, both suction and gas pressure are needed. We calculated $s$ from the TOUGH capillary pressure, which in turn is calculated from gas- and liquid-phase pressures according to Equation (4.1-4). Moreover, in TOUGH-FLAC, the concept of net mean stress for unsaturated soils is implemented by transferring the maximum of the gas- or liquid-phase pressure from TOUGH to FLAC ${ }^{3 \mathrm{D}}$ according to

$$
p^{\phi}=\operatorname{MAX}\left(p^{l}, p^{g}\right)
$$

This approach enables simulation of both saturated and unsaturated soils. Under single-fluid phase conditions, the first primary variable is $p^{g}$ for single gas phase or $p^{l}$ for single liquid phase. For two fluid phase conditions, the primary variable is gas pressure, which is greater than the liquid pressure. As a result, for fully liquid saturated conditions, the conventional effective stress applies according to Equation (2), whereas for unsaturated conditions, the mechanical behavior depends on the two stress variables net, stress and suction, defined in Equations (4.1-3) and (4.14). 
The strain tensor can-similarly to the stress tensor-be expressed as the sum of a hydrostatic part $(1 / 3)$ trace $(\varepsilon) \mathrm{I}=(1 / 3) \varepsilon_{v} \mathrm{I}$ and deviatoric part e $=\varepsilon-(1 / 3) \varepsilon_{v} \mathrm{I}$, where $\varepsilon_{v}$ is the volumetric strain associated with change in net mean stress, $p^{\prime}$, and can be explicitly expressed as

$$
\varepsilon_{v}=\left(\varepsilon_{1}+\varepsilon_{2}+\varepsilon_{3}\right)
$$

where $\varepsilon_{1}, \varepsilon_{2}$, and $\varepsilon_{3}$ are principal strains.

An equivalent deviatoric strain, associated with distortion and changes in deviatoric stress $q$, may be defined as

$$
\varepsilon_{q}=\frac{2}{3} \sqrt{3 J_{2}^{\prime}}=\frac{2}{3} \sqrt{3 \frac{1}{2} \mathbf{e} \cdot \mathbf{e}}=\frac{2}{\sqrt{6}} \sqrt{\left(\varepsilon_{1}-\varepsilon_{2}\right)^{2}+\left(\varepsilon_{2}-\varepsilon_{3}\right)^{2}+\left(\varepsilon_{3}-\varepsilon_{1}\right)^{2}}
$$

where $J_{2}^{\prime}$ stands for stands for the second invariant of the deviatoric-strain tensor e.

For nonisothermal behavior of unsaturated soils, we may partition the total incremental strain into elastic, plastic, suction, and thermal strains:

$$
\mathrm{d} \boldsymbol{\varepsilon}=\mathrm{d} \boldsymbol{\varepsilon}^{\mathrm{e}}+\mathrm{d} \boldsymbol{\varepsilon}^{\mathrm{p}}+\mathrm{d} \boldsymbol{\varepsilon}^{\mathrm{s}}+\mathrm{d} \boldsymbol{\varepsilon}^{\mathrm{T}}
$$

where the suction strain corresponds to the hydraulic strain term suggested by Kristensson and Åkesson (2008a) and represents the strain associated with changes in suction. Each of these types of strain are described in the following subsections.

\section{Elastic Strain}

The mechanical volumetric elastic strain increment is associated with changes in net mean stress $\mathrm{d} p^{\prime}$ according to

$$
\mathrm{d} \varepsilon_{v}^{e}=\frac{1}{K} \mathrm{~d} p^{\prime}
$$

where the bulk modulus $K$ is defined as

$$
K=\frac{(1+e) p^{\prime}}{\kappa_{p s}(s)}
$$

in which the compressibility function $\kappa_{P S}(s)$ is defined as

$$
\kappa_{p s}(s)=\kappa_{p s 0}\left\lfloor 1+s \alpha_{p s}\right\rfloor
$$

The deviatoric elastic strain increment is defined as

$$
d \varepsilon_{q}^{e}=\frac{1}{3 G} d q
$$

where $G$ may be obtained using a constant Poisson's ratio $v$ in 


$$
G=\frac{3(1-2 v)}{2(1+v)} K
$$

Thus, the equations for elastic mechanical strain indicate the dependency of bulk modulus on suction (and hence fluid saturation) in which dry clay can be significantly stiffer than watersaturated clay.

In current FLAC ${ }^{3 \mathrm{D}}$ MCC implementation, there is the option of either inputting a constant $v$ and calculate $G$ from Equation (4.1-14) or using a constant $G$ and calculating $v$ from Equation (4.114). When implementing the BBM, this approach can be readily extended into unsaturated conditions, in which $K$ is governed by Equation (4.1-11).

\section{Plastic Strain}

The temperature- and suction-dependent loading collapse (LC) yield surface (Figure 4.1-1) bounds the elastic region according to

$$
f_{L C}=\frac{q^{2}}{g_{y}(\theta)^{2}}-\frac{M^{2}}{g_{y}(\theta=0)^{2}}\left(p^{\prime}+p_{s}(s, T)\right)\left(p_{0}(s, T)\right)-p^{\prime}=0
$$

where $\theta$ is the Lode's angle, and the function $g_{y}(\theta)$ describes the shape of the yield surface in the deviatoric plane (Kristensson and Åkesson, 2008b). $M$ is the constant slope of the critical state line (Figure 4.1-1), whereas

$$
p_{s}(s, T)=p_{s 0}+k_{s} s \exp \left[-\rho_{s} \Delta T\right]
$$

represents the increases in cohesion with suction and temperature change $\Delta T=T-$ $T_{0}$, where $k_{s}$ and $\rho_{s}$ are empirical material constants.

In Equation (4.1-15), the function

$$
p_{0}(s, T)=p^{c}\left(\frac{p_{0 T}^{*}(T)}{p^{c}}\right)^{\left[\lambda_{P s 0}-\kappa_{P s 0}\right] /\left[\lambda_{P s}-\kappa_{P s}\right]}
$$

is the net mean yield stress (or apparent pre-consolidation stress) at current suction and temperature, where

$$
p_{0 T}^{*}(T)=p_{0}^{*}+2\left(\alpha_{1} \Delta T+\alpha_{3} \Delta T|\Delta T|\right)
$$

is the temperature-dependent net mean yield stress (or pre-consolidation stress) at full saturation and

$$
\lambda_{P S}(s)=\lambda_{P S 0}\left(\left(1-r_{\lambda}\right) \exp \left(-\beta_{\lambda} s\right)+r_{\lambda}\right)
$$

is a compressibility parameter in virgin soil states at suction $s$. $\lambda_{P s}$ determines the shape of the LC yield surface, which increases in size with suction, whereas the temperature-dependent preconsolidation stress $p_{0 T}^{*}(T)$ results in a reduction of the yield surface with temperature (Figure 4.1-1). 
When the stress state is on the yield surface, the plastic strains are obtained from the plastic flow rule

$$
\begin{aligned}
& \mathrm{d} \varepsilon_{P}^{P}=\mathrm{d} \Lambda \frac{\partial g}{\partial p^{\prime}} \\
& \mathrm{d} \varepsilon_{q}^{P}=\mathrm{d} \Lambda \frac{\partial g}{\partial q}
\end{aligned}
$$

where $d \Lambda$ is the plastic multiplier obtained from the consistency condition $d f_{L C}=0$, and $g_{L C}$ is the plastic potential defined by

$$
g_{L C}=\frac{\alpha_{a} q^{2}}{g_{y}(\theta)^{2}}-\frac{M^{2}}{g_{y}(\theta=0)^{2}}\left(p^{\prime}+p_{s}(s, T)\right)\left(p_{0}\left(p_{0}^{*}, s\right)\right)-p^{\prime}
$$

where $\alpha_{a}$ is a parameter that gives rise to the nonassociative model, i.e. $g_{L C} \neq f_{L C}$.

In the implementation of the BBM in $\mathrm{FLAC}^{3 \mathrm{D}}$, substantial extensions of existing MCC equations must be implemented and programmed for calculating the mechanical plastic strain. These extensions include considering the saturation and temperature dependency of many parameters in Equations (4.1-15) to (4.1-21) that define the shape of the LC yield surface, as well as extension to nonassociative plasticity.

\section{Thermal Strain}

Thermally induced strains are purely volumetric:

$$
\mathrm{d} \varepsilon_{v}^{T}=\left(\alpha_{0}+2 \alpha_{2} \Delta T\right) \mathrm{d} T
$$

where $\alpha_{0}$ and $\alpha_{2}$ are material parameters defining the temperature-dependent volumetric thermal expansion coefficient. Equation (4.1-22) is implemented as a simple extension of the existing thermal strain capability in FLAC ${ }^{3 \mathrm{D}}$.

\section{Suction Strain}

In analogy with thermally induced strains, the suction strain is purely volumetric:

$$
d \varepsilon_{v}^{s}=\frac{1}{K^{s}} d s
$$

in which we (similarly to Kristensson and Åkesson, 2008b) define $K^{s}$ to be the suction bulk modulus

$$
K^{s}=\frac{(1+e)\left(s+p_{a t m}\right)}{\kappa_{s p}\left(p^{\prime}, s\right)}
$$

where $\kappa_{S P}$ is a compressibility parameter for suction induced strain defined as 


$$
\kappa_{s p}\left(p^{\prime}, s\right)=\kappa_{s p 0}\left(1+\alpha_{s p} \ln \frac{p^{\prime}}{P_{r e f}}\right) \exp \left(\alpha_{s s} s\right)
$$

Suction strain was added to TOUGH-FLAC in an analogous manner to treatment of thermal strain in FLAC $^{3 \mathrm{D}}$, by adding an equivalent mean stress increment according to

$$
d p^{s}=K d \varepsilon_{v}^{s}=\frac{K}{K^{s}} d s
$$

This is implemented in FLAC ${ }^{3 \mathrm{D}}$ by adding increments to the normal stresses:

$$
\begin{aligned}
& d \sigma_{x x}^{s}=\frac{K^{m}}{K^{s}} d s \\
& d \sigma_{y y}^{s}=\frac{K}{K^{s}} d s \\
& d \sigma_{z z}^{s}=\frac{K}{K^{s}} d s
\end{aligned}
$$

Both $K$ and $K^{s}$ are dependent on suction and mean net stress, according to Equations (4.1-11) and (4.1-24), and are calculated within the new FLAC ${ }^{3 \mathrm{D}} \mathrm{BBM}$ module, whereas the stress increments are added in a separate routine using FISH, which is a programming capability attached to FLAC $^{3 \mathrm{D}}$ (Itasca, 2009).

\section{Evolution of specific volume}

In the existing FLAC ${ }^{3 \mathrm{D}}$ implementation of the MCC model, the evolution parameter is the specific volume $v$, defined as,

$$
v=\frac{V}{V^{s}}
$$

where $V^{S}$ is the volume of solid particles contained in a volume, $V$, of soil. The incremental relation between volumetric strain and specific volume is

$$
\mathrm{d} \varepsilon_{v}=\frac{\mathrm{d} v}{v}
$$

and an updated specific volume for a new step, $i+1$, is calculated according to

$$
v^{i+1}=v^{i}\left(1-\mathrm{d} \varepsilon_{v}\right)
$$

The initial value for specific volume $v_{i}$ is dependent on the initial net mean stress and is calculated from

$$
v_{i}=v^{c}-\lambda_{p s} \ln \left(\frac{p_{0 T}^{*}}{p^{c}}\right)+\kappa_{P S} \ln \left(\frac{p_{0 T}^{*}}{p_{i}^{\prime}}\right)
$$

where $v^{c}$ is a material input value of the specific volume at the reference net mean stress $p^{c}$. 
From the evolution of the specific volume, porosity, $\phi$, and void ratio, $e$, are evaluated as

$$
\begin{aligned}
& \phi=\frac{V^{\phi}}{V}=\frac{v-1}{v} \\
& e=\frac{V^{\phi}}{V^{s}}=v-1
\end{aligned}
$$

where $V^{\phi}$ is the pore volume. When implementing the BBM into TOUGH-FLAC, these concepts are readily expanded into the unsaturated soil domain.

\subsubsection{TOUGH-FLAC BBM module and input data}

The thermo-elasto-plastic BBM was programmed in $\mathrm{C}++$ and invoked into FLAC $^{3 \mathrm{D}}$ according to the UDM capability available in FLAC ${ }^{3 \mathrm{D}}$. The new $\mathrm{C}++$ routine was compiled as a DLL file (dynamic link library) that can be loaded into FLAC ${ }^{3 \mathrm{D}}$ whenever needed. In a TOUGH-FLAC implementation of the BBM, we also developed a few FISH routines, such as one for calculating suction strain.

The extension of the MCC model to unsaturated media and nonisothermal conditions adds to the complexity and the number of input parameters required. Five parameters are required to define the MCC model, and seven additional parameters are required for the BBM model. In the thermo-elasto-plastic version of the BBM implemented in this study, the failure surface also depends on the temperature, and total of twenty-one material parameters are possible. Discussions on how to determine these parameters from laboratory experiments are given in Alonso et al. (1990) and Gens (1995), and more recently in Kriststensson and Åkesson (2008a). Frequently, the number of laboratory tests may be sparse, and some parameters may therefore be determined by model calibration. Kristensson and Åkesson (2008b) developed numerical tools in a Mathcad environment for a quick assessment of BBM parameters from laboratory experiments.

\subsubsection{Simulation Test to Verify the BBM Implementation}

A number of simulation tests were conducted to verify the implementation of the thermo-elastoplastic BBM within the FLAC ${ }^{3 \mathrm{D}}$ UDM framework. These included basic tests at saturated conditions for the standard FLAC ${ }^{3 \mathrm{D}}$ MCC model (Itasca, 2009), and tests under unsaturated conditions of the BBM using published literature data. Table 4.1-1 summarizes a few examples of the small-scale simulation tests. AGJ1 and AGJ2 simulation tests examples enable comparison to analytical results of Alonso et al. (1990), whereas the $K \& \AA 1, K \& \AA 2$ and $K \& \AA \AA 3$ provide comparison to both independent model simulations and actual experimental data on MX-80 bentonite reported in Kristensson and Åkesson (2008a). The key simulation results from four of these tests are presented in Figure 4.1-2, as described in the second column of Table 4.1-1. One of the experiments, the $K \& \AA 1$, is presented in more detail because it shows important loading and unloading behavior, including nonassociative plasticity. 

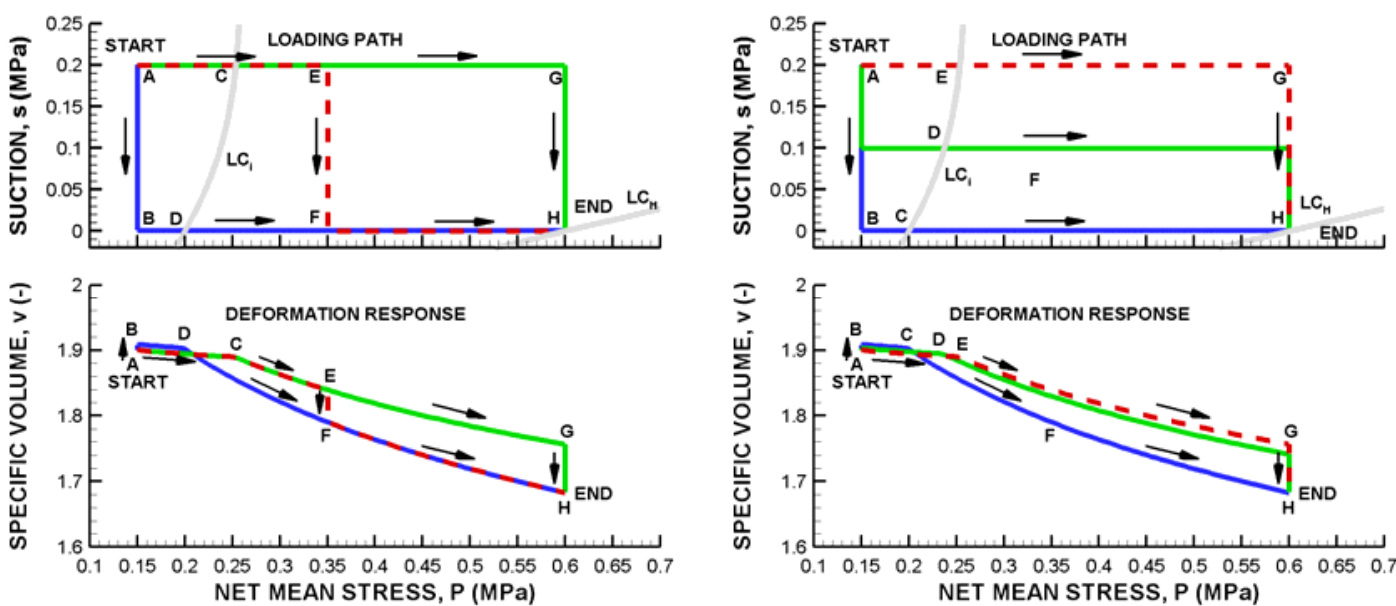

(a)

(b)

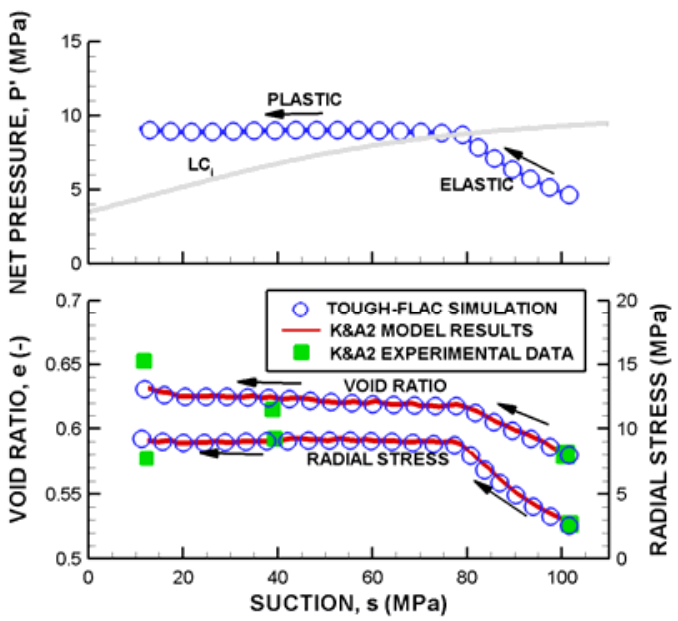

(c)

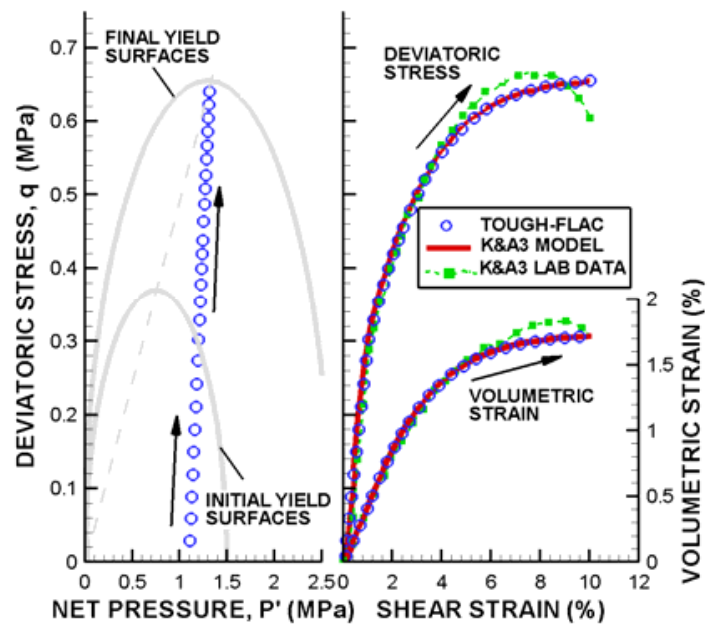

(d)

Figure 4.1-2. Result of simulation tests to verify the BBM implementation within the UDM capability of FLAC $^{3 \mathrm{D}}$ : (a) Swelling and collapse at increasing confining stress (AGJ1), (b) swelling and collapse at alternate load paths (AGJ2), (c) swelling of MX-80 under constant axial load (K\&Å2), (d) triaxial compression and shear of MX-80 (K\&Å3). 
Table 4.1-1. Description of a few of the simulation tests that have been conducted to verify the BBM implementation in TOUGH-FLAC.

\begin{tabular}{|c|c|}
\hline Test and source & Description and Results \\
\hline $\begin{array}{l}\text { AGJ1 } \\
\text { Swelling and collapse at } \\
\text { increasing confining } \\
\text { stress (Case } 1 \text { in Alonso } \\
\text { et al., 1990). }\end{array}$ & $\begin{array}{l}\text { Involves three different loading paths for inducing volumetric } \\
\text { deformation by wetting at increasing confining stress (Figure } 4.1-2 \mathrm{a} \text { ). } \\
\text { In all three cases loading collapse is induced by the movements of the } \\
\text { LC curve from its initial position LCi. TOUGH-FLAC results in } \\
\text { Figure } 4.1 \text {-2a agree with analytical results presented in Figure } 4.1-11 \\
\text { of Alonso et al. (1990). }\end{array}$ \\
\hline $\begin{array}{l}\text { AGJ2 } \\
\text { Swelling and collapse at } \\
\text { alternate load paths (Case } \\
2 \text { in Alonso et al., 1990). }\end{array}$ & $\begin{array}{l}\text { Volumetric deformation is induced along three alternate paths of } \\
\text { mechanical loading and suction (Figure } 4.1-2 \mathrm{~b} \text { ). The different } \\
\text { combinations of wetting and loading induce either expansion or } \\
\text { collapse, but the final volumetric deformation is the same at the final } \\
\text { position F. TOUGH-FLAC results in Figure } 4.1-2 \mathrm{~b} \text { agree with } \\
\text { analytical results presented in Figure } 12 \text { of Alonso et al. (1990). }\end{array}$ \\
\hline $\begin{array}{l}\text { K\&Å1 } \\
\text { Compression of MX-80 } \\
\text { (Section } 5.1 \text { in } \\
\text { Kristensson and Åkesson, } \\
\text { 2008b). }\end{array}$ & $\begin{array}{l}\text { A compression test with axial loading in steps followed by two } \\
\text { unloading steps. The experiment provides the evolution of axial and } \\
\text { the radial stresses as well as the void ratio. The TOUGH-FLAC } \\
\text { modeling of this experiment is described in more detail in Section } 4 \\
\text { and Figure 4.1-3. }\end{array}$ \\
\hline $\begin{array}{l}\text { K\&Å2 } \\
\text { Swelling of MX-80 under } \\
\text { constant axial load } \\
\text { (Section } 5.2 \text { in } \\
\text { Kristensson and Åkesson, } \\
\text { 2008b). }\end{array}$ & $\begin{array}{l}\text { A swelling test subjected to a constant axial stress level. Wetting with } \\
\text { associated suction decrease induces an increase in void ratio and } \\
\text { compressive radial stress (Figure 2c). TOUGH-FLAC results are in } \\
\text { agreement with modeling results and experimental data presented in } \\
\text { Kristensson and Åkesson, (2008b). }\end{array}$ \\
\hline $\begin{array}{l}\text { K\&Å3 } \\
\text { Triaxial compression and } \\
\text { shear of MX-80 (Section } \\
5.3 \text { in Kristensson and } \\
\text { Åkesson, 2008b). }\end{array}$ & $\begin{array}{l}\text { A triaxial experiment performed by applying an increasing axial strain } \\
\text { to a test sample, while monitoring triaxial stress state and } \\
\text { displacements (Figure } 4.1-2 \mathrm{~d}) \text {. TOUGH-FLAC results are in } \\
\text { agreement with modeling results and experimental data presented in } \\
\text { Kristensson and Åkesson, (2008b). }\end{array}$ \\
\hline
\end{tabular}

The K\&Å1 test example involves a laboratory compression test at constant suction with comparison to experimental data of MX-80 bentonite, as presented by Kristensson and Åkesson (2008b, c). This test was conducted in an oedometer, consisting of a steel ring around a sample subjected to humidified air through filters on both sides (Kristensson and Åkesson, 2008c; Duek, 2007). Pistons and force transducers were placed axially above the sample and radially through the steel ring, allowing for measurements of both axial and radial stresses.

Kristensson and Åkesson (2008b) studied this experiment, evaluated the BBM parameters using their Mathcad tool and presented simulation results using the CODE_BRIGHT finite element 
code with BBM. In our model, we directly adopt the material parameter developed and used by Kristensson and Åkesson (2008b), because our main interest is to use these data to conduct a detailed code-to-code verification of the TOUGH-FLAC BBM implementation.

The laboratory experiment by Duek (2007) was conducted by first loading the sample with axial compressive stress from $0.18 \mathrm{MPa}$ to $19.77 \mathrm{MPa}$, and subsequently unloading the sample to 1.0 $\mathrm{MPa}$. The loading and unloading was performed under a constant confining compressive stress of $2.97 \mathrm{MPa}$ and a constant suction of $28 \mathrm{MPa}$. Both the experimental and numerical results show a significant irreversible volumetric deformation as a result of plastic collapsing soils (Figure 4.1-3). Kristensson and Åkesson (2008b) evaluated the parameters, first determining elastic parameters at relatively low stress and then defining the yield surface and plastic model parameters. This included a pre-consolidation pressure tuned to $7.7 \mathrm{MPa}$ and $\lambda_{p s 0}$ to 0.101 . Finally, the nonassociativity parameter $\alpha_{a}$ was calibrated to 0.72 , to match the evolution of the radial stress during the unloading (Kristensson and Åkesson, 2008b).

Figure 4.1-3 shows that for the input parameters listed in Table 4.1-2-including the nonassociativity parameter $\alpha_{a}$ set to 0.72 -an excellent agreement is achieved between TOUGHFLAC simulation results and independent model data published in Kristensson and Åkesson (2008a). To illustrate the effect of the nonassociative plasticity, we also present the results of an alternative simulation using associative plasticity $\left(\alpha_{a}=1.0\right)$. Using associative plasticity $\left(\alpha_{a}=\right.$ 1.0 ) the simulation results deviates more significantly from the experimentally $q$-vs- $p^{\prime}$ and radial stress evolution. Thus, it is important to consider nonassociative plasticity to replicate the stressstrain behavior observed in the laboratory for this type of material, which necessitated our implementation of nonassociative plasticity.
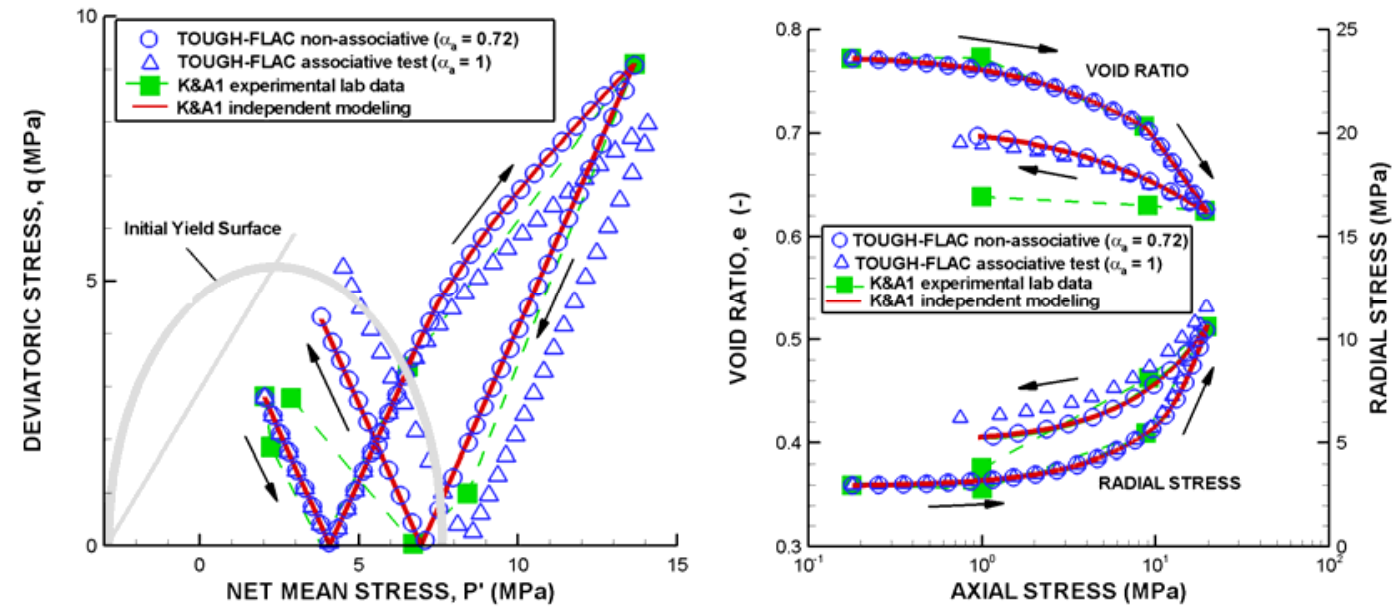

Figure 4.1-3. Comparison of TOUGH-FLAC with BBM simulation resultsI with experimental and modeling results presented in Kristensson and Åkesson (2008b) for MX-80 bentonite. 
Table 4.1-2. Thermo-elasto-plastic BBM input parameters for simulation tests.

\begin{tabular}{|c|c|c|c|c|c|c|}
\hline Parameter & AGJ1 & AGJ2 & K\&Å1 & K\&Å2 & K\&Å3 & FEBEX \\
\hline$\kappa_{P S O}(-)$ & 0.02 & 0.02 & 0.057 & 0.06 & 0.1 & 0.05 \\
\hline$\kappa_{S P 0}(-)$ & 0.008 & 0.008 & 0 & 0.3 & 0 & 0.25 \\
\hline$G(\mathrm{MPa})$ & 10 & 10 & NA & NA & NA & NA \\
\hline$v(-)$ & NA & NA & 0.224 & 0.2 & 0.3 & 0.4 \\
\hline$\alpha_{S S}(-)$ & 0 & 0 & 0 & 0 & 0 & 0 \\
\hline$\alpha_{\mathrm{PS}}\left(\mathrm{MPa}^{-1}\right)$ & 0 & 0 & 0 & 0 & 0 & -0.003 \\
\hline$\alpha_{\mathrm{SP}}(-)$ & 0 & 0 & 0 & 0 & 0 & -0.161 \\
\hline $\mathrm{P}_{\text {ref }}(\mathrm{MPa})$ & 0.1 & 0.1 & 0 & 0.1 & 0 & 0.5 \\
\hline$\alpha_{0}\left({ }^{\circ} \mathrm{C}^{-1}\right)$ & 0 & 0 & 0 & 0 & 0 & $1.5 \mathrm{e}-4$ \\
\hline$\alpha_{2}\left({ }^{\circ} \mathrm{C}^{-1}\right)$ & 0 & 0 & 0 & 0 & 0 & 0 \\
\hline$\lambda_{P S O}(-)$ & 0.2 & 0.2 & 0.101 & 0.9 & 0.135 & 0.15 \\
\hline$R_{\lambda}(-)$ & 0.75 & 0.75 & 0 & 0.75 & 0 & 0.925 \\
\hline$\beta_{\lambda}\left(\mathrm{MPa}^{-1}\right)$ & 12.5 & 12.5 & 0 & 0.03 & 0 & 0.1 \\
\hline$\rho_{s}\left({ }^{\circ} \mathrm{C}^{-1}\right)$ & 0 & 0 & 0 & 0 & 0 & 0 \\
\hline$k_{s}(-)$ & 0.6 & 0.6 & 0.1 & 0.1 & 0.1 & 0.1 \\
\hline$P_{S 0}(\mathrm{MPa})$ & 0 & 0 & 0 & 0 & 0 & 0 \\
\hline$P^{C}(\mathrm{MPa})$ & 0.1 & 0.1 & 0.1 & 0.2 & 0.1 & 0.5 \\
\hline$M(-)$ & 1 & 1 & 1 & 1 & 0.5 & 1 \\
\hline$\alpha_{a}(-)$ & 0.4 & 0.4 & 0.72 & 1 & 0.5 & 0.53 \\
\hline$v_{\lambda}(-)$ & 2.033 & 2.033 & 2.140 & 4.173 & 2.135 & 1.937 \\
\hline$P_{0}^{*}(\mathrm{MPa})$ & 0.2 & 0.6 & 7.7 & 3.5 & 1.5 & 12.0 \\
\hline
\end{tabular}

\subsubsection{Simulation Tests Using TOUGH-FLAC with BBM and Swelling}

The interaction of the TOUGH-FLAC simulator with the newly implemented thermo-elastoplastic BBM and suction strain capability were tested using two example problems:

1) A laboratory swelling stress experiment.

2) A bentonite-backfilled horizontal nuclear waste emplacement tunnel. 
The two examples are simulated using two options:

A) A linear elastic (LE) swelling model using a swelling strain that is linearly dependent on saturation changes.

B) A full BBM simulation with suction-dependent swelling.

The use of the LE swelling model example enabled a comparison of simulated results to simple analytical calculations to verify the implemented routines for TOUGH-FLAC modeling of suction strain, whereas modeling of the full BBM provides a check and demonstration of the applicability of the entire TOUGH-FLAC and BBM system. Table 4.1-3 lists thermal and hydraulic properties of the bentonite, which were derived in a previous study from experimental data or by model calibration (Rutqvist and Tsang, 2004; Alonso et al. 2005) for the modeling of the FEBEX in situ experiment. For the LE swelling model, only a few mechanical input parameters were needed (as described in Section 4.1.1). The input parameters for the BBM simulations were extracted from Gens et al. (2009) and represent BBM material parameters derived specifically for the bentonite buffer at the FEBEX experiment (Table 4.1-2, last column).

Table 4.1-3. Thermal and hydraulic material parameters for the FEBEX buffer material used in the numerical modeling of swelling experiment and multiple barrier repository.

\begin{tabular}{|l|l|}
\hline \multicolumn{1}{|c|}{ Parameter } & \multicolumn{1}{c|}{ Value/Function } \\
\hline Initial dry density, $\rho_{d}\left[\mathrm{~kg} / \mathrm{m}^{3}\right]$ & $1.6 \cdot 10^{3}$ \\
\hline Initial porosity, $\phi[-]$ & 0.41 \\
\hline Saturated permeability, $k\left[\mathrm{~m}^{2}\right]$ & $2.0 \cdot 10^{-21}$ \\
\hline Relative permeability, $k_{r}[-]$ & $k_{r l}=S_{l}^{3}$ \\
\hline $\begin{array}{l}\text { Van Genuchten's }(1980) \text { parameter, } P_{V G} \\
\text { [MPa] }\end{array}$ & 30 \\
\hline Van Genuchten's $(1980)$ parameter, $\lambda_{V G}[-]$ & 0.32 \\
\hline Thermal expansion, $\beta\left[1 /{ }^{\circ} \mathrm{C}\right]$ & $1.5 \cdot 10^{-4}$ \\
\hline Dry specific heat, $\mathrm{C}_{\mathrm{s}}\left[\mathrm{J} / \mathrm{kg} \cdot{ }^{\circ} \mathrm{C}\right]$ & $c_{s}=1.38 T+732.5$ \\
\hline Thermal conductivity, $\lambda_{m}\left[\mathrm{~W} / \mathrm{m} \cdot{ }^{\circ} \mathrm{C}\right]$ & $\lambda_{m}=1.28-\frac{0.71}{1+e^{\left(S_{l}-0.65\right) / 0.1}}$ \\
\hline $\begin{array}{l}\text { Effective molecular diffusion coefficient, } D_{v} \\
{\left[\mathrm{~m}^{2} / \mathrm{s}\right]}\end{array}$ & $D_{v}=2.16 e-5 \times \tau \times \phi \times S_{g}\left(\frac{T_{a b k}}{273.8}\right)^{1.8}$ \\
\hline Mass flow times tortuousity factor, $\tau[-]$ & 0.8 \\
\hline
\end{tabular}




\subsubsection{TOUGH-FLAC Simulation of a Laboratory Swelling Stress Experiment}

Swelling pressure tests are conducted on fully confined samples wetted to full saturation. In this case, the experiments were conducted on bentonite material used in the FEBEX in situ experiment and part of the international collaborative project DECOVALEX (Alonso et al., 2005). For a dry density of $1.6 \mathrm{~g} / \mathrm{cm}^{3}$ and $65 \%$ initial saturation, a swelling pressure of about 5 to 6 MPa developed at full saturation in the swelling experiments (Alsonso et al. 2005).

For the LE swelling model, the model input parameters can be determined analytically to achieve a desired maximum swelling stress of $5 \mathrm{MPa}$. In such a case, the bentonite is assumed to behave elastically, with a volumetric swelling and a swelling stress that depends on the changes in water saturation, $\Delta S_{l}$, according to:

$$
\Delta \sigma_{s w}^{\prime}=3 K \Delta \varepsilon_{s w}=K \Delta S_{l} \beta_{s w}
$$

where $\Delta \sigma_{s w}^{\prime}$ is the induced swelling stress (an effective stress), $K$ is the bulk modulus, and $\beta_{s w}$ is a moisture swelling coefficient. For an average bulk modulus of $20 \mathrm{MPa}$, the appropriate moisture swelling coefficient can be calculated using Equation (4.1-34) as:

$$
\beta_{s w}=\frac{\Delta \sigma_{s w}^{\prime}}{3 K \Delta S_{l}}=\frac{5 \cdot 10^{6}}{3 \cdot 20 \cdot 10^{6} \cdot 0.35}=0.238
$$

The swelling stress experiments is simulated using a 3D $20 \times 20 \times 20 \mathrm{~mm}$ model with 20 elements in the vertical direction (Figure 4.1-4). The model boundaries are fixed for displacement normal to the boundaries, which means that the model is fully confined from a mechanical viewpoint. The model is also hydraulically confined (no flow across boundaries) except at the bottom (water inlet) where a fully saturated condition and a slightly elevated pressure are applied. The simulation is conducted for about 10 days under isothermal conditions at a temperature of $25^{\circ} \mathrm{C}$. Figure 4.1-4 shows a plot of the saturation distribution after about 4 days.
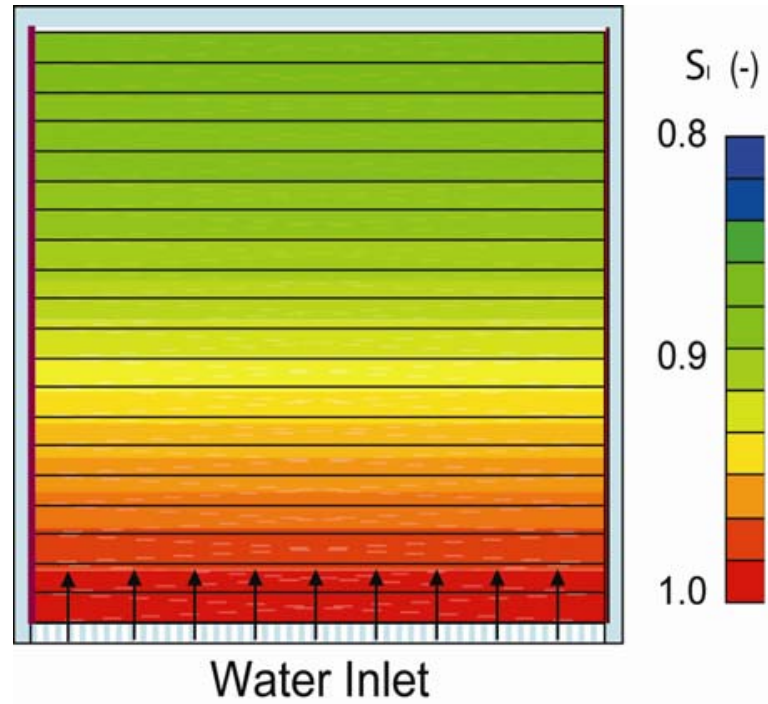

Figure 4.1-4. TOUGH-FLAC model of a swelling stress experiment and results of liquid saturation after 4 days of water infiltration. 
In the simulation, the soil sample becomes practically fully saturated in about 10 days (Figure 4.1-5a). The compressive stress increases proportionally to the saturation, but does achieve a maximum value of about 5.56 MPa, higher than the expected $5 \mathrm{MPa}$ (Figure 4.1-5b). The reason for a higher-than-expected stress is that gas is trapped in a hydraulically confined model, and gas pressure increases by about $0.5 \mathrm{MPa}$ (from 0.1 to maximum $0.6 \mathrm{MPa}$ ), creating an additional poro-elastic stress increase of about 0.5 MPa (Figure 4.1-5b). The effect of gas pressure on stress can be eliminated by setting Biot's constant to zero $\left(\alpha_{B}=0\right)$. In such a case, the final stress is 5.12 MPa, i.e., exactly $5 \mathrm{MPa}$ above the initial stress of $0.12 \mathrm{MPa}$ (Figure 4.1-5b). This shows that the implemented routines for suction strain in TOUGH-FLAC work as intended.

The full BBM model simulation results in a swelling stress of $5.35 \mathrm{MPa}$, which is in agreement with experimental data and similar to the final swelling stress of the LE swelling model (Figure 4.1-5b). However, a significant difference exists in the time evolution of stress in the results from the full BBM compared to those of the LE swelling model. The time evolution achieved in the case of the full BBM is the most realistic, because it accurately relates the volumetric change to changes in suction, in which most of the swelling takes place at high saturation values. In the case of the LE swelling model, the swelling is linearly related to saturation changes, but may be calibrated to achieve the correct final swelling pressure.

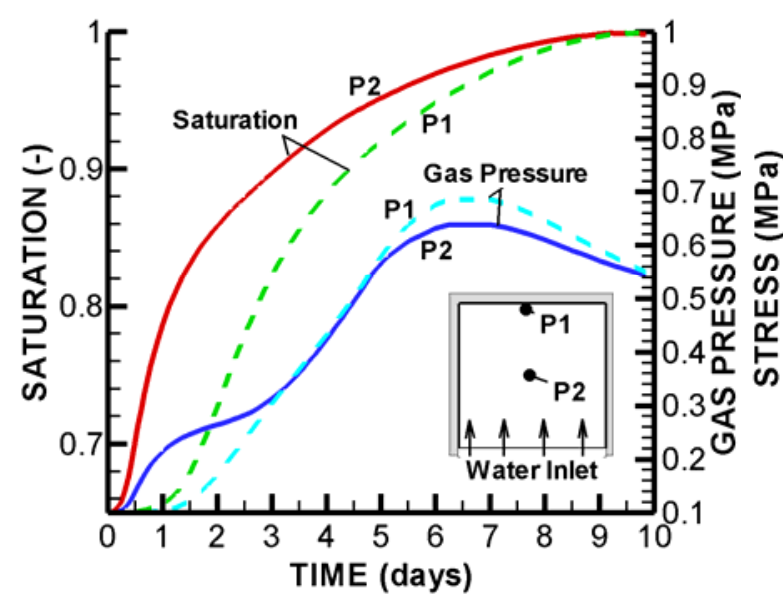

(b)

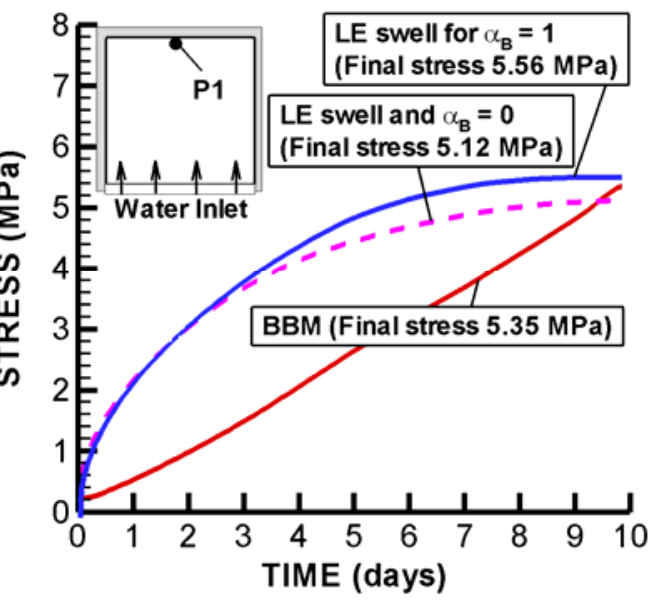

Figure 4.1-5. TOUHG-FLAC modeling of numerical swelling test: Simulated time evolution of (a) saturation and gas pressure at P1 and P2, and (b) stress at P1 for LE swelling model and BBM.

\subsubsection{TOUGH-FLAC Simulation of a Bentonite-Backfilled Nuclear Waste Emplacement Tunnel}

This modeling example is taken from the international DECOVALEX project involving a horizontal nuclear waste emplacement tunnel at $500 \mathrm{~m}$ depth (Rutqvist et al., 2008b, 2009). Here, we present new model simulations of this example using TOUGH-FLAC to check and demonstrate the applicability of this coupled modeling approach to a problem involving complex, multimedia (canister, bentonite, rock) coupled THM interactions. The model simulation was conducted in a nonisothermal mode with a time-dependent heat power input over 
100,000 years of simulation time (Figure 4.1-6). In this study we focus on the coupled THM behavior of the buffer, whereas the surrounding rock mass and its hydraulic and thermal properties affect the temperature and fluid pressure evolution. In this simulation, the rock permeability is sufficiently high $\left(\mathrm{k}=1 \times 10^{-17} \mathrm{~m}^{2}\right)$ so as to avoid suction-induced desaturation of the rock that could otherwise significantly affect the buffer resaturation (e.g., Rutqvist et al., 2005). The overall temperature evolution is controlled by the thermal decay function, assumed tunnel spacing (Figure 4.1-6), and rock-mass thermal properties. The rock thermal conductivity is set to $3 \mathrm{~W} / \mathrm{m}^{\circ} \mathrm{C}$, whereas the heat capacity is determined from a specific heat constant equal to $900 \mathrm{~J} / \mathrm{kg} \cdot{ }^{\circ} \mathrm{C}$, a $1 \%$ rock porosity, and a bulk density of $2700 \mathrm{~kg} / \mathrm{m}^{3}$ (Rutqvist et al., 2008b). A direct code-to-code comparison of simulation results is provided using results from an independent numerical analysis with the finite element code ROCMAS (Rutqvist et al., 2001).

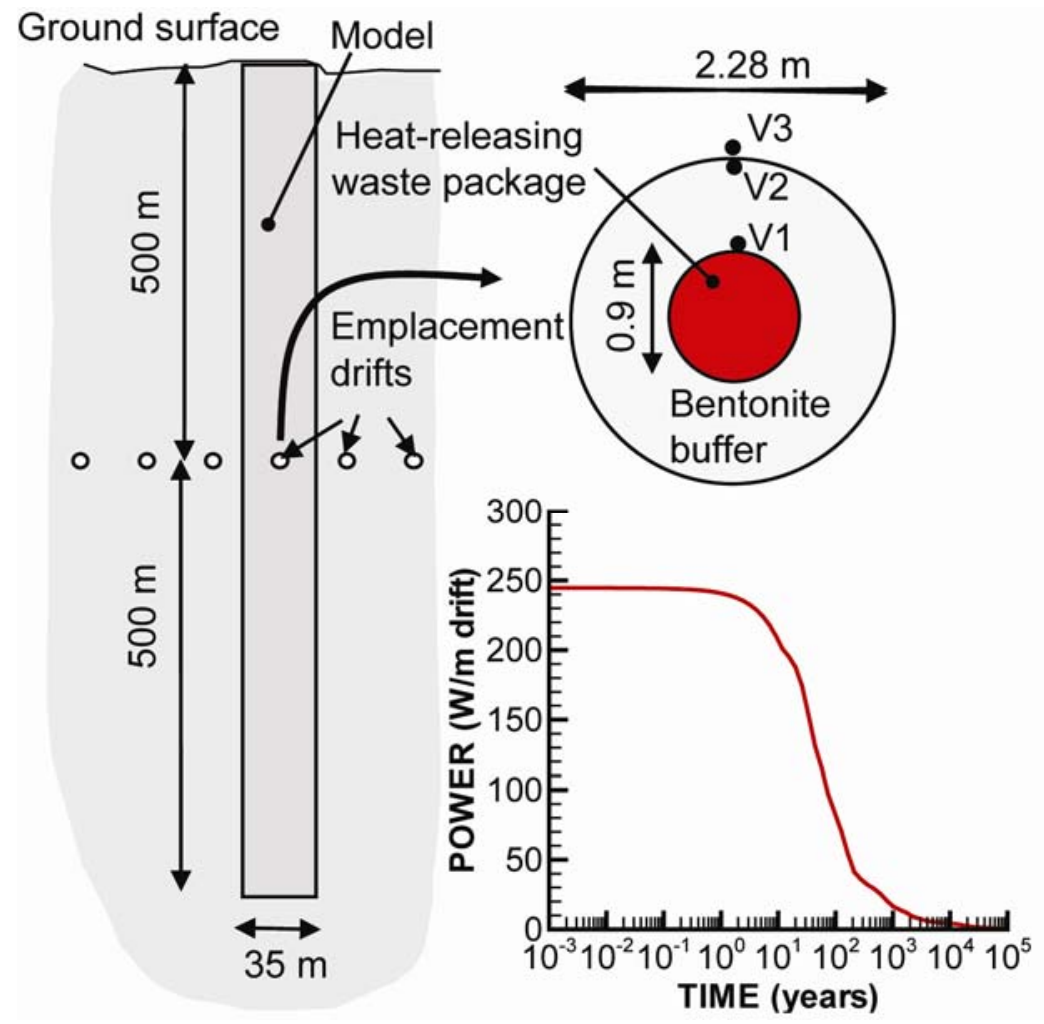

Figure 4.1-6. Model domain for a TOUGH-FLAC test example of a bentonite back-filled horizontal emplacement drift at $500 \mathrm{~m}$ depth (Rutqvist et al., 2009d).

Figure 4.1-7 presents the calculated evolution of temperature, saturation, fluid pressure, and stress within the buffer. The figure shows a good agreement between the simulation results of the TOUGH-FLAC and ROCMAS codes. The slight disagreement that can be observed in Figure 4.1-7 can be attributed to differences in the modeling approach. Indeed, ROCMAS is a finite element code for fully coupled THM analysis under single phase, unsaturated flow conditions, whereas TOUGH-FLAC is based on the sequential coupling of a finite volume fluid flow code to a finite difference geomechanical code, but with full multiphase flow capability-see Wang et al., (2010), for a recent discussion on single-versus-multiphase fluid flow modeling approaches for this type of problem). The results in Figure 4.1-7 are also in general agreement with 
simulation results of other numerical models for the same DECOVALEX bench-mark test presented in Rutqvist et al. (2008b, 2009d).

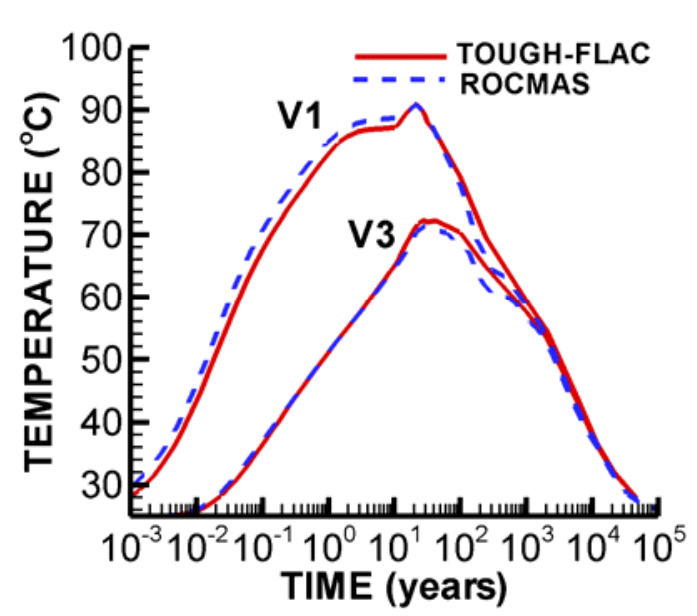

(a)

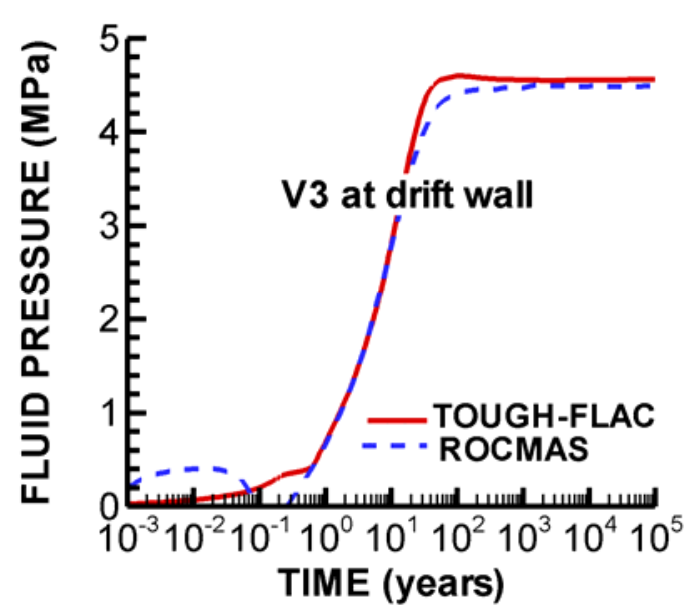

(c)

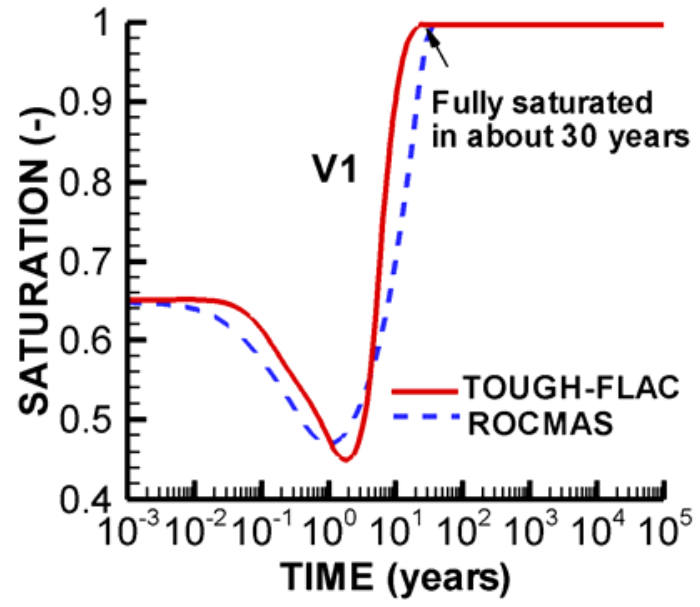

(b)

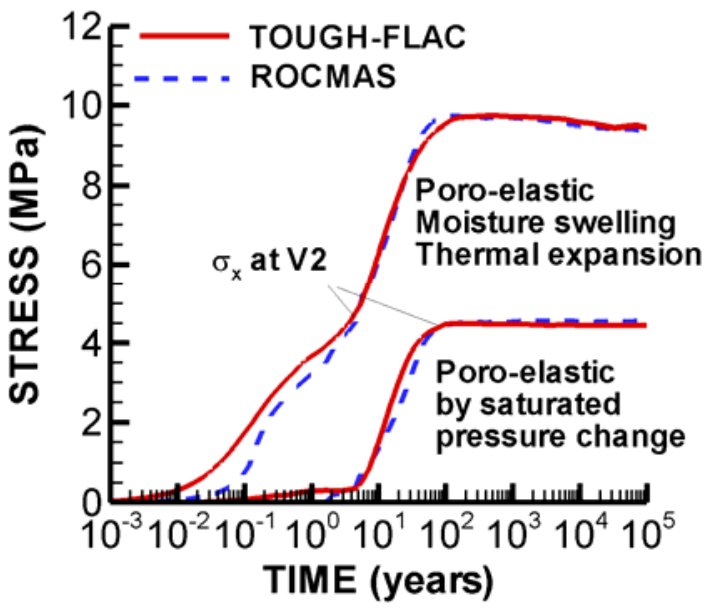

(d)

Figure 4.1-7. Simulated evolution of THM processes in the buffer: (a) temperature at $\mathrm{V} 1$ and $\mathrm{V} 3$, (b) liquid saturation at $\mathrm{V} 1$, (c) fluid pressure at $\mathrm{V} 3$, and (d) total radial stress $\left(\sigma_{\mathrm{x}}\right)$ at $\mathrm{V} 2$.

Figure 4.1-7d is of utmost interest here because it shows the evolution of stress as a result of three sources: (1) swelling stress caused by saturation changes, (2) poro-elastic stress from fluid pressure changes under saturated conditions, and (3) thermal stress. The poro-elastic stress resulting from the restoration of fluid pressure accounts for about $4.5 \mathrm{MPa}$ of total stress. Indeed, this contribution is proportional to the evolution of fluid pressure in Figure 4.1-7c. The swelling caused by saturation changes amounts to about $5 \mathrm{MPa}$, leading to a total stress change of 9.5 $\mathrm{MPa}$. The contribution to the total buffer stress from the thermal expansion is about $0.4 \mathrm{MPa}$ at the thermal peak. This is reasonable considering the magnitudes of temperature increase $\Delta T \approx$ $55^{\circ} \mathrm{C}$, a bulk modulus $K=20 \mathrm{MPa}$, and thermal expansion coefficient of $\alpha_{T}=1.5 \times 10^{-4}{ }^{\circ} \mathrm{C}^{-1}$.

Figure 4.1-8 and 4.1-9 present the geomechanical results for TOUGH-FLAC simulations employing the thermo-elasto-plastic BBM with the material parameters representing the 
bentonite buffer taken from Gens et al. (2009), used for modeling of the FEBEX in situ heater experiment. Figure 4.1-8a shows that the stress evolution is relatively uniform within the buffer; the stress evolution near the canister (point V1) follows the stress evolution near the rock wall (point V2). The stresses at V1 and V2 increase and peak at about 8 to $9.5 \mathrm{MPa}$, but then decrease to about 6.5 to $7.5 \mathrm{MPa}$ towards the end of the simulation. A stress peak of about 9.5 MPa could be expected as a result of the combined effect of swelling and pressure restoration, consistent with the results of the linear swelling model in Figure 4.1-7d. The relatively strong reduction in stress towards 100,000 years in Figure 4.1-8a is a result of cooling shrinkage at the time when the buffer has become relatively stiff. Indeed, Figure 4.1-8a also shows that the bulk modulus increases with stress and is affected by suction changes. The initial bulk modulus is about $2 \mathrm{MPa}$ and peaks at about $200 \mathrm{MPa}(0.2 \mathrm{GPa})$, i.e., a 100-fold increase in stiffness.

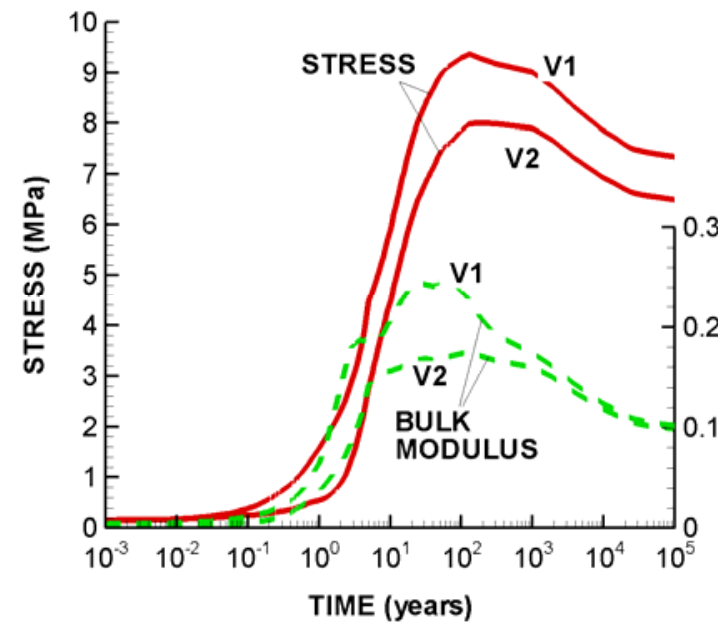

(a)

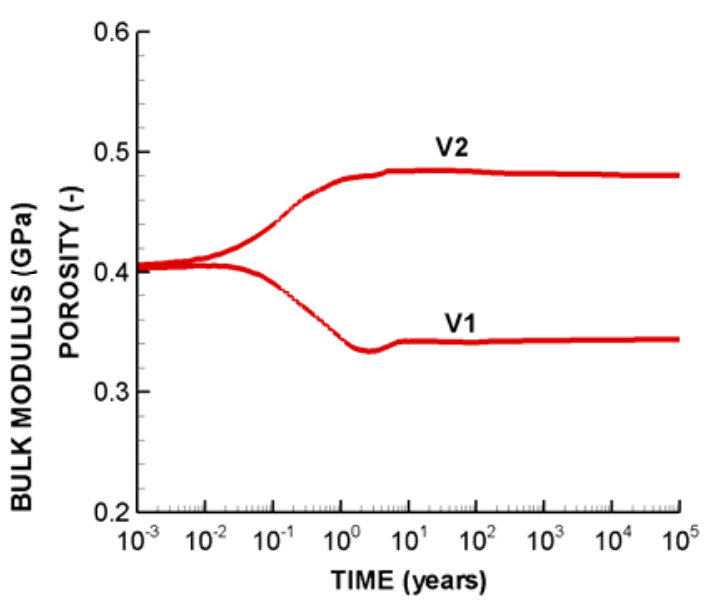

(b)

Figure 4.1-8. Simulated evolution of THM processes in the buffer when using the BBM: (a) tangential stress and bulk modulus, and (b) porosity for point V1 and V2 located within the buffer.

Figure 4.1-8b shows the evolution of porosity. A nonuniform porosity evolution can be observed with decreasing porosity at the canister (point V1) and increasing porosity at the rock wall (point V2). The porosity decreases near the canister as a result of drying and suction, which tends to contract the buffer. Meanwhile, the porosity increases near the buffer-rock interface as a result of wetting, which tends to expand the buffer. Interestingly, the porosity change occurring during the first few years never recovers even after full saturation and restoration of fluid pressure. The porosity does not recover because the buffer becomes stiff with the stress increases occurring after the first few years.

Figure 4.1-9 shows that at the end of the simulation, a nonuniform dry density is obtained that is consistent with the nonuniform porosity distribution. The nonuniformity of the buffer density is a result of the complex nonlinear elastic behavior and interactions of the outer and inner parts of the buffer. This is an eye-opening result, one which warrants further detailed studies and confirmation with independent models that are out of the scope of this paper. However, we conclude from this study that the mechanical evolution of the buffer is far more complex than what could be captured with the LE swelling model. The BBM implementation into TOUGH- 
FLAC provides a practical tool for a more realistic and rigorous analysis of the mechanical behavior associated with bentonite back-filled nuclear waste repository tunnels.

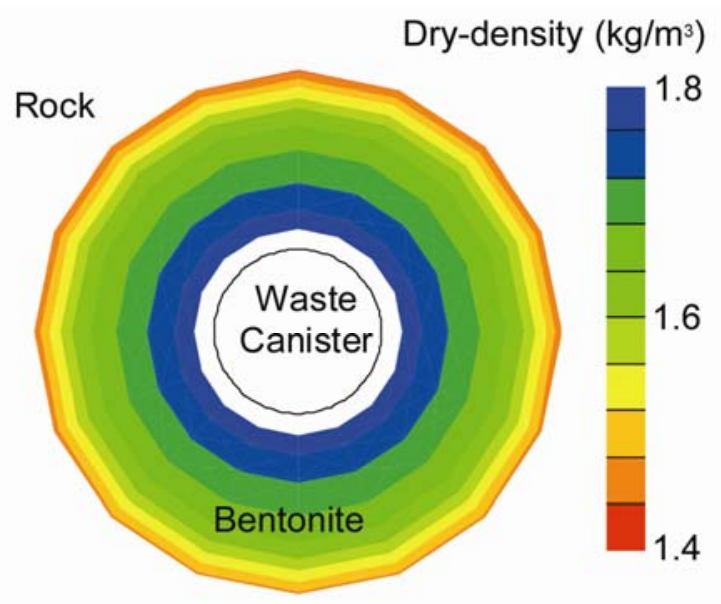

Figure 4.1-9. Calculated distribution dry-density in the buffer after full resaturation and restoration of ambient pressure and temperature (at 100,000 years) showing a relatively high density near the canister and a relatively low density near the rock wall.

\subsubsection{Simulation of a Generic Repository in Clay Host Rock}

This section presents the initial results of the simulation of coupled THM processes in the EBS and host rock for high-level radioactive waste repository in clay formations. It is our intent to investigate the coupled THM behavior for a range of clay host rocks, including plastic clay and indurated more brittle claystone. In our first base case simulation scenario we will use clay host rock properties derived from the Opalinus clay stone at Mont Terri, Switzerland (Table 4.1-4), and will use a repository design and EBS with emplacement into horizontal tunnels that are back-filled with bentonite-based swelling clays as a protective buffer. We adopt the heat load developed for the Generic Disposal System Environment (GDSE) within the UFD for Pressurized Water Reactor (PWR) used nuclear fuel. The first step in this analysis is to design the repository in terms of spacing between emplacement tunnels and individual waste packages along the tunnels, to achieve a distributed heat load that would meet criteria for desired maximum temperature. 
Table 4.1-4. Some basic THM rock properties for a repository hosted in clay stone.

\begin{tabular}{|l|l|}
\hline \hline Parameter & \\
\hline \hline Bulk Density, $\left[\mathrm{kg} / \mathrm{m}^{3}\right]$ & 2400 \\
\hline Matrix Porosity [-] & 0.15 \\
\hline Young's Modulus, $[\mathrm{GPa}]$ & 5 \\
\hline Poisson's ratio, $[-]$ & 0.3 \\
\hline Specific heat, $\left[\mathrm{J} / \mathrm{kg} \cdot{ }^{\circ} \mathrm{C}\right]$ & 900 \\
\hline Thermal conductivity, $\left[\mathrm{W} / \mathrm{m} \cdot{ }^{\circ} \mathrm{C}\right]$ & 2.2 \\
\hline Thermal expansion coefficient, $\left[{ }^{\circ} \mathrm{C}^{-1}\right]$ & $1.0 \times 10^{-5}$ \\
\hline Permeability, $\left[\mathrm{m}^{2}\right]$ & $5.0 \times 10^{-20}$ \\
\hline Biot's effective stress parameter & 1.0 \\
\hline Van Genuchten water retension parameter, $\mathrm{m}$ & 0.41 \\
\hline Van Genuchten water retnesion parameter, $\mathrm{P}_{0}[\mathrm{MPa}]$ & 48 \\
\hline
\end{tabular}

\subsubsection{The Repository Design and Heat Load}

We chose a repository design similar to the one considered in Swiss nuclear waste disposal program for a repository in Opalinus Clay. We assume that the drift is located at a depth of 500 $\mathrm{m}$ and the top boundary located at the ground surface. The heat load for individual emplacement tunnels and their spacing are designed by a constraint of a maximum temperature of $100{ }^{\circ} \mathrm{C}$ max in the contact between the canister and the bentonite. In repository designs with bentonitebackfilled repository tunnels, the PWR type of used fuel is typically packed into a waste package (or canister) with the dimensions of about $1 \mathrm{~m}$ in diameter and about $4 \mathrm{~m}$ long. This is dictated by the length of individual PWR fuel elements and the number of fuel elements per waste package. 4 PWR elements per waste package are commonly adopted for bentonite-backfilled repositories in various host rocks, including crystalline and clay (e.g. Swedish and Finish, Swiss, and Spanish proposed repository designs). Moreover, the emplacement tunnels may be typically up to $1 \mathrm{~km}$ long. The basic material properties used in this initial simulation are presented in Table 4.1-3.

The thermal decay curves for a 10 PWR element waste package was scaled down by multiplying by $4 / 10$ to obtain the decay curve for a 4 PWR element waste package that would match the adopted repository design. This leads to an initial thermal power of $3144 \mathrm{~W}$ per waste package. Assuming a waste deposition after 60 years of interim storage, the heat power has decayed to 1818 Watts per waste package. With the assumption of the $50 \mathrm{~m}$ tunnel spacing and $500 \mathrm{~m}$ emplacement depth, the average thermal power per meter drift may be scaled by adjusting the spacing between individual waste packages along the tunnel. Using model calibration and a maximum temperature kept below $100^{\circ} \mathrm{C}$, we adopted an average thermal power of $200 \mathrm{~W}$ per meter drift. This would mean that if the individual waste packages are $4 \mathrm{~m}$ long, the spacing 
would be $4 \mathrm{~m}$. Alternatively, for 3 PWR elements per waste package the spacing would be $2 \mathrm{~m}$. For the adopted average thermal conductivity of the rock $\left(2.2 \mathrm{~W} / \mathrm{m}^{\circ} \mathrm{C}\right)$, an average thermal power of $200 \mathrm{~W}$ per meter drift seems to be the upper practical limit for this type of repository design.

Figure 4.1-10 presents the model dimensions and the heat decay curve for these simulations. Note that in comparison to the earlier simulation test shown in Figure 4.1-6, the initial thermal power per meter drift is lower and the tunnel spacing is larger. This is a result of the relatively lower thermal conductivity adopted in this case, which corresponds to an average thermal conductivity for Opalinus Clay (Gens et al. 2007).

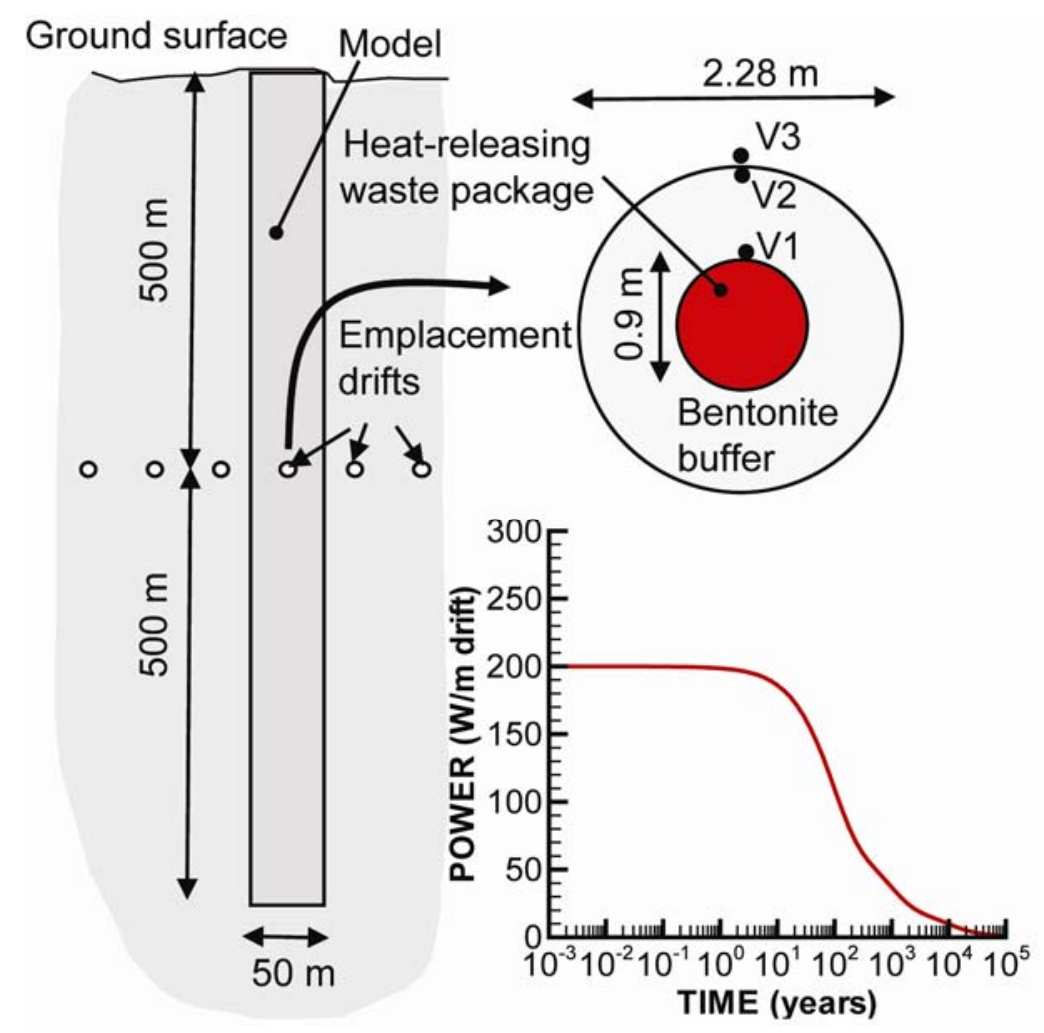

Figure 4.1-10. Model domain for a repository hosted in clay stone.

\subsubsection{Modeling Sequence, Boundary and Initial Conditions}

Figure 4.1-11 presents the detailed modeling sequence, boundary and initial conditions for the coupled THM simulation. The initial conditions for the rock mass are established at the preexcavation stage (Figure 4.1-11a). The initial stress was defined as $\sigma_{\mathrm{h}}=\sigma_{\mathrm{H}}=\sigma_{\mathrm{v}}=2400 \cdot 9.81 \cdot \mathrm{D}$ where $\mathrm{D}$ is elevation relative to ground surface ( $\mathrm{D}=\mathrm{z}-500$ and tensile stress is positive). The vertical thermal gradient is assumed to be $30^{\circ} \mathrm{C} / \mathrm{km}$ with a fixed average temperature of $10^{\circ} \mathrm{C}$ on the ground surface and a fixed temperature of $40{ }^{\circ} \mathrm{C}$ at the bottom boundary. The groundwater table is assumed to be located at the ground surface where the pressure is fixed to $0.1 \mathrm{MPa}$ (atmospheric). At the bottom of the model the fluid pressure is set to $9 \mathrm{MPa}$, which slightly less then hydrostatic. The excavation sequence can be simulated in a one-step steady state calculation with the elements in the drift removed and constant temperature $25^{\circ} \mathrm{C}$ and pressure of $0.1 \mathrm{MPa}$ at 
the drift boundary (Figure 4.1-11b). After the steady state excavation simulation is completed, the waste canister, bentonite buffer and back-fill are installed instantaneously and the postclosure simulation can start (Figure 4.1-11c and 4.1-11d).

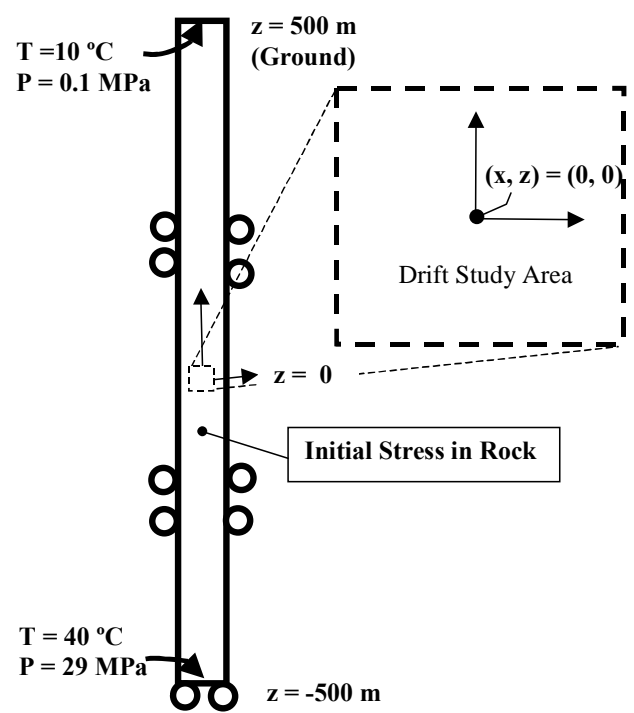

1) Pre-excavation Conditions

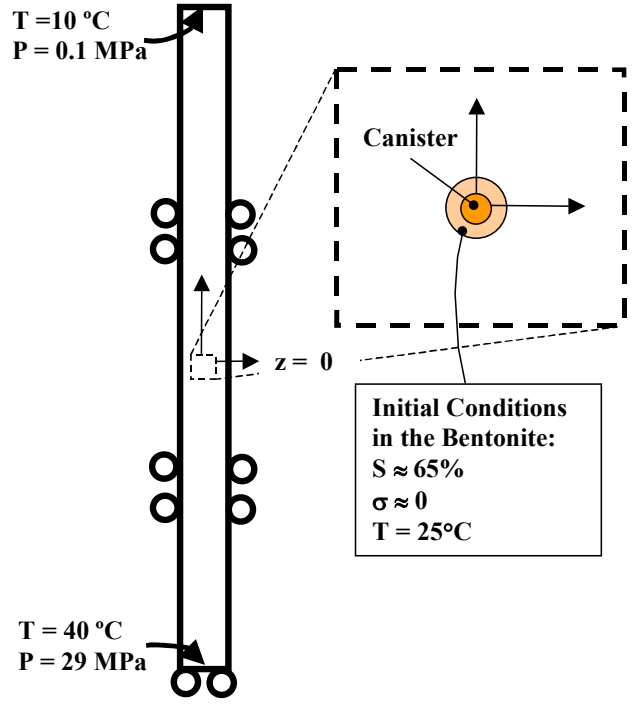

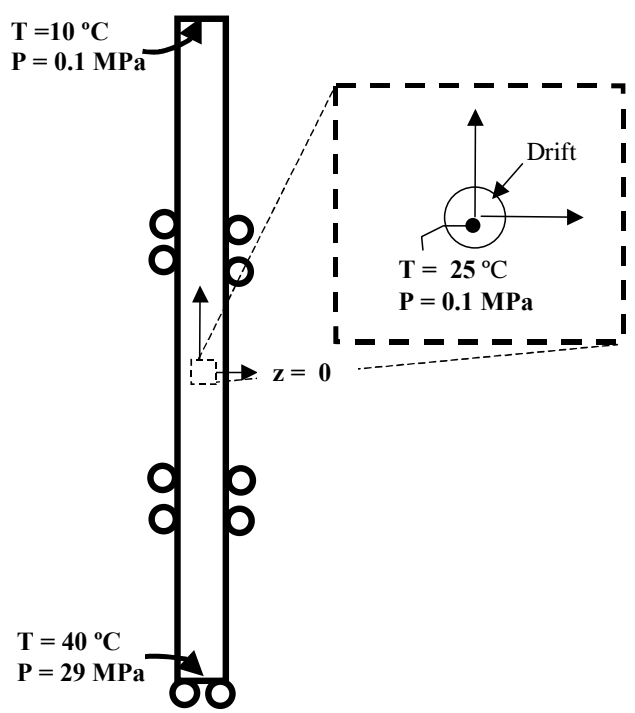

2) Steady State Simulation of Excavation

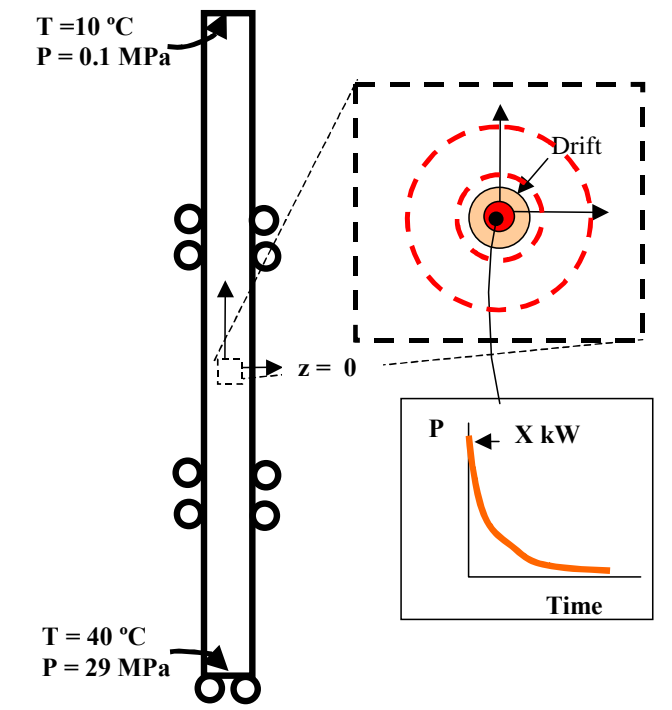

4) Transient Simulation of Post-closure THM

3) Installation of Bentonite Buffer

Figure 4.1-11. Modeling sequence, boundary and initial conditions.

\subsubsection{Basic THM simulation results}

Figure 4.1-12 presents the calculated evolution of temperature, saturation, fluid pressure, and stress within the buffer. The temperature peaks at about $95^{\circ} \mathrm{C}$, which is below the $100^{\circ} \mathrm{C}$ 
maximum temperature criterion. The resaturation of the buffer is delayed as a result of the low rock permeability and a slight desaturation of the rock can be observed in Figure 4.1-12b. The fluid pressure indicates a strong coupling to the temperature field, and as a result of the low rock permeability a significant thermal pressurization occurs (Figure 4.1-12c). This increase in fluid pressure has a direct impact on the stress evolution in the buffer (Figure 4.1-12d). Thus, in this case we observe strong interaction between the host rock coupled processes and the THM evolution of the buffer. The results presented are valid for an average permeability representative of $5 \mathrm{e}-20 \mathrm{~m}^{2}$. If the permeability is lower, a much stronger thermal pressurization can occur.

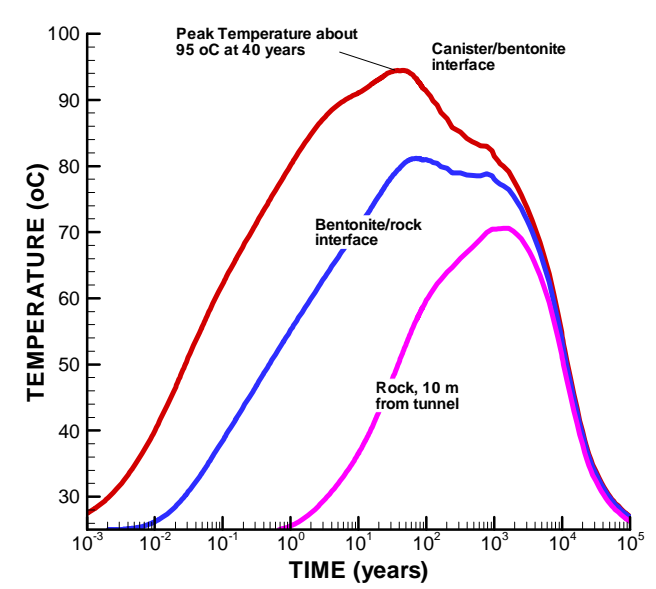

(a)

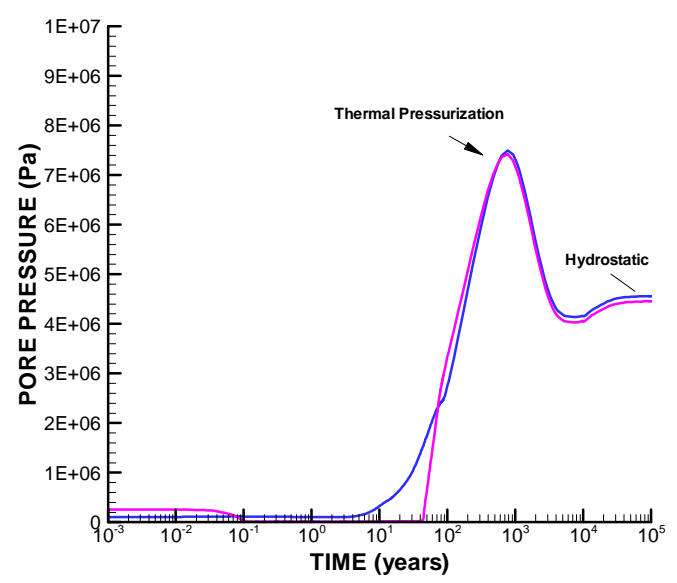

(c)

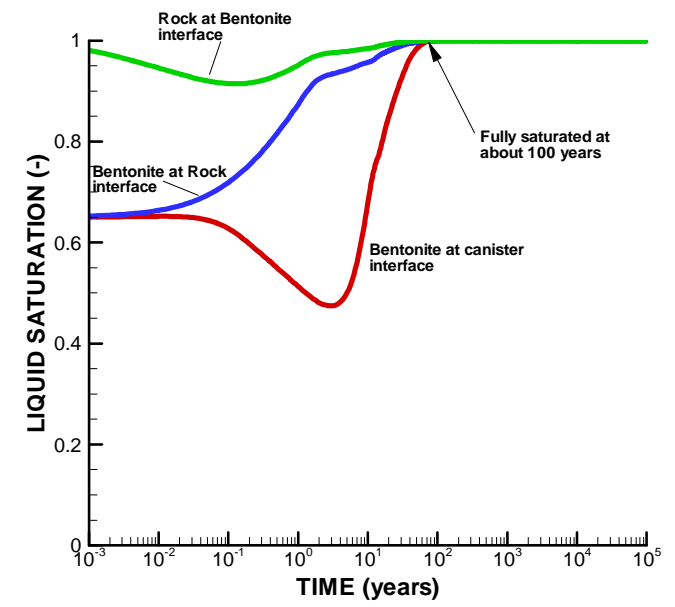

(b)

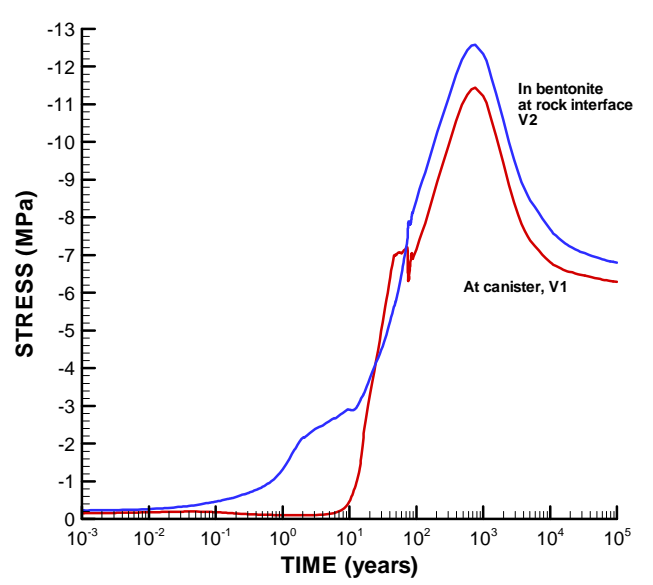

(d)

Figure 4.1-12. Simulated evolution of THM processes in the buffer: (a) temperature at V1, V3, and V6 (b) liquid saturation at $\mathrm{V} 1$, (c) fluid pressure at $\mathrm{V} 3$, and (d) total radial stress $\left(\sigma_{\mathrm{x}}\right)$ at $\mathrm{V} 1$ and $\mathrm{V} 2$.

Figure 4.1-13 shows the evolution of stress, bulk modulus and porosity in the buffer. A quite uniform porosity is achieved in the buffer. 


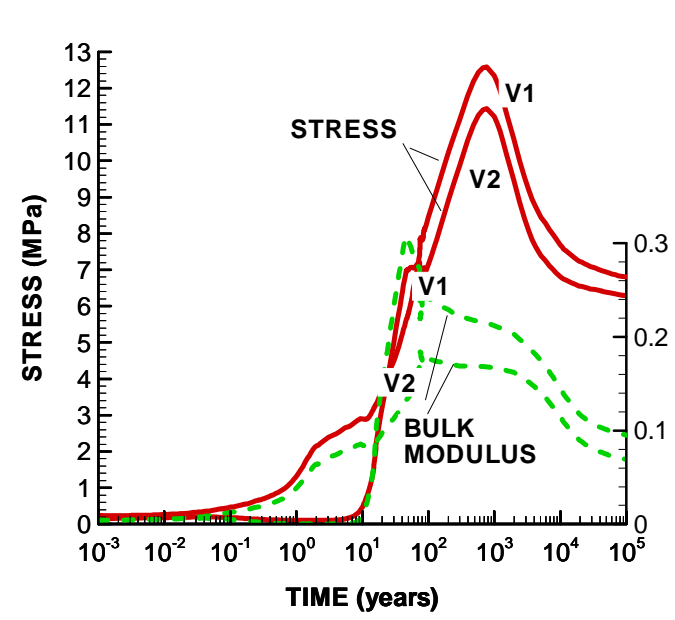

(a)

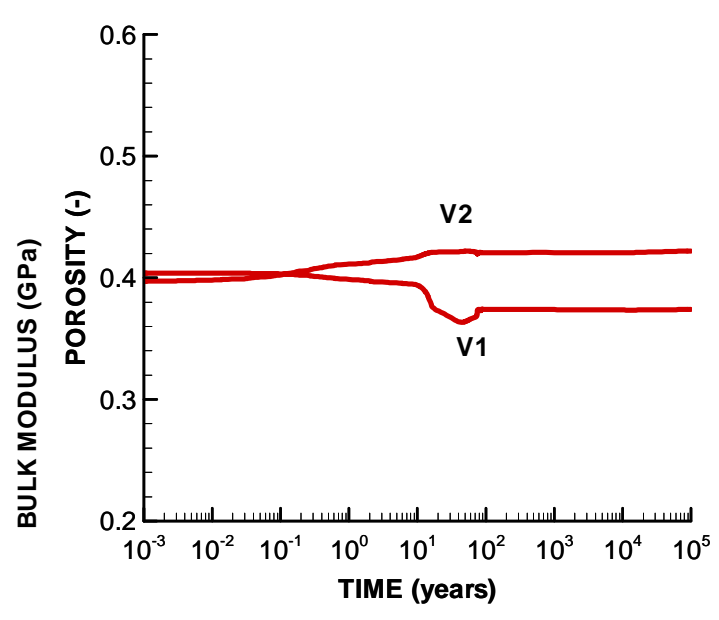

(b)

Figure 4.1-13. Simulated evolution of THM processes in the buffer when using the BBM: (a) tangential stress and bulk modulus, and (b) porosity for point V1 and V2 located within the buffer.

\subsubsection{Summary of THM EBS Research and Next Step}

A thermo-elasto-plastic constitutive model based on the Barcelona Basic Model (BBM) for mechanical behavior of unsaturated soils has been implemented into TOUGH-FLAC. The model has been tested using a number of simulation examples, both with regard to its implementation using the FLAC ${ }^{3 \mathrm{D}}$ user defined model capability and with regard to modeling of suction-induced swelling in TOUGH-FLAC. The test simulations included comparison to both independent calculation results and experimental data from bentonite-sand mixtures considered for use in back-fill and protective buffers around disposed spent nuclear fuel in geological nuclear waste repositories. Excellent agreement was achieved between TOUGH-FLAC modeling results and independent analytical and numerical simulation results, which where in satisfactory agreement with experimental data Moreover, the TOUGH-FLAC with BBM was also tested on a full-scale nuclear waste repository problem involving the interaction of multiple components (buffer, canister, rock) over a 100,000 year simulation time. The simulation indicated complex geomechanical behavior of the bentonite backfill, including a nonuniform distribution of buffer porosity and density that could not be captured in an alternative, simplified linear-elastic swelling model. The thermo-elasto-plastic BBM implemented into TOUGH-FLAC is now fully operational and ready to be applied to nuclear waste disposal and other scientific and engineering problems related to the geomechanical behavior of unsaturated soils.

We also conducted initial simulation studies of coupled THM processes in the EBS and host rock for high-level radioactive waste repository in clay formations. This study highlight the important interactions between the buffer and the host rock, in particular regarding the potential for desaturation of the rock and thermal pressurization which can have a significant impact of the coupled THM evolution in the EBS.

Future work is proposed to include an extension of the current BBM implementation in TOUGHFLAC to more complete modeling of expansive clays, including double-structured behavior. In 
such an approach, the material consists of two structural levels: a microstructure in which interactions occur at particle level and a macrostructure that accounts for the overall arrangement of the material comprising aggregates and macropores (Gens et al. 2006, Sánchez et al., 2005, Gens and Alonso, 1992).

\subsection{Simulation of Transport Experiments using Diffuse Layer and Ion Equilibrium Approaches}

A summary of the new diffuse layer capabilities within CrunchFlow was presented at the Chemistry Workshop of the EBS task force in Speyer, Germany held June 30 and July 1, 2010. In attendance were representatives from the University of Bern in Switzerland, SKB in Sweden, the Clay Technology group in Sweden, the French geological survey (BRGM), and Spain, along with a single representative from Lawrence Berkeley National Laboratory. In addition, the group heard a concise presentation on the ionic equilibrium approach to modeling diffusive transport through compacted bentonite from Martin Birgersson of Clay Technology. The approach of Birgersson and Karnland (2009) consists of considering the diffusive transport as driven by chemical potential rather than concentration gradients. Concentration is discontinuous between the bulk water and the bentonite interlayers where the electrical double layers balancing mineral surface charge overlap. In contrast, the chemical potential based on the assumption of ionic equilibrium (essentially a Donnan equilibrium approach) is continuous and can be used to explain the rates of diffusive transfer. The Birgersson and Karnland approach turned out to be equivalent to consideration of transport within a single domain (no bulk water) consisting of overlapping double layers, and can in fact be modeled with the capabilities in CrunchFlow by setting the bulk water porosity to zero (or a very small number).

Based primarily on these two presentations (from Steefel and Birgersson), the group decided to pursue testing of the diffuse layer and ionic equilibrium approaches. Two benchmark data sets are to be prepared to which modeling can be applied using alternate porosity concepts (multiporous, including DDL, and ion-equilibrium). (1) data set from advective-diffusive multicomponent column experiment (Fernandez-Mäder). (2) a select number of diffusion experiments (PSI \& Clay Technology), including some data sets with measured associated swelling pressures (Birgersson). It is proposed that interested teams can test/apply their models to these data sets. First opportunity to report and discuss results is the upcoming EBS-TF Meeting in Prague, November 2-3, 2010. There is also potential interest by external scientists to have access to such a benchmark (e.g., Ulrich Mayer, UBC [Vancouver CA], connected via NWMO; Tony Appelo, who participated in the Task Force previously).

In addition, the Chemistry group decided that it would be advantageous to couple the Donnan equilibrium (or ionic equilibrium) calculations with calculations of swelling pressure. A preliminary version of this will be attempted in CrunchFlow in the coming year. 


\section{KNOWLEDGE GAPS AND R\&D PLAN}

\subsection{Knowledge Gaps}

The technical issues outlined below describe critical knowledge gaps that point to R\&D needs. An integrated research plan in these areas would involve detailed process-oriented studies including coupled-processes simulation tools, laboratory experiments, and in-situ tests. The latter will not be conducted soon in the U.S., but several major experiments with bentonite have been or will be conducted internationally. Examples are the Canister Retrieval Tests (CRT), Thermal bentonite test (TBT), and the to-be-conducted Bentonite-Rock Interaction Experiment (BRIE). Participation in the analysis, interpretation and modeling of such tests would be very helpful. Some of the data may be found from the published literature or open company reports, while others may be available only through participation in international cooperative projects. Such participation, however, is an effective way to be positioned at the forefront of the state of science in this field.

1. Studies of bentonite hydration to include new processes not included in conventional formulation of THM models. These processes include thermo-osmosis, microstructure evolution, existence of different states of water in the bentonite, and existence of a threshold hydraulic gradient for water flow.

2. Studies of THM behavior of bentonite pellets and pellet mixtures, and irreversible swelling or compression of bentonite in large gap fillings. This is related to homogenization of the bentonite density in the EBS. Bentonite blocks, pellets, and gaps need to be homogenized to about the same density (heterogeneity to be limited) for bentonite to serve as an effective isolation barrier to radionuclide leakage.

3. Studies of piping and erosion of bentonite. The loss of mass into flowing water needs to be limited. It is further complicated by the localized feature of flow from the host rock. We need to develop conceptual models and computer codes for these processes, as well as experimental data to verify our understanding.

4. Studies of radionuclide transport through bentonite interlayer porosity. By comparing the topics discussed in the Literature Review and the existing capabilities for modeling of diffusive transport in compacted bentonite, it is clear that a capability for modeling transport through montmorillonite interlayer porosity needs to be developed. In addition, almost no validation of the models has been carried out to date, so this is an important activity that requires effort in the relatively near term.

5. Studies of swelling and self-sealing. While it is well known that swelling and self-sealing exist in both clay buffer materials and clay host rock, well established model methodologies to deal with these important phenomena and their relations to reactive transport are still lacking in the literature.

6. Studies of gas generation and its modeling. Due to canister corrosion, gas is generated and flows through EBS (including bentonite) to natural systems (host rock). Gas generation and flow have an important impact on mechanical, chemical, and hydraulic processes in the EBS. 
[Note that gas flow is relatively sensitive to small-scale heterogeneity.] Although some studies on this topic are available, significant uncertainty remains in this area, in part because models for gas generation and corrosion are de-coupled from models for near-field and natural systems behavior. Gas pressure and migration may result in preferential pathways for gas flow and radionuclides that partition into the gas phase. Preferential gas flow along higher-permeability pathways through the EBS could result in fast gas-phase transport to more permeable formations external to the host rock or even the ground surface. Gas flow will also lead to aqueous phase displacement and aqueous radionuclide transport. Potential cycling of gas flow and rewetting of the bentonite could result in greater aqueous radionuclide transport than possible from a simple single-displacement process.

7. Studies considering explicit interactions between host rock and EBS and between different EBS components. Most previous studies have been focused on detailed understanding/prediction of one or only a few EBS components, while interactions between other components are disregarded or highly simplified (such as waste form interaction with corrosion products and buffer materials). Inclusion of these interactions between different EBS components makes the coupled processes models more complicated, but at the same time more reliable and usually less conservative. At this point, we are lacking the capability to investigate the interplay between the different components and their interactions via mechanistic process coupling. This interplay may have an important impact on radionuclide release from the EBS.

8. Studies of chemical/mineralogical changes in bentonite. A variety of aqueous chemical and mineralogical changes, including illitization, $\mathrm{Na} / \mathrm{Ca}$ exchange, reactions with alkaline waters from cementitious materials, reactions with corrosion products, and secondary mineral precipitation affect mineral volume and mechanical characteristics. The potential for induration of the bentonite through these changes and fracturing caused by changes in mineral volumes, thermal expansion/contraction, volume changes associated with changes in pore-water composition, and volume changes caused by mineral transformations need to be evaluated as part of the chemical/mineralogical evolution of the bentonite. The impact on development of preferential flow and transport channels over long time periods needs to be addressed. (Gaucher et al. 2004)

9. Studies of glass dissolution mechanisms. Evidence indicates that glass dissolution is affected by the presence of bentonite. However, the effects are a complex balance between the dissolved silica concentrations and the solubility limits in the presence of clay. The controls that lead to either a decrease in dissolution rates or continued high dissolution rates in the presence of clays need to be investigated. (Houseworth 2010, Section 2.5; Lemmens 2001)

10. Studies of radionuclide sorption on bentonite for varying conditions, including temperature, $\mathrm{pH}$, Eh, mineral phase (e.g., illitization), and $\mathrm{Na} / \mathrm{Ca}$ exchange. Numerous observations of sorption indicate varying levels of sensitivity to temperature, pore-water and mineral compositions, depending on radionuclide species. The effects of iron corrosion products on bentonite include increased $\mathrm{pH}$ and precipitation of magnetite, which can lead to stronger sorption in the backfill. The large number of potential combinations of conditions and radionuclides means that generating empirical sorption results to cover all potential 
combinations of conditions and radionuclides is impractical. Therefore, a modeling approach is needed. For this to be successful, thermodynamic databases need to be expanded so that predictions of radionuclide sorption can be made over the range of conditions that may occur. (Houseworth 2010, Section 2.8; Sabodina et al. 2006; Khan 2002; Donat et al. 2005; Samper et al. 2008).

11. Further integration of THM \& C models for simulating THMC coupled processes. Significant chemical-mechanical couplings for bentonite mean that the traditional separation of THM and THC coupled processes in most existing software may not be adequate. Given the compatibilities of their software structure, integration of TOUGHREACT with TOUGHFLAC as a fully-coupled THMC software code is one avenue to consider to attain this goal.

12. Analysis of recent field data from major bentonite experiments. Examples are the Canister Retrieval Tests (CRT), Thermal Bentonite Test (TBT), and the to-be-conducted BentoniteRock Interaction Experiment (BRIE). Some of the data may be found from the published literature or open company reports, while others may be available only through participation in international cooperative projects. Such participation, however, is an effective way to be positioned at the forefront of the state of science in this field.

\subsection{Research \& Development Plans for the EBS}

The R\&D plans to address the technical issues identified above are divided into near-term (FY11) plans and longer-term plans.

\subsubsection{Near-term R\&D Plans}

Near-term R\&D plans refer to activities that could start in the next fiscal year.

\subsubsection{Transport through Compacted Bentonite}

Compacted bentonite has been proposed as backfill material in many international repository programs because of its very low permeability and its strong sorptive properties, both of which will limit the release of radionuclides. For undisturbed conditions, the very low permeability of the compacted bentonite implies that transport of radionuclides away from the waste forms will be almost exclusively by molecular diffusion, with effective diffusivities far below that in water. In much of the compacted bentonite, the pores are so small ( $<1$ nanometer) that the electrical double layers balancing the charge of the bentonite (typically negative at circumneutral $\mathrm{pH}$ ) overlap, thus potentially excluding anions altogether, or creating a deficiency of them within the diffuse electrical double layer balancing the surface mineral charge. Near-term tasks are:

1. Develop software for representing diffusion through interlayer porosity. This effort will involve 1) algorithm development, and 2) verification of the numerical approach through analytical solutions where available, and 3) validation against laboratory experiments.

2. Validate explicit Diffuse Double Layer model using laboratory experiments involving tracer diffusion through bentonite. 


\subsubsection{Bentonite Erosion in a Fractured Host Rock}

Where flowing fractures contact the compacted bentonite surrounding a waste package, a variety of phenomena will occur including swelling of the clay, chemical reaction between solutes in the groundwater and the clay, and clay erosion due to chemical and physical forces on the clay at these locations. Erosion of the bentonite will reduce the storage security of the disposed waste, and this behavior needs to we well understood if this option is selected. Near-term tasks are:

1. A complete literature review will be performed to gather relevant information on the erosion of bentonite in repository-relevant conditions. The results will guide the subsequent work, as needed.

2. Using the literature review, a selected number of tests will be performed examining compacted bentonite erosion. The tests will examine the ionic strength of the groundwater, the chemical composition (relative concentration of monovalent and polyvalent ions), and $\mathrm{pH}$. The tests will require that simple test cells to be designed and constructed.

\subsubsection{Expansive Double-Structure Clay Model for Bentonite}

The long-term chemical and mechanical stability of protective bentonite buffers and tunnel backfill are a key issues in the long-term performance of backfilled, multiple barrier nuclear waste repositories. For example, a certain swelling pressure should be maintained to keep the buffer homogenous, to prevent canister sinking, to prevent adverse effects of external rock shear movements, to limit colloid transport, and to prevent the buffer from being a preferred pathway of radionuclide transport. However, various thermal and chemical conditions can, over time, lead to a loss of swelling pressure. The near-term task is to implement and test the double structure elasto-plastic formulation in TOUGH-FLAC.

\subsubsection{Longer-term R\&D Plans}

Longer-term R\&D plans are for activities that require some prerequisite activities to complete or additional plan development.

\subsubsection{Transport through Compacted Bentonite}

Two complementary sets experiments on bentonite are proposed to test the theory of doublelayer diffusion and to develop effective diffusion properties. Tracer diffusion experiments will be set up to investigate and quantify the diffusion properties of the bentonite. Two complementary experiment techniques will be used to quantify the diffusivity of tracer solutes through the studied materials. First, the conventional through-diffusion experiment setup will be used together with wet chemistry analysis to determine the effective diffusion coefficient of tracer solutes of both anionic and cationic form through bentonite. As a second method, synchrotron radiation based X-ray fluorescence (XRF) and X-ray absorption mapping techniques will also be used to directly monitor the diffusion fronts of tracer solutes in the clays and clay-rich rock. In this approach, samples with the diffused tracer solutes are irradiated with high energy of synchrotron X-rays. The spatial distributions of tracer solutes inside the host rock materials are mapped according to their corresponding X-ray fluorescence or X-ray absorption signals at a 
given experimental time intervals, thereby providing the temporal and spatial data of trace diffusion fronts. The diffusion samples will be scanned periodically to monitor the progress of tracer diffusion fronts and the data obtained will be used to directly calculate the corresponding tracer diffusion coefficients. The tracer experimental data will be used to further develop and validate the models developed for diffusion through nanopores in compacted bentonite.

\subsubsection{Bentonite Erosion in a Fractured Host Rock}

A series of short duration hydrological tests will be performed using specific chemistries identified in FY11 tasks. These tests will consider flow interaction geometry specifically (currently unclear from the literature, but important for modeling) and provide data useful for process modeling. Erosion rates will primarily be measured by quantifying eroded bentonite, however, the locations and mechanisms of erosion will also be considered.

The short-duration hydrological tests will measure erosion primarily using small scale measurements. A remaining question is if the compacted bentonite is eroded from a fracture and erosion continues into the backfill region, how does the erosion continue? Long-term tests (several months duration) will be performed to examine continued erosion within the backfill. Multiple arrangements of fracture and backfill will be considered, with those likely to provide the best results tested. Conceptual models will be proposed and evaluated so that the results are applicable to extension by numerical modeling.

\subsubsection{Expansive Double-Structure Clay Model for Bentonite} The implementation of a double-structure model for bentonite, implemented in TOUGH-FLAC during FY11 is then implemented in TOUGHREACT within the framework of electro-chemical processes, including the electric double layer effects. The modified TOUGHREACT will then be compared with results from independent model calculations and experimental data to demonstrate code capability. After verifying the model, additional simulations will be performed to investigate long-term behavior of a hypothetical bentonite-backfilled repository subject to THMC processes.

\subsubsection{Additional Longer-term R\&D}

As outlined in Section 5.1, a number of additional R\&D topics remain to be investigated beyond those with specific plans given in Sections 5.2.1 and 5.2.2. In particular, specific plans need to be developed to address items 1 and 5 through 10 in Section 5.1.

\section{SUMMARY AND FEPS CROSSWALK}

\subsection{Summary}

Bentonite and bentonite-sand mixtures have been found to have favorable properties for use as a backfill/buffer material for nuclear waste repositories. This report focuses on analyses of bentonite as a component of the EBS. Specific analyses presented here highlight progress made in areas of THM coupled processes models and reactive transport models for bentonite. A literature review provided in this report and Features, Events, and Processes (FEP) analyses 
reported separately (Houseworth 2010) document several more technical areas that may require additional research and development.

\section{THMC Processes in Benonite}

A literature review highlights the key issues concerning THMC processes in bentonite as well as information on important on-going research activities in international programs. Key issues include bentonite hydration mechanisms, bentonite homogenization, piping and erosion, mineral dissolution and precipitation, $\mathrm{Na} / \mathrm{Ca}$ exchange and illitization of smectites. The on-going research activities in international programs provides opportunities for testing for bentonite homogenization in the SKB test, Bentonite Rock Interaction Experiment (BRIE), at the Äspö Hard Rock Laboratory URL and THMC processes for the near field and EBS in the SCK-CEN test, TIMODAZ, being conducted in clay formations at the Belgian, Swiss, and French URLs.

There are several software codes available for analyzing THM processes in geologic media. The TOUGH-FLAC and ROCMAS codes were reviewed in detail for this report. The code TOUGHFLAC uses a continuum method to represent fractures and couples thermal-hydrologic modeling using TOUGH with geomechanical modeling using FLAC to address THM processes. The current version of TOUGH-FLAC includes the recently developed BBM, a geomechanical constitutive relationship for thermo-elastoplastic behavior that is observed in bentonite. The code ROCMAS provides a discrete fracture representation for THM process including single-phase unsaturated flow. ROCMAS has several options for geomechanical constitutive relationships but currently does not include the BBM. The ROCMAS code and TOUGH-FLAC are two different types of simulators that complement each other, have been extensively applied, and yet have the flexibilities for modifications and future improvements.

The implementation of the BBM constitutive relationship in TOUGH-FLAC reported here is a major improvement for modeling of EBS bentonite. The BBM is the most advanced and accepted constitutive model used for modeling of bentonite-buffer behavior in the various European and Japanese nuclear waste programs. The implementation of the BBM in TOUGHFLAC was shown to give results in excellent agreement with independent analytical and numerical simulation results, and was found to be in reasonable agreement with experimental data. The TOUGH-FLAC with BBM was also tested on a full-scale nuclear waste repository problem involving the interaction of multiple components (buffer, canister, rock) over a 100,000 year simulation time. The simulation indicated complex geomechanical behavior of the bentonite backfill, including a nonuniform distribution of buffer porosity and density that could not be captured in an alternative, simplified linear-elastic swelling model. Simulation studies were also performed to investigate coupled THM processes in the EBS in a low-permeability clay host rock. This study highlight the important interactions between the buffer and the host rock, in particular regarding the potential for desaturation of the rock and thermal pressurization, which can have a significant impact of the coupled THM evolution in the EBS.

\section{Reactive-Diffusive Transport in Bentonite}

A review of reactive-diffusive transport phenomena in bentonite highlights the important differences between diffusion in macroporous materials and nanoporous materials. Nanoporous materials contain a significant fraction of pore spaces with dimensions on the order of a nanometer, whereas macroporous materials are dominated by pore spaces dimensions much larger than a nanometer. The main differences in transport behavioar between these two categories of materials result from electrochemical interactions that become significant when the 
pore size approaches the thickness of the electric double layer. This is particularly important for compacted bentonite because of the large proportion of pore space that is within the nanometer scale. Diffusive transport is therefore connected with (1) the degree of compaction that influences the ionic structure of the clay interlayer and electric double layer, (2) the ionic strength that influences the electric double layer size, and (3) the interaction of chemical species between the macropores and the electric double layer. Current diffusive-reactive transport modeling is limited by the assumption of equilibrium between the macropores and the electric double layer.

Modeling tools for reactive-diffusive transport in the EBS include the software codes CruchFlow and TOUGHREACT. CrunchFlow is capable of modeling solute partitioning into an explicit diffuse double layer and associated diffusion within this layer, but does not account for diffusion into the clay interlayers. This is done using a charge balance equation for the diffuse layer balancing the mineral surface charge present in the Stern Layer and an equilibrium model relating chemical exchange between the double layer and macropore water. TOUGHREACT is a comprehensive non-isothermal multi-component reactive fluid flow and geochemical transport simulator. Aqueous complexation, acid-base, redox, gas dissolution/exsolution, and cation exchange are considered under the local equilibrium assumption. Mineral dissolution and precipitation can proceed either subject to local equilibrium or kinetic conditions. Linear adsorption and decay can be included. The chemical-hydrological couplings between mineral dissolution/precipitation and fluid flow are included through the treatment of temporal changes in porosity, permeability, and unsaturated hydrologic properties. Transport of aqueous and gaseous species by advection and molecular diffusion are considered in both liquid and gas phases.

Two modeling approaches have been proposed for reactive-diffusive transport through bentonite at the recent Chemistry Workshop of the EBS task force in Speyer, Germany held June 30 and July 1, 2010. These are the multi-porous, diffuse double layer approach and the ion-equilibrium approach. Two benchmark data sets are to be prepared to which modeling can be applied using the alternate concepts. The data sets will be generated from (1) advective-diffusive multicomponent column experiments and; (2) diffusion experiments, including some measurements of associated swelling pressures.

\subsection{Crosswalk between this Report and FEPs}

The following table identifies work done in this report with the used fuel disposition (UFD) FEPs (Houseworth 2010) associated with the EBS. 
Table 6.1. FEPs crosswalk

\begin{tabular}{|c|c|c|c|}
\hline $\begin{array}{l}\text { UFD FEP } \\
\text { number }\end{array}$ & UFD FEP name & $\begin{array}{l}\text { Report } \\
\text { Sections }\end{array}$ & Information Provided \\
\hline 2.1.04.01 & $\begin{array}{l}\text { Evolution and Degradation of } \\
\text { Backfill }\end{array}$ & 2 through 5 & $\begin{array}{l}\text { Detailed treatment of THM } \\
\text { modeling, general review of } \\
\text { THMC processes. }\end{array}$ \\
\hline 2.1 .08 .01 & Flow Through the EBS & 2 through 5 & See FEP 2.1.08.03. \\
\hline 2.1.08.03 & Flow in Backfill & 2 through 5 & $\begin{array}{l}\text { Detailed treatment of THM } \\
\text { modeling, general review of } \\
\text { THMC processes. }\end{array}$ \\
\hline 2.1.08.06 & $\begin{array}{l}\text { Alteration and Evolution of } \\
\text { EBS Flow Pathways }\end{array}$ & 2 through 5 & $\begin{array}{l}\text { Detailed treatment of THM } \\
\text { modeling, general review of } \\
\text { THMC processes. }\end{array}$ \\
\hline 2.1 .09 .05 & $\begin{array}{l}\text { Chemical Interaction of Water } \\
\text { with Corrosion Products }\end{array}$ & 5 & Brief identification of issues \\
\hline 2.1.09.51 & $\begin{array}{l}\text { Advection of Dissolved } \\
\text { Radionuclides in EBS }\end{array}$ & 2 through 5 & $\begin{array}{l}\text { Closely related to flow and } \\
\text { degradation of backfill }\end{array}$ \\
\hline 2.1.09.52 & $\begin{array}{l}\text { Diffusion of Dissolved } \\
\text { Radionuclides in EBS }\end{array}$ & 2 through 5 & $\begin{array}{l}\text { Detailed treatment of coupled } \\
\text { process effects on diffusion }\end{array}$ \\
\hline 2.1.09.53 & $\begin{array}{l}\text { Sorption of Dissolved } \\
\text { Radionuclides in EBS } \\
\end{array}$ & 5 & Brief identification of issues \\
\hline 2.1.11.03 & $\begin{array}{l}\text { Effects of Backfill on EBS } \\
\text { Thermal Environment }\end{array}$ & 2 through 5 & $\begin{array}{l}\text { Detailed treatment of THM } \\
\text { modeling. }\end{array}$ \\
\hline 2.1 .11 .04 & $\begin{array}{l}\text { Effects of Drift Collapse on } \\
\text { EBS Thermal Environment }\end{array}$ & None & $\begin{array}{l}\text { Generally considered not } \\
\text { applicable if backfill is used. }\end{array}$ \\
\hline 2.1.11.08 & $\begin{array}{l}\text { Thermal-Mechanical Effects } \\
\text { on Backfill }\end{array}$ & 2 through 5 & $\begin{array}{l}\text { Detailed treatment of THM } \\
\text { modeling. }\end{array}$ \\
\hline 2.1.11.10 & $\begin{array}{l}\text { Thermal Effects on Flow in } \\
\text { EBS }\end{array}$ & 2 through 5 & $\begin{array}{l}\text { Detailed treatment of THM } \\
\text { modeling. }\end{array}$ \\
\hline 2.1.11.11 & $\begin{array}{l}\text { Thermally-Driven Flow } \\
\text { (Convection) in EBS }\end{array}$ & 2 through 5 & $\begin{array}{l}\text { Detailed treatment of THM } \\
\text { modeling. }\end{array}$ \\
\hline 2.1.11.12 & $\begin{array}{l}\text { Thermally-Driven Buoyant } \\
\text { Flow / Heat Pipes in EBS }\end{array}$ & None & $\begin{array}{l}\text { Generally considered not } \\
\text { applicable for sub-boiling } \\
\text { conditions. }\end{array}$ \\
\hline 2.1.12.01 & Gas Generation in EBS & 2 and 5 & General review of issues \\
\hline 2.1.12.02 & $\begin{array}{l}\text { Effects of Gas on Flow } \\
\text { Through the EBS }\end{array}$ & 2 and 5 & General review of issues \\
\hline 2.1.12.03 & Gas Transport in EBS & 2 and 5 & General review of issues \\
\hline
\end{tabular}




\section{ACKNOWLEDGMENT}

This report has been authored by Lawrence Berkeley National Laboratory under Contract No. DE-AC02-05CH11231 with the U.S. Department of Energy.

\section{REFERENCES}

Alonso EE, Gens A, Josa A. A constitutive model for partially saturated soils. Geotechnique 40: 405-430, 1990.

Alonso E.E., Alcoverro, J., et al. (26 co-authors) The FEBEX benchmark test. Case definition and comparison of modelling approaches. International Journal of Rock Mechanics \& Mining Sciences 42, 611-638, 2005.

Appelo, C.A.J. and Wersin, P., Multicomponent diffusion modeling in clay systems with application to the diffusion of tritium, iodide, and sodium in Opalinus Clay. Environ. Sci. Technol. 41, 5002-5007,2007.

Appelo, C.A.J., Vinsot, A., Mettler, S. and Wechner, S. Obtaining the porewater composition of a clay rock by modeling the in- and out-diffusion of anions and cations from an in-situ experiment. J. Contam. Hydrol. 101, 67-76, 2008.

Appelo, C.A.J., and Postma, D., Geochemistry, groundwater and pollution, Rotterdam, The Netherlands, Balkema, 536 pp., 1993.

Bazer-Bachi, F., M. Descostes, E. Tevissen, P. Meier, B. Grenut, M.-O.. Simonnot and M. Sardin, Characterization of sulphate sorption on Callovo-Oxfordian argillitby batch, column and through-diffusion experiments, Phys. Chem. Earth 32, pp. 552-558, 2007.

Biot, M.A., General theory of three dimensional consolidation. J. Applied Physics, 12, 155-164., 1941.

Bourg, I.C., A.C.M. Bourg and G. Sposito, Modeling diffusion and adsorption in compacted bentonite: a critical review, J. Contam. Hydrol. 61, pp. 293-302, 2003.

Bourg, I.C., G. Sposito and A.C.M. Bourg, Tracer diffusion in compacted, water-saturated bentonite, Clays Clay Miner. 54, pp. 363-374, 2006.

Bourg, I.C., Sposito, G. and Bourg, A.C.M. Modeling cation diffusion in compacted watersaturated sodium bentonite at low ionic strength. Environ. Sci. Technol. 41, 8118-8122, 2007.

Bower, K.M. and Zyvoloski, G. A numerical model for thermo-hydro-mechanical coupling in fractured rock. Int. J. Rock Mech. Min. Sci. \& Geomech. Abstr., 34, 1201-1211, 1997. 
Börgesson, L., ABAQUS. In Stephansson, O., Jing, L., and Tsang, C.-F. editors, Coupled Thermo-hydro-mechanical Processes of Fractured Media. Developments in Geotechnical Engineering, Elsevier, 79, pp. 565-570, 1996.

Chatterji, S. Ionic diffusion through thick matrices of charged particles, J. Colloid Interface Sci.269, pp. 186-191, 2004.

Dobson, P.F., T.J. Kneafsey, E.L. Sonnenthal, N.F. Spycher, and J.A. Apps, Experimental and numerical simulation of dissolution and precipitation: Implications for fracture sealing at Yucca Mountain, Nevada. Journal of Contaminant Hydrology. 62-63: 459-476, 2003.

Davis J.A. and Kent D.B. Surface ciews inMineralogy 23, 177-260, 1990.

Donat, R.; Akdogan, A.; Erdem, E.; Cetisli, H. Thermodynamics of $\mathrm{Pb}^{2+}$ and $\mathrm{Ni}^{2+}$ Adsorption onto Natural Bentonite from Aqueous Solutions, Journal of Colloid and Interface Science, Vol. 286, pp. 43-52, 2005.

Dueck, A. Results from suction controlled laboratory tests on unsaturated bentonite Verification of a model, In: Schanz, T. (Ed.) Experimental Unsaturated Soil Mechanics, Springer Proceedings in Physics 112, pp. 329-335, 2007.

Dzombak, D.A and Morel, F.M.M., Surface Complexation Modeling: Hydrous Ferric Oxide, Wiley Interscience, New York, 393 pp., 1990.

Eriksen, T.E., Jansson, M., Molera, M. Sorption effectgs on cation diffusion in compacted bentonite. Engineering Geology 54, 231-236. 1999.

Gaucher, E.C.; Blanc, P.; Matray, J-M.; Michau, N. Modeling Diffusion of an Alkaline Plume in a Clay Barrier, Applied Geochemistry 19 (2004), 1505-1515, 2004.

Gaucher, E. P. Blanc, F. Barot, G. Braibant, S. Buschaert, C. Crouzet, A. Gautier, J.P. Girard, E. Jacquot, A. Lassin, G. Negrel, C. Tournassat, A. Vinsot and S. Altmann, Modeling the porewater chemistry of the Callovo-Oxfordian formation at a regional scale, $C$. R. Geosci. 338 (12-13), pp. 917-930, 2006.

Gens, A. Constitutive Laws, In: Gens, A., Jouanna, P., Schrefler, B.A. (Eds.) Modern Issues in Non-saturated Soils. Springer-Verlag, Wien, New York, pp. 129-158, 1995.

Gens, A, Alonso, E.E. A framework for the behaviour of unsaturated expansive clays. Canadian Geotechnical Journal 29, 1013-1032, 1992.

Gens, A., Garcia-Molina, A.J., Olivella, S., Alonso, E.E. and Huertas, F. Analysis of a full scale in situ test simulating repository conditions. Int. J. Numer. Anal. Meth. Geomech., 22, 515548, 1998.

Gens A., Sanchez M., Do L., Guimaraes N., Alonso E., Lloret A., Olivella S., Villar M.V., Huertas F. A full-scale in situ heating test for high-level nuclear waste disposal: observations, analysis and interpretation. Geotechnique 59, 1-23,2009. 
Gens, A., Vaunat, J., Garitte, B. \& Wileveau, Y. In situ behaviour of a stiff layered clay subject to thermal loading: observations and interpretation. Geotechnique 57, No. 2, 207-228. 2007.

Gens, A., Sánchez, M., Sheng, D. On constitutive modelling of unsaturated soils. Acta Geotechnica 1, 137-147, 2006.

Giambalvo, E.R., Steefel, C.I., Fisher, A.T., Rosenberg, N.D., and Wheat, C.G., Effect of fluid sediment reaction on hydrothermal fluxes of major elements, eastern flank of the Juan de Fuca Ridge. Geochimica et. Cosmochimica Acta 66, 1739-1757, 2002.

Gonçalvès, I., P. Rousseau-Gueutin and A. Revil, Introducing interacting diffuse layers in TLM calculations: a reappraisal of the influence of the pore size on the swelling pressure and the osmotic efficiency of compacted bentonites, J. Colloid Interface Sci. 316, pp. 92-99, 2007.

Guvanasen, V. and Chan, T. A new three-dimensional finite-element analysis of hysteresis thermohydromechanical deformation of fractured rock mass with dilatance in fractures. Proceedings of the $2^{\text {nd }}$ Conference on Mechanics of Jointed and Faulted Rocks, Vienna, Austria, April 10-14, 1995, pp. 347-442.

Houseworth, J.E. The DOE Used Fuel Disposition Campaign Features, Events, and Processes (FEP) Evaluation Report for Bentonite/Clay/Shale Systems, DOE Used Fuel Disposition Campaign, Lawrence Berkeley National Laboratory. 2010.

Israelsson, J.I., Short description of FLAC version 3.2. In Stephansson, O., Jing, L., and Tsang, C.-F. editors. Coupled Thermo-hydro-mechanical Processes of Fractured Media. Developments in Geotechnical Engineering, Elsevier, 1996a, 79, pp. 513-522.

Israelsson, J.I., Short description of UDEC and 3DEC. In Stephansson, O., Jing, L., and Tsang, C.-F. editors. Coupled Thermo-hydro-mechanical Processes of Fractured Media. Developments in Geotechnical Engineering, Elsevier, 1996b, 79, pp. 523-528.

Itasca Consulting Group, FLAC3D, Fast Lagrangian Analysis of Continua in 3 Dimensions, Version 4.0, Minneapolis, Minnesota, Itasca Consulting Group, 2009.

Jougnot, D., Revil, A., and Leroy, P. Diffusion of ionic tracers in the Callovo-Oxfordian clayrock using the Donnan equilibrium model and the formation factor. Geochimica et Cosmochimica Acta 73, 2712-2726. 2009.

Khan, S.A. Sorption of Long-Lived Radionuclides Cesium-134, Strontium-85 and Cobalt-60 on Bentonite, Journal of Radionanalytical and Nuclear Chemistry, Vol. 258, No. 1, pp. 3-6, 2002.

Kim, H., T. Suk, S. Park and C. Lee, Diffusivities for ions through compacted Na bentonite with varying dry bulk density, Waste Manag. 13 (1993), pp. 303-308.

Kohl, T. and Hopkirk, R.J. The finite element program "FRACTure" for the simulation of Hot Dry Rock reservoir behavior. Geothermics, 24, 345-359, 1995. 
Kolditz O., Bauer S., Beinhorn M., de Jonge J., Kalbacher T., McDermott C., Wang W., Xie M., Kaiser R., Kohlmeier M. ROCKFLOW - Theory and Users Manual, Release 3.9, Groundwater Group, Center for Applied Geosciences, University of Tübingen, and Institute of Fluid Mechanics, University of Hannover, 2003.

Koutsabeloulis, N.C. and Hope, S.A., Coupled stress/fluid/thermal multi-phase reservoir simulation studies incorporating rock mechanics. Proceedings of SPE/ISRM EUROCK-98 symposium, Norway, 1998, pp. 449-454.

Kozaki, T., Fujishima, A., Saito, N., Sato, S. and Ohashi, H. Self-diffusion of sodium ions in compacted sodium montmorillonite. Nucl. Technol. 121, 63-68. 1998.

Kozaki, T., Liu, J. and Sato, S. Diffusion mechanism of sodium ions in compacted montmorillonite under different $\mathrm{NaCl}$ concentration. Phys. Chem. Earth 33, 957-961. 2008.

Kristensson O., Åkesson M. Mechanical modeling of MX-80 - Quick tools for BBM parameter analysis. Physics and Chemistry of the Earth 33, S508-S515, 2008 a.

Kristensson, O., Åkesson, M. Mechanical modeling of MX-80 - Quick tools for BBM parameter analysis. Physics and Chemistry of the Earth 33, S508-S515, 2008b.

Kristensson O., Åkesson M. Mechanical modeling of MX-80 - Development of constitutive laws. Physics and Chemistry of the Earth 33, S504-S507, 2008c.

Lasaga, A. C. Chemical kinetics of water-rock interactions, J. Geophys. Res., v. 89, p. 40094025, 1984.

Lemmens, K. The Effect of Clay on the Dissolution of Nuclear Waste Glass”, Journal of Nuclear Materials, Vol. 298, pp. 11-18, 2001.

Leroy, P., and A. Revil, A triple-layer model of the surface electrocheproperties of clay minerals, J. Colloid Interface Sci. 270 (2), pp. 371-380, 2004.

Leroy, P., A. Revil and D. Coelho, Diffusion of ionic species in bentonite, J. Colloid Interface Sci. 296 (1), pp. 248-255, 2006.

Leroy P., Revil A., Altmann S., Tournassat C. Modeling the composition of a pore water in a clay-rock geological formation (Callovo-Oxfordian, France). Geochimica Cosmochimica Acta 71(5), 1087-1097, 2007.

Lichtner, P. C. Continuum formulation of multicomponent-multiphase reactive transport, in Lichtner, P. C., Steefel, C. I., and Oelkers, E. H. (eds.), Reactive transport in porous media, Reviews in Mineralogy, Mineral Society of America, v. 34, p. 1-79, 1996.

Lichtner, P. C. The quasi-stationary state approximation to coupled mass transport and fluid-rock interaction in a porous medium, Geochim. Cosmochim. Acta, v. 52, p. 143-165, 1988. 
Liu, H.H., J. Rutqvist, and J.C. Berryman, On the relationship between stress and elastic strain for porous and fractured rock, Int J Rock Mech \& Min Sci 46, 289-296, 2009.

Liu Q., Zhang C., Liu X. A practical method for coupled THM simulations of the Yucca Mountain and FEBEX case samples for task D of the DECOVALEX-THMC Project. Proc. GEOPROC2006 International symposium: 2nd International Conference on Coupled Thermo-hydro-mechanical-chemical processes in Geosystems and Engineering, HoHai University, Nanjing, China, May 22-25, 2006, 220-225, HoHai University.

Madsen, F.T. Clay mineralogical investigations related to nuclear waste disposal. Clay Miner. 33, 109-129, 1998.

Melkior, T., D. Mourzagh, S. Yahiaoui, D. Thoby, J.C. Alberto, C. Brouard and N. Michau, Diffusion of an alkaline fluid through clayey barriers and its effect on the diffuproperties of some chemical species, Appl. Clay Sci. 26, pp. 99-107, 2004.

Melkior, T., S. Yahiaoui, D. Thoby, S. Motellier and V. Barthes, Diffusion coefficients of alkaline cations in Bure mudrock, Phys. Chem. Earth 32, pp. 453-462, 2007.

Molera, M., Eriksen, T. Diffusion of ${ }^{22} \mathrm{Na}^{+},{ }^{85} \mathrm{Sr}^{2+},{ }^{134} \mathrm{Cs}^{+}$and ${ }^{57} \mathrm{Co}^{2+}$ in bentonite clay compacted to different densities: experiments and modeling. Radiochimica Acta 90, 753-760. 2002.

Muurinen, A., Karnland, O. and Lehikoinen, J. Effect of homogenization on the microstructure and exclusion of chloride in compacted bentonite. Phys. Chem. Earth 32, 485-490. 2007.

Muurinen, A., P. Penttilä-Hiltunen and K. Uusheimo, Diffusion of chloride and uranium in compacted sodium bentonite. In: W. Lutze and R.C. Erwing, Editors, Scientific Basis of Nuclear waste Management XII, Materials Research Society, Pittsburg, PA, pp. 743-748, 1998.

Muurinen A. Diffusion of anions and cations in compacted sodium bentonite. VTT Publication 168, Espoo Technical Centre, Finland, 1994.

Nguyen, T.S. Description of the computer code FRACON. In Stephansson, O., Jing, L., and Tsang, C.-F. editors. Coupled Thermo-hydro-mechanical Processes of Fractured Media. Developments in Geotechnical Engineering, Elsevier, 1996, 79, pp. 539-544.

Noorishad, J., Tsang, C.-F. and Witherspoon, P.A. Coupled thermal-hydraulic-mechanical phenomena in saturated fractured porous rocks: numerical approach. J. Geophys. Res., 89, 10365-10373, 1984.

Noorishad, J., and Tsang, C.-F. ROCMAS-simulator: A Thermohydromechanical Computer Code. In Stephansson, O., Jing, L., and Tsang, C.-F. editors. Coupled Thermo-hydromechanical Processes of Fractured Media. Developments in Geotechnical Engineering, Elsevier, 1996, 79, pp. 551-558.

Nordstrom, D. K., and Muñoz, J. L. Geochemical Thermodynamics, The Benjamin/Cummings Pub. Co., Menlo Park, California, 477 pp., 1986. 
Ochs, M., B. Lothenbach, H. Wanner, H. Sato and M. Yui, An integrated sorption-diffusion model for the calculation of consistent distribution and diffusion coefficients in compacted bentonite, J. Contam. Hydrol. 47 (2001), pp. 283-296.

OECD, Engineering barrier systems and the safety of deep geological repositories (State-of-theart Report), ISBN 92-64-18498-8, 2003.

Olivella, S., Carrera, J., Gens, A. and Alonso, E.E. Nonisothermal multiphase flow of brine and gas through saline media. Transport in Porous Media, 15, 271-293, 1994.

Ohnishi, Y. and Kobayashi, A., THAMES. In Stephansson, O., Jing, L., and Tsang, C.-F. editors. Coupled Thermo-hydro-mechanical Processes of Fractured Media. Developments in Geotechnical Engineering, Elsevier, 79, pp. 545-549, 1996.

Palandri, J., and Kharaka, Y. K. A compilation of rate parameters of water-mineral interaction kinetics for application to geochemical modeling, US Geol. Surv. Open File Report 20041068, 64 pp., 2004.

Philip, J.R. and de Vries, D.A. Moisture movement in porous material under temperature gradients. EOS Trans., AGU, 38, 222-232, 1957.

Pine, R.J. and Cundall, P.A. Application of the fluid rock interaction program (FRIP) to the modeling of hot dry rock geothermal energy systems. In Stephansson, O., editor. Proceedings of the International Symposium on Fundamentals of Rock Joints, Björkliden, Sweden, pp. 293-302, 1985.

Pruess, K., Oldenburg, C.M., and Moridis, G.M. TOUGH2 User's Guide Version 2. E. O. Lawrence Berkeley National Laboratory Report LBNL-43134, November 1999.

Pruess, K., TOUGH2: A general numerical simulator for multiphase fluid and heat flow, Lawrence Berkeley Laboratory Report LBL-29400, Berkeley, California, 1991.

Pruess, K. TOUGH user's guide, Nuclear Regulatory Commission, report NUREG/CR-4645 (also Lawrence Berkeley Laboratory Report LBL-20700, Berkeley, California), 1987.

Pusch, R. The microstructure of MX-80 clay with respect to its bulk physical propertiunder different environmental conditions. SKB, TR-01-08, 111 p., 2001.

Raffensperger, J. P. Numerical simulation of sedimentary basin-scale hydrochemical processes, In Advances in Porous Media, Corapcioglu, Y. C., (ed.), Amsterdam, The Netherlands, Elsevier Science, 440 pp., 1996.

Revil, A. and P. Leroy, Governing equations for ionic transport in porous shales, J. Geophys. Res. 109, p. B03208, 2004.

Revil, A. and D. Jougnot, Diffusion of ions in unsaturated porous materColloid Interface Sci. 319 (1), pp. 226-235, 2008. 
Romero E., Alonso E.E, Knobelsdorf J. Laboratory tests on compacted bentonite-sand material for the GMT emplacement project. University of Catalonia, NAGRA NPB 02-05. 2002. p. 68. 2002.

Roscoe, K.H., Burland, J.B. On the generalized stress-strain behaviour of the 'wet' clay, In: Heyman, J., Leckic, F.A. (Eds.), Engineering Plasticity, Cambridge University Press, Cambridge, pp. 535-609, 1968.

Rutqvist J. Status of the TOUGH-FLAC simulator and recent applications related to coupled fluid flow and crustal deformations. Computers and Geosciences, 2010.

Rutqvist J., Börgesson L., Chijimatsu M., Hernelind J., Jing L., Kobayashi A. and Nguyen S. Modeling of damage, permeability changes and pressure responses during excavation of the TSX tunnel in granitic rock at URL, Canada. Environ Geol, 57:1263-1274, 2009a.

Rutqvist J., Bäckström A., Chijimatsu M., Feng X-T, Pan P-Z., Hudson J, Jing L., Kobayashi A., Koyama T., Lee H-S, Huang X-H, Rinne M. and Shen B. Multiple-Code Simulation Study of the Long-term EDZ Evolution of Geological Nuclear Waste Repositories. Environ Geol, 57, 1313-1324, 2009b.

Rutqvist, J., Y. Ijiri, and H. Yamamoto, Implementing the Barcelona Basic Model into TOUGHFLAC for analysis of geomechanical behavior of unsaturated soils. Proceedings of the TOUGH symposium 2009, Lawrence Berkeley National Laboratory, Berkeley, Sept 14-16, 2009c.

Rutqvist, J., Barr, D., Birkholzer, J.T., Fujisaki, K., Kolditz, O., Liu, Q.-S., Fujita, T., Wang, W., Zhang, C.-Y. A comparative simulation study of coupled THM processes and their effect on fractured rock permeability around nuclear waste repositories. Environmental Geology 57, 1347-1360, 2009d.

Rutqvist J. and Moridis G.J. Numerical Studies on the Geomechanical Stability of HydrateBearing Sediments. Society of Petroleum Engineers SPE Journal 14: 267-282. SPE-126129, 2009.

Rutqvist J, Freifeld B, Min K-B, Elsworth D, Tsang Y. Analysis of thermally induced changes in fractured rock permeability during eight years of heating and cooling at the Yucca Mountain Drift Scale Test. Int J Rock Mech \& Min Sci 45, 1373-1389, 2008a.

Rutqvist, J, Barr, D., Birkholzer, J.T., Chijimatsu, M., Kolditz, O., Liu, Q., Oda, Y., Wang, W., Zhang, C. Results from an international simulation study on coupled thermal, hydrological, and mechanical (THM) processes near geological nuclear waste repositories. Nuclear Technology 163, 101-109, 2008b.

Rutqvist J. and Tsang C.-F. Review of SKB's Work on Coupled THM Processes Within SRCan: External review contribution in support of SKI's and SSI's review of SR-Can. Swedish Nuclear Power Inspectorate (SKI) Technical Report 2008:08, 2008. 
Rutqvist, J., Tsang, C.-F. A study of caprock hydromechanical changes associated with CO2injection into a brine formation. Environmental Geology, 42: 296-305. 2002.

Rutqvist, J., Chijimatsu, M., Jing, L., De Jonge, J., Kohlmeier, M., Millard, A., Nguyen, T.S., Rejeb, A., Souley, M., Sugita, Y., Tsang, C.F. Numerical study of the THM effects on the near-field safety of a hypothetical nuclear waste repository - BMT1 of the DECOVALEX III project. Part 3: Effects of THM coupling in fractured rock. International Journal of Rock Mechanics \& Mining Sciences 42, 745-755, 2005.

Rutqvist, J., Tsang, C.-F. A fully coupled three-dimensional THM analysis of the FEBEX in situ test with the ROCMAS code: prediction of THM behavior in a bentonite barrier, In: Stephansson, O., Hudson, J.A., Jing, L., (Eds.) Coupled T-H-M-C Processes in GeoSystems: Fundamentals, Modelling, Experiments and Applications. Elsevier GeoEngineering Book Series, Oxford, p. 143-148, 2004.

Rutqvist J., Y.-S. Wu, C.-F. Tsang, and G. Bodvarsson A Modeling Approach for Analysis of Coupled Multiphase Fluid Flow, Heat Transfer, and Deformation in Fractured Porous Rock Int. J. Rock Mech. \& Min. Sci. 39, 429-442, 2002.

Rutqvist J., Börgesson L., Chijimatsu M., Nguyen T. S., Jing L., Noorishad J., and Tsang C.-F. Coupled Thermo-hydro-mechanical Analysis of a Heater Test in Fractured Rock and Bentonite at Kamaishi Mine - Comparison of Field Results to Predictions of Four Finite Element Codes. Int. J. Rock Mech. \& Min. Sci. 38, 129-142, 2001.

Sabodina, M.N.; Kalmykov, S.N.; Sapozhnikov, Yu. A.; Zakharova, E.V. Neptunium, Plutonium, and 137Cs Sorption by Bentonite Clays and their Speciation in Pore Waters, Journal of Radioanalytical and Nuclear Chemistry, Vol. 270, No. 2, pp. 349-355, 2006.

Samper, J.; Lu, C.; Montenegro, L. Reactive Transport Model of Interactions of Corrosion Products and Bentonite, Physics and Chemistry of the Earth 33 (2008) S306-S316, 2008.

Sánchez, M., Gens, A., Guimarães, L. do N., Olivella, S. A double structure generalized plasticity model for expansive materials. International Journal of Numerical and Analytical Methods in Geomechanics 29, 751-787, 2005.

Sato, H., M. Yui and H. Yoshikawa, Diffusion behavior for Se and Zr inbentonite, Mater. Res. Soc. Symp. Proc. 353, pp. 269-276, 1995.

Settari, A., and F.M. Mourits, A Coupled reservoir and Geomechanical Simulation System, SPE Journal, 27(9), 219-226, SPE paper 50939, 1998.

Slider, H. C., Practical petroleum reservoir engineering methods, An Energy Conservation Science. Tulsa, Oklahoma, Petroleum Publishing Company, 1976.

Sonnenthal, E. Chapter 5 in: Birkholzer, J. Rutqvist, E. Sonnenthal, and D. Barr, 2008, LongTerm Permeability/Porosity Changes in the EDZ and Near Field due to THM and THC Processes in Volcanic and Crystalline-Bentonite Systems, DECOVALEX-THMC Project Task D Final Report, 2008. 
Steefel, C.I., K. Maher, Fluid-rock interaction: A reactive transport approach. Reviews in Mineralogy and Geochemistry 70: 485-532, DOI: 10.2138/rmg.2009.70.11, 2009.

Steefel, C. I., and Lasaga, A. C. A coupled model for transport of multiple chemical species and kinetic precipitation/dissolution reactions with applications to reactive flow in single phase hydrothermal system, Am. J. Sci., v. 294, p. 529-592, 1994.

Steefel, C. I., and MacQuarrie, K. T. B. Approaches to modeling of reactive transport in porous media, In Lichtner, P. C., Steefel, C. I., and Oelkers, E. H. (eds.), Reactive transport in porous media, Reviews in Mineralogy, Mineral Society of America, v. 34, p. 83-129, 1996.

Stumm, W. Chemistry of the Solid Water Interface: Processes at the Mineral Water Particle Water Interface in Natural Systems, John Wiley \& Sons, 428 p., 1992.

Swenson, D.V., DuTeau, R. and Sprecker, T. A coupled model of fluid flow in jointed rock applied to simulation of a hot dry rock reservoir. Int. J. Rock Mech. Min. Sci. \& Geomech. Abstr., 34, Paper 308, 1997.

Thomas, H.R. and Sansom, M.B. Fully coupled analaysis of heat, moisture, and air transfer in unsaturated soil. J. Engng. Mech., ASCE, 121, 392-405, 1995.

van Genuchten, MT. A closed-form equation for predicting the hydraulic conductivity of unsaturated soils. Soil Sciences Society of America Journal 44, 892-898, 1980.

Verma, A., Pruess, K. Thermohydrologic Conditions and Silica Redistribution Near High-Level Nuclear Wastes Emplaced in Saturated Geological Formations, J. Geophysical Res., 93, B2:1159-1173. 1988.

Walter, A.L., Frind, E.O., Blowes, D.W., Ptacek, C.J., Molson, J.W., 1994. Modeling of multicomponent reactive transport in groundwater, 1, Model development and evaluation. Water Resour. Res., 30 (11), 3137-3148.

Wang, W., Rutqvist, J., Görke, U.-J., Birkholzer, J.T., Kolditz, O. Non isothermal flow in low permeable porous media: A comparison of Richards' and two-phase flow approaches. Environmental Earth Sciences (In press), 2010.

Wersin, P., Curti, E. and Appelo, C.A.J. Modelling bentonite-water interactions at high solid/liquid ratios: swelling and diffuse double layer effects. Appl. Clay Sci. 26, 249-257, 2004.

Wolery, T. J., EQ3/6: Software package for geochemical modeling of aqueous systems: Package overview and installation guide (version 8.0), Lawrence Livermore National Laboratory Report UCRL-MA-110662 PT I, Livermore, California, 1992.

$\mathrm{Xu}, \mathrm{T}$., and K. Pruess, Coupled modeling of nonisothermal multiphase flow, solute transport andreactive chemistry in porous and fractured media: 1 . Model development and validation, Lawrence Berkeley National Laboratory Report LBNL-42050, Berkeley, California, 38 pp., 1998. 
$\mathrm{Xu}, \mathrm{T}$., and Pruess, K. Modeling multiphase fluid flow and reactive geochemical transport in variably saturated fractured rocks: 1. Methodology, Am. J. Sci., v. 301, p. 16-33, 2001.

Xu, T., Sonnenthal E., Spycher, N. and K. Pruess, TOUGHREACT User's guide: A simulation program for nonisothermal multiphase reactive geochemical transport in variably saturated geologic media. Lawrence Berkeley National Report LBNL-55460-2008, 2008.

Yeh, G. T., and Tripathi, V. S. A model for simulating transport of reactive multispecies components: model development and demonstration, Water Resour. Res., v. 27, p. 30753094, 1991. 


\section{APPENDIX: KEY REFERENCES FOR THMC PROCESSES IN EBS- BENTONITE}

\section{General:}

Åkesson, M. (2010) Summary Report of Bentonite Working Group. Proceedings of European Commission THERESA-TIMODAZ Coupled THMC Conference, Luxembourg, September 29-October 1, 2009. To be published by European Commission, 2010.

Alonso, E.E. and Ledesma, A (2005). Advances in Understanding Engineered clay barriers. A.A. Balkema Publishers, Leiden, 583 p., 2005.

Birgersson, M., Börgesson, L., Hedström, M., Karnland, O. and Nilsson, U. (2009) Bentonite Erosion, final report from Clay Technology, SKB report TR-09-34, Swedish Nuclear Waste Management Company, Sweden, 2009.

Bock, C.D., Bosgiraud, J-M., Weber, H., Rothfuches, T., Verstricht, J., Breen, B., and Johnson, M. (2008). Achievements of the ESDRED Project in Buffer Construction Technology, Proceedings of EURADWASTE ’08 Conference, Luxembourg, October 20-22, 2008.

Börgesson, L., Hernelind, J., (1999). Coupled thermo-hydro-mechanical calculations of the water saturation phase of a KBS-3 deposition hole. Swedish Nuclear Fuel and Waste Management Co., Stockholm, Technical Report TR-99-41.

Chijimatsu, M., Börgensson L., Fujita T., Jussila P., Nguyen, S., Rutquist, J., and Ling, L., (2009). Model development and calibrataion for the coupled thermal, hydraulic and mechanical phenomena of the bentonite. Environmental Geology, 57, 1255-1261, DOI 10.1007/S00254-008-1401-2.

EC (2007) EURATOM FP6 Research Projects and Training Activities (2007) Project Synopses. Published by the European Commission, Directorate-general for Research Communication Unit, Volume III, EUR 22385.

EC (2010). Proceedings of European Commission THERESA-TIMODAZ Coupled THMC Conference, Luxembourg, September 29-October 1, 2009. To be published by European Commission, 2010.

Gatabin C., Billaud P., (2005). Bentonite THM mock-up experiments. Sensors data report, CEA, France.

Nguyen, T.S., Börgesson, L., Chijimatsu, M., Hernelind, J., Jing, L., Kobayashi, A. and Rutqvist, J., (2009) A Case Study on the influence of THM coupling on the near field safety of a spent fuel repository in sparsely fractured granite. Environmental Geology, 57:1239-1254, DOI 10.1007/s00254-008.15565-9, 2009.

Pusch, R. (2006). The performance of clay barriers in Repositories for high-level radioactive waste. Nuclear Engineering and Technology, Vol. 38, No 6, pp 483-488, 2006. 
Pusch R. and Yong, R. (2006). Microstructure of Smectite clays and engineering performance. Taylor \& Francis, London and New York. (ISBNIO:0-415-36863-4), 2006.

Rothfuchs, T. Joclewer, N. and Zhang, C-L, (2007) Self-sealing Barriers of Clay (Mineral Mixtures - the SB-project at the Mont Terri Rock Laboratory. Physics and Chemistry of the Earth, Parts A/B/C, Vol. 32, Issues 1-7, pp 106-115.

SKB, 2009. Äspö Hard Rock Laboratory, Annual Report, 2008. Swedish Nuclear Fuel and Waste Management Company (SKB), Technical Report TR-09-10.

Tsang, C.F., Stephansson, O., Jing, L., Kautsky, F. (2009): DECOVALEX project: from 1992 to 2007. Environmental Geology, Volume 57, Issue 6, pp. 1221-1237.

Tsang C.F., Åkesson M, Barnichon J-D., Jing L., Li X. L., and Schulze O. (2010) A Combined Review of Key Issues Related to Coupled THMC Processes in the Near-field of Radioactive Waste Repositories in Salt, Clays and Bentonite-Crystalline Rock Systems. Proceedings of European Commission THERESA-TIMODAZ Coupled THMC Conference, Luxembourg, September 29-October 1, 2009. To be published by European Commission, 2010.

\section{THMC Processes in Bentonite:}

Birgersson M, Åkesson M, Hökmark H, 2008. Gas intrusion in saturated bentonite - A thermodynamic approach. Phys Chem Earth 2008; 33:248-251.

Castellanos, E., Villar, M.V., Romero, E., Lloret, A., Gens, A. (2008). Chemical impact on the hydro-mechanical behaviour of high-density FEBEX bentonite. Physics and Chemistry of the Earth, 33, S516-S526.

Dueck, A. 2008. Laboratory results from hydro-mechanical tests on a water unsaturated bentonite. Engineering Geology, Volume 97, Issues 1-2, 12 March 2008, Pages 15-24.

Dueck, A. \& Börgesson, L. 2007. Model suggested for an important part of the hydromechanical behaviour of a water unsaturated bentonite. Engineering Geology, Volume 92, Issues 3-4, 10 July 2007, Pages 160-169.

Lloret, A., Villar, M.V., Sanchez, M., Gens, A., Pintado, X,, Alosnso, E.E. (2003). Mechanical behaviour of a heavily compacted bentonite under high suction changes. Géotechnique, 53, 27-40.

Romero, E., Gens, A., Lloret, A. (2003). Suction effects on a compacted clay under nonisothermal conditions. Géotechnique, 53, 65-81 
Sánchez, M., Gens, A., Guimaraes, L. do N., Olivella, S (2005). “A double generalized plasticity model for expansive materials”. International Journal for Numerical and Analytical Methods in Geomechanics, 29:751-787.

Schanz, T., Tripathy, S., (2009), “Swelling pressure of a divalent-rich bentonite: Diffuse doublelayer theory revisited”, Water Resourses Res, 45, doi:10.1029/2007WR006495.

Sánchez, M., A Gens, LJDN Guimarães, and S Olivella, (2005). A double structure generalized plasticity model for expansive materials. International Journal for Numerical and Analytical Methods in Geomechanics, 29: 751-787.

Thomas, H.R., Siddiqua, S., Seetharam, S., (2009), "Inclusion of higher temperature effects in a soil behaviour model”, Géotechnique, 59(3), p279-282

Thomas, H., and Vardon P. (2010). The TH(C)M behaviour of highly-compacted bentonite clay related to high-level nuclear waste disposal - some recent developments. Proceedings of ECTimodaz-Theresa THMC Conference, 29 Sept-01 Oct 2009, to be published, European Commission, 2010.

Tong F. G., Jing L, Zimmerman R. W.. An effective thermal conductivity model of geological porous media for coupled thermo-hydro-mechanical systems with multiphase flow. Int $\mathrm{J}$ Rock Mech Min Sci. 2009; 46:1358-1369.

Tripathy, S., Schanz, T., (2007), “Compressibility behaviour of clays at very large pressures”, Canadian Geotechnical Journal, 44, p355-362.

Tripathy, S., Subba Rao, K.S., (2009), “Cyclic swell-shrink behaviour of a compacted expansive soil”, Geotechnical and Geological Engineering, 27 (1), p89-103.

Zheng, L. and J. Samper, (2008), Coupled THMC model of FEBEX mock-up test, Physics and Chemistry of the Earth, Physics and Chemistry of the Earth, Vol. 33, S486-S498. doi:10.1016/j.pce.2008.10.023.

Zheng, L., J. Samper, L. Montenegro, A. M. Fernández. (2010): A coupled THMC model of a heating and hydration laboratory experiment in unsaturated compacted FEBEX bentonite. Journal of Hydrology, vol. 386, issue 1-4, pp. 80-94.

\section{THM numerical models:}

Chen Y., Zhou C., Jing L. Modelling coupled THM processes of geological porous media with multiphase flow: Theory and validation against laboratory and field scale experiments. Computers and Geotechnics 36 (2009) 1308-1329. 
Cleall, P.J., Thomas, H.R., Melhuish, T.A., Owen, D.H., (2006), "Use of parallel computing and visualisation techniques in the simulation of large scale geoenvironmental engineering problems”, Future Generation Computer Systems, 22, p460-467.

Kimura, M., Nakama, S., Suzuki, H., Fugita, T. (2010), Development of Prototype Numerical model on the coupled thermo-Hydro-Mechanical-chemical processes in the near-field of a high-level radioactive waste repository, Proceedings of EC-Timodaz-Theresa THMC Conference, 29 Sept-01 Oct 2009, to be published, European Commission, 2010.

Sánchez, M., Gens, A., Guimarães, L., Olivella, S. (2008). "Implementation algorithm of a generalised plasticity model for swelling clays”. Computers and Geotechnics, 35 (6), 860871.

Seetharam, S.C., Thomas, H.R., Cleall, P., (2007), “Coupled thermo/hydro/ chemical/mechanical model for unsaturated soils - numerical algorithm”, International Journal for Numerical Methods in Engineering, 70(12), p1490-1511.

Thomas, H.R., Yang, H.T., He, Y., Cleall, P.J., (2003), “A multi-level parallelised substructuring frontal solution for coupled thermo/hydro/mechanical problems in unsaturated soil”. International Journal for Numerical and Analytical Methods in Geomechanics, 27, p951965.

Tong F.G., Jing L., Zimmerman R. W. (2010). A fully coupled thermo-hydro-mechanical model for simulating multiphase flow, deformation and heat transfer in buffer material and rock masses. International Journal of Rock Mechanics and Mining Sciences, Volume 47, Issue 2, February 2010, Pages 205-217.

Vardon, P.J., Cleall, P.J., Thomas, H.R., Philip, R.N., Banicescu, I., (2009), Three-dimensional field-scale coupled Thermo-Hydro-Mechanical modelling: a parallel computing implementation, Submitted by invitation for publication in the special issue of the $A S C E$ International Journal of Geomechanics, Environmental Geotechnology: Contemporary Issues.

Wang W, Kosakowski G, Kolditz O. (2009) A parallel finite element scheme for thermo-hydromechanical (THM) coupled problems in porous media. Comput Geosci 2009; 35(8):16311641.

Wang W, Kolditz O. (2007) Object-oriented finite element analysis of thermo-hydro-mechanical (THM) problems in porous media. Int J Numer Methods Eng 2007;69(1):162-201.

Xie M, Agus S, Schanz T, Kolditz O. (2004). An upscaling method and numerical modelling of swelling/shrinking processes in compacted bentonite/sand mixtures. Int J Numer Anal Methods Geomech 2004; 28:1479-1502. 


\section{Chemistry:}

Birgersson, M. \& Karnland, O. 2009. Ion equilibrium between montmorillonite interlayer space and an external solution - Consequences for diffusional transport. Geochimica et Cosmochimica Acta, Vol. 73, no7, pp. 1908-1923.

Cleall, P.J., Seetharam, S.C., Thomas, H.R., (2007), "On the inclusion of some aspects of chemical behaviour of an unsaturated soil in thermo/hydro/mechanical models: Part 1, Model development" American Society of Civil Engineers Journal of Engineering Mechanics, 133(3), p338-347.

Cleall, P.J., Seetharam, S.C., Thomas, H.R., (2007), “On the inclusion of some aspects of chemical behaviour of an unsaturated soil in thermo/hydro/mechanical models: Part II, Application: transport of soluble salts in a compacted bentonite”, ASCE Journal of Engineering Mechanics, 133(3), p348-356.

Guimaraes, L. do N., Gens, A., Olivella, S. (2007). Coupled thermo-hydro-mechanical and chemical analysis of expansive clay subjected to heating and hydration. Transport in porous media, 66: 341-372.

Guimaraes, L. do N., Gens, A., Sánchez, M., Olivella, S. (2006). THM and reactive transport of expansive clay barrier. Communications in Numerical Methods in Engineering, 22: 849-859.

Li, Y., Cleall, P.J., Thomas, H.R., (2009), Multi-dimensional chemo-osmotic consolidation of clays, Submitted to Computers and Geotechnics.

Mata, C., Guimaraes, L. do N., Ledesma, A., Gens, A., Olivella, S. (2005). A hydro-geochemical analysis of the saturation process with salt water of a bentonite crushed granite rock mixture in an engineered nuclear barrier. Engineering Geology, 81: 227-245.

Musso, G., Romero, E., Gens, A., Castellanos, E. (2003). The role of structure in the chemically induced deformations of FEBEX bentonite. Applied Clay Science, 23, 229-237.

Seetharam, S.C., Cleall, P.J., Thomas, H.R., (2006), Modelling some aspects of ion migration in a compacted bentonitic clay, Engineering Geology, 85, p221-228.

Seetharam, S.C., Thomas, H.R., Vardon, P.J., (2009), Non-isothermal multi-component reactive transport model for unsaturated soil, Submitted by invitation for publication in the special issue of the ASCE International Journal of Geomechanics, Environmental Geotechnology: Contemporary Issues.

Xie M., Bauer S., Kolditz O., Nowak T., Shao H. (2006) Numerical simulation of reactive processes in an experiment with partially saturated bentonite. J Contam Hydrol 2006; 3:122147. 


\section{Experiments and their Modelling:}

Alonso EE, Alcoverro J, Coste F, Malinsky L, Merrien-Soukatchoff V, Kadiri I, Nowak T, Shao H, Nguyen TS, Selvadurai APS, Armand G, Sobolik SR, Itamura M, Stone CM, Webb SW, Rejeb A, Tijani M, Maouche Z, Kobayashi A, Kurikami H, Ito A, Sugita Y, Chijimatsu M, Börgesson L, Hernelind J, Rutqvist J, Tsang CF, Jussila P. The FEBEX benchmark test: case definition and comparison of modelling approaches. Int J Rock Mech Min Sci 2005;42(56):611-638.

Cho, W-J., Lee, J-O., and Kwon, S. (2010) Simulation of Thermo-hydro-mechanical process in the engineered barrier system of a high-level waste repository. Proceedings of EC-TimodazTheresa THMC Conference, 29 Sept-01 Oct 2009, to be published, European Commission, 2010.

Cleall, P.J., Melhuish, T.A. Thomas, H.R., (2006), "Modelling of the three-dimensional behaviour of a prototype nuclear waste repository”, Engineering Geology, 85, p212-220.

Dixon, D., Lundin, C., Örtendahl, E., Hedin, M and Ramqvist, G. (2008). Deep repositoryengineeering barrier systems. Half-scale tests to examine water uptake by bentonite pellets in a block-bentonite backfill system. SKB R-08-132. Swedish Nuclear Waste Management Company, Sweden, 2008.

Gens A., Sánchez, M., Guimarães, L. do N., Alonso, E.E., Lloret, A., Olivella, S., Villar, M.V., Huertas, F. (2009). "A full-scale in situ heating test for high-level nuclear waste disposal: observations, analysis and interpretation”. Geotechnique, 59, 377-399.

Herklotz, M., Jobmann, M., and Yildizdag, K. (2010) Investigation on the TH-behaviour of a heated bentonite barrier by measurements and numerical calculations. Proceedings of ECTimodaz-Theresa THMC Conference, 29 Sept-01 Oct 2009, to be published, European Commission, 2010.

Millard, A., Slimane, K.B., and Barnichon J.D. (2010). Preliminary investigation of the Canister Retrieval Test, Influence of the flow parameters on the THM behaviour (1020). Proceedings of EC-Timodaz-Theresa THMC Conference, 29 Sept-01 Oct 2009, to be published, European Commission, 2010.

Thomas, H.R., Cleall, P.J., Chandler, N., Dixon, D., Mitchell, H.P., (2003), Water infiltration into a large scale in-situ experiment in an underground research laboratory - physical measurements and numerical simulation Géotechnique, 53(2), p207-224.

Thomas, H.R., Cleall, P.J., Dixon, D., Mitchell, H., (2009), The coupled thermal-hydraulicmechanical behaviour of a large scale in-situ heating experiment, Géotechnique, 59(4), p401413. 
Van Geet, M.m Volckaert, G., Bastiens, W., Maes, N., Weetjens, E., Sillen, X., Vallejan, B., Gens, A. (2007). Efficiency of a borehole seal by means of pre-compacted bentonite blocks. Physics and Chemistry of the Earth, 32, 123-134.

Vaunat, J., A., Gens, A (2005). Analysis of the hydration of a bentonite seal in a deep radioactive waste repository. Engineering Geology, 81: 317-328.

Villar M.V., Sánchez, M., Gens, A. (2008). Behaviour of a bentonite barrier in the laboratory: Experimental results up to 8 years and numerical simulation. Physics and Chemistry of the Earth, 33, S476-S485.

Zandarin, M.T., Olivella, S., Gens, A. and Alonso, E. (2010). A 1-D thermo-hydro-mechanical model of the middle section of the Canister Retrieval Test. Proceedings of EC-TimodazTheresa THMC Conference, 29 Sept-01 Oct 2009, to be published, European Commission, 2010. 